QE365

.W58

1946

STORY OF THE

Minerals

HERBERT P. WHITLOCK

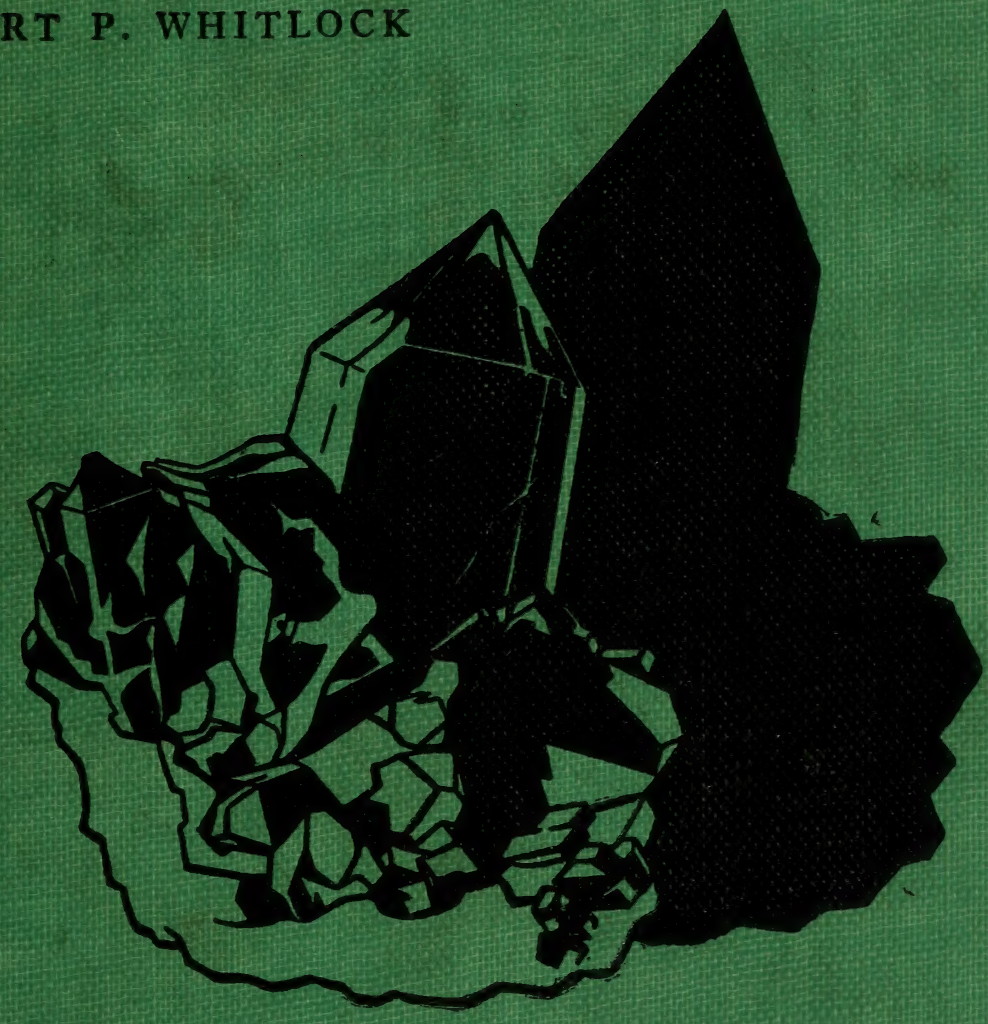




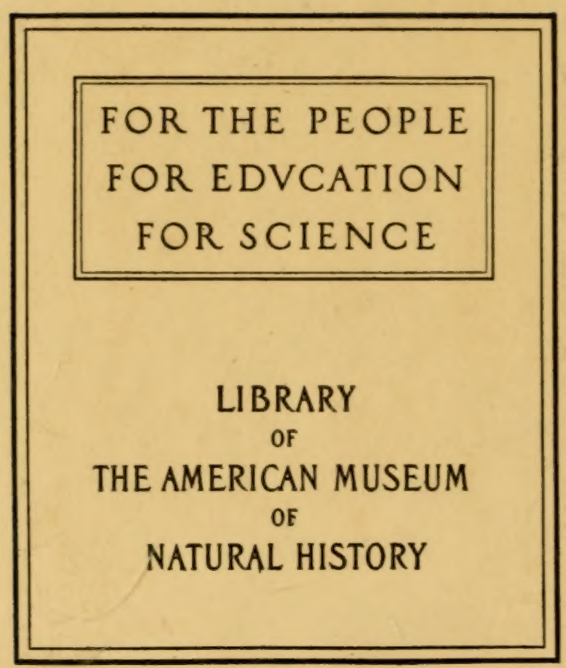




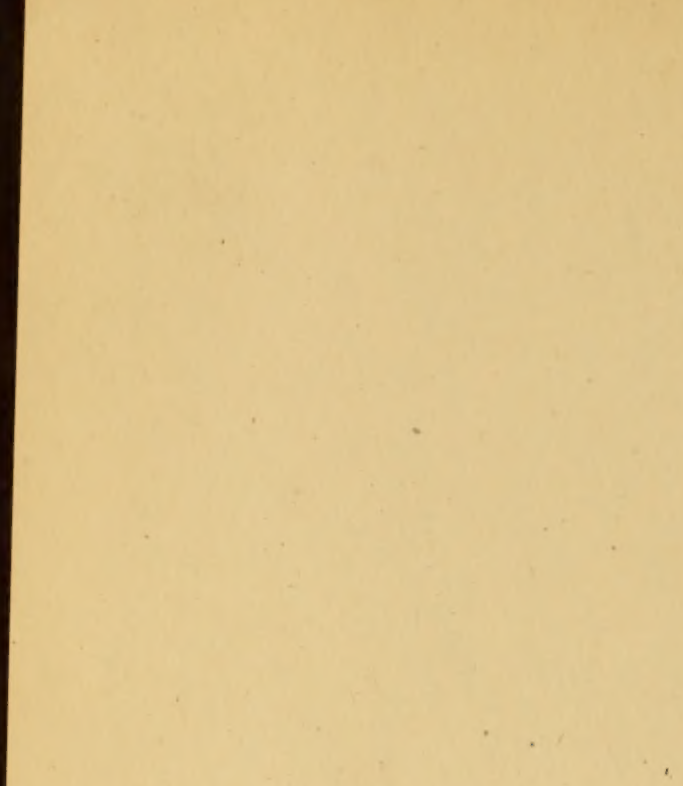





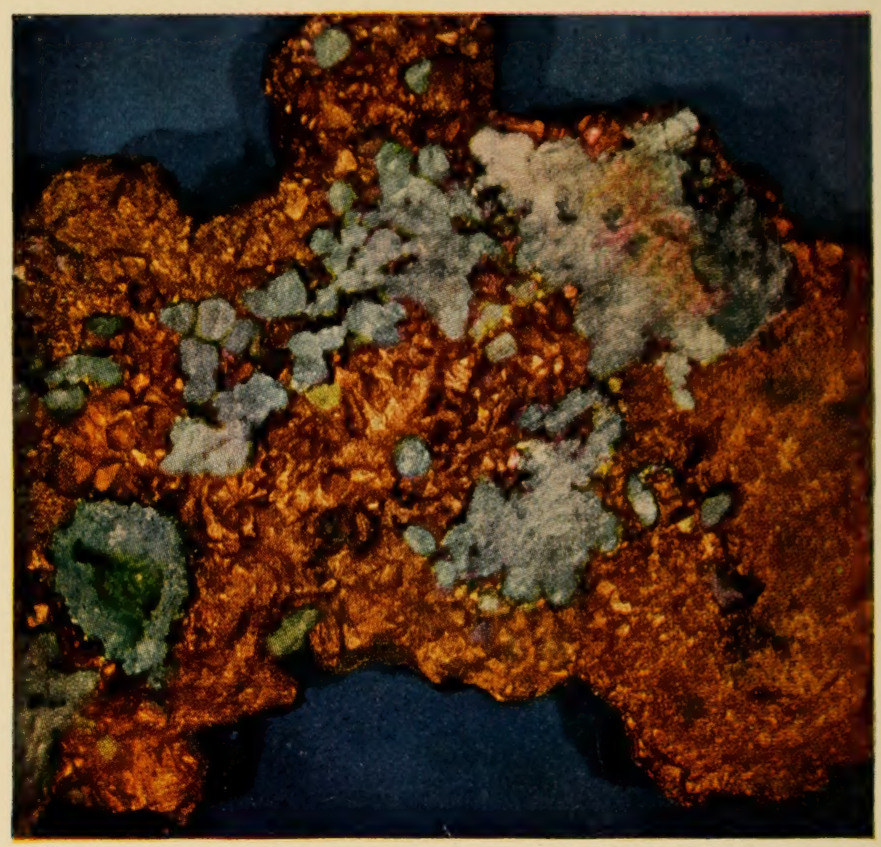

COPPER 


\title{
THE STORY OF THE Minerals
}

\author{
$B Y \mu$ \\ HERBERT P. WHITLOCK \\ Curator Emeritus of Mineralogy
}

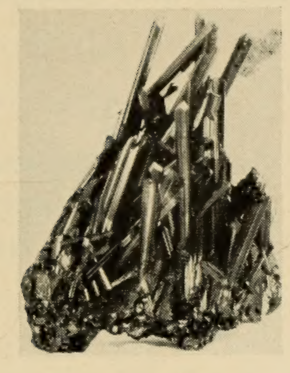

Handbook No. I 2

NEW YORK CITY

The American Museum of Natural History

1946 
COPYRIGHT 1946-THE AMERICAN MUSFUM OF NATURAL HISTORY

$$
\begin{gathered}
47-167078-\operatorname{Dec} 29 \\
C .1
\end{gathered}
$$

$$
\begin{aligned}
& \text { QE } 365 \\
& . W 58 \\
& 1946
\end{aligned}
$$

PRINTED IN THE UNITED STATES OF AMERICA 


\section{TABLE OF CONTENTS}

PAGE

INTRODUCTION

PART ONE

CHAPTER

I. HISTORY AND SOURCES OF THE MINERAL COLLECTION I

II. WHAT IS A MINERAL 5

III. NATURE'S MATHEMATICS I2

IV. THE MIMICRY OF MINERALS 29

V. WATER AS A MAKER OF MINERALS 38

VI. CHANGE AND DECAY IN MINERALS 47

\section{PART TWO}

VII. ELEMENTS, SULPHIDES AND HALOIDES 52

$\begin{array}{ll}\text { VIII. OXIDES } & 68\end{array}$

IX. CARBONATES $\quad 78$

X. SILICATES 88

XI. SILICATES (continued) 97

XII. SILICATES (continued) 107

XIII. PHOSPHATES AND SULPHATES I I 4

$\begin{array}{ll}\text { INDEX } & \text { I23 }\end{array}$ 



\section{INTROI)UCTION}

IN TIIE preparation of this little book the writer has striven to answer questions rather than to rehearse facts. It has been made increasingly plain to him, in the course of his experience that the bulk of the Museum public demand not a text book, howerer simple, but a statement of the principles upon which may be built up an understanding of such an assemblage of natural objects as the one that has been brought together in the Morgan Memorial Hall of the American Muscum of Natural History. The present volume is then an attempt to put into a simple and popular form the "How?" and the "Ithy?" of mineralogy, to the end that the visitor may be enabled to interpret what he sees around him in this Hall. To an extent it has been written around the Introductory Series of the Collection, but in a larger sense the book and the exhibit have been prepared together, so that they are closely linked in idea and presentation.

Much of the text has been suggested by questions put to the writer by those who in times past have sought information regarding the things of which it treats, and it is in the hope that some of these questions may thus be answered that he now presents it to them. 

PART ONE 



\section{Chapter I}

\section{HISTORY AND SOURCES \\ OF THE MINERAL COLLECTION}

IN MANY ways unique among the great mineral collections of the world, the Collection of the American Museum of Natural History presents one feature that commands our attention in reviewing its history. It owes an incomparable debt to one man for its rank among the world's collections. Were it not for the public spirited generosity of Mr. John Pierpont Morgan, the mineral collection representing the American Museum would, in all probability, rank today below many public collections in America, as well as some that are privately owned. Although not himself a collector of minerals, Mr. Morgan was keenly appreciative of the beauty and interest embodied in them, and his interest in this branch of science was stimulated by his association with Dr. George F. Kunz, who pointed out to him the far reaching value to the public of placing the Bement Collection in the American Museum, and arranged the details of this gift.

Like most of the large mineral collections of the world, the collection displayed in the Morgan Hall of Minerals has been the result of slow growth over a considerable period of time. Prior to the year i 875 the mineral collection, which was then displayed in the Old Arsenal Building at Fifth Avenue and $65^{\text {th }}$ Street, was composed of a few specimens acquired by miscellaneous and unrelated gifts, and entirely inadequate to the presentation of the subject of the earth's minerals for either the layman or the scientist. From such a small beginning the collection has grown to its present rank as one of the five great 
mineral collections of the world, and preëminently the largest and best in America.

In 1875 the S. C. H. Bailey Collection was purchased. This acquisition had the effect of placing the exhibited series upon a sound basis. For the first time visitors to the American Museum of Natural History were enabled to study minerals and to acquire a knowledge of their relations and relative importance.

The collection was now a good one, not large or remarkable for the brilliancy or rarity of its contents, but serviceable and representative. And so essentially it remained through the next I o years, added to from time to time by many gifts, and constituting a usable tool to the hand of the many who came to it for knowledge, student and layman alike. It was in this period that the writer first came to know the collection, and to find help and inspiration from it.

In I 89 I the remainder of the great Norman L. Spang Collection, much of which had been previously purchased by Mr. Clarence S. Bement, was secured by the Museum through purchase. This addition very materially improved the collection in that it increased the number of represented species of minerals, as well as the number of localities for important species, and the size and impressiveness of the specimens.

With this accession the collection began to assume a distinct rank among notable mineral collections. There were still many gaps in the series, gaps which represented rare species, but the general excellence of the material exhibited is testified by the fact that in the present display of large and impressive specimens which fills the case panels a very appreciable percentage are derived from the Spang Collection.

It was in 1900 , however, that the collection took rank as the most complete as well as the richest in notable specimens in America. Through the gift of the late J. Pierpont Morgan, Esq., the Museum acquired the remarkable collection of minerals brought together by Mr. Clarence S. Bement of Philadelphia. This addition, which comprises a large percentage of the specimens now displayed in the Morgan Memorial Hall of Minerals, 


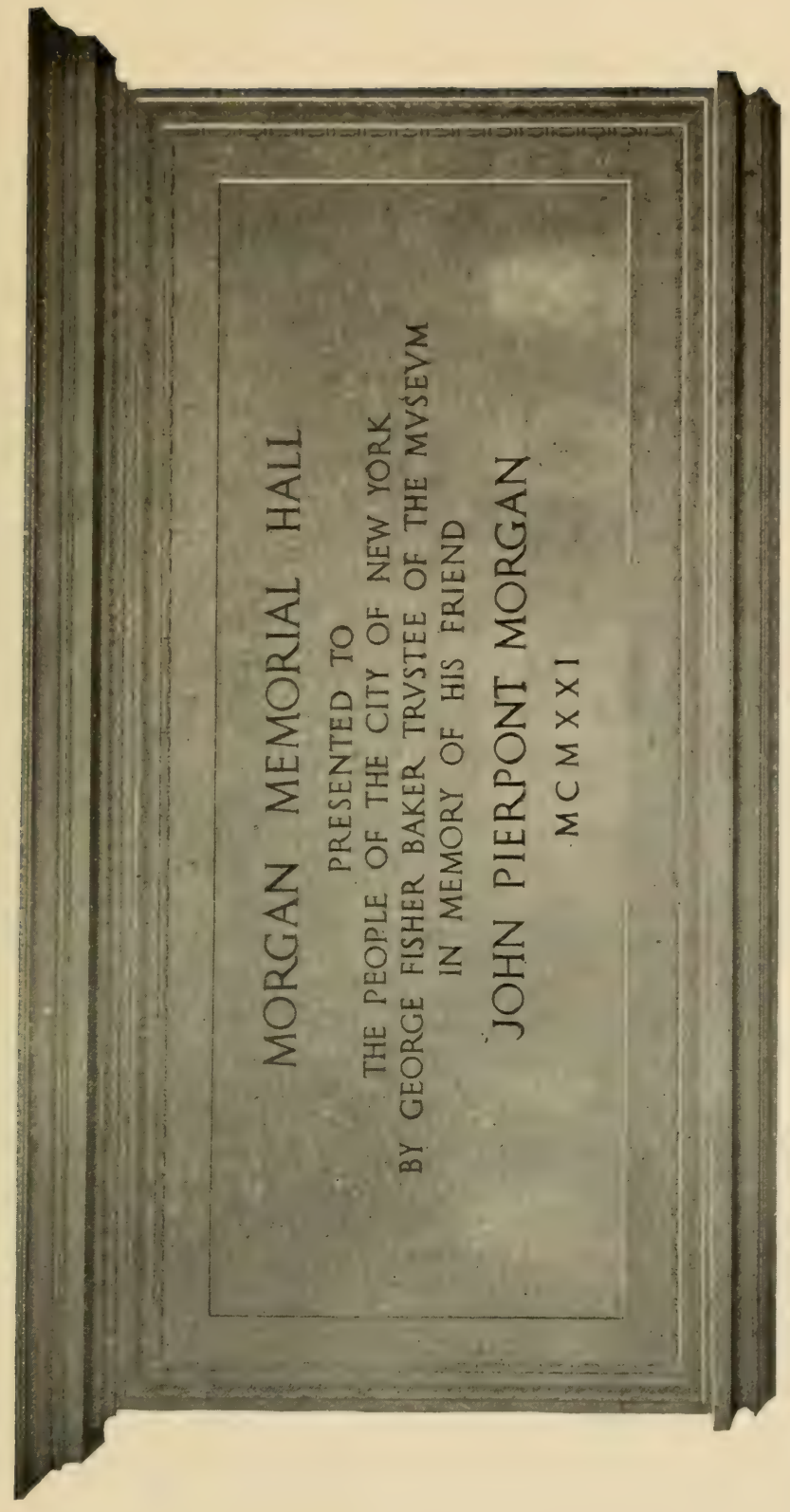


is famous for the exceptional perfection of the material comprising it. The quality of this material, both from the point of view of its scientific interest, and the size and beauty of its examples, may be best understood when one considers the fact that Mr. Bement, a collector of rare judgment and appreciation, not infrequently purchased an entire small collection in order to acquire a single specimen of unique value. In this way the Mineral Collection of the American Museum became, as it were a "collection of collections" some of its components representing the time and labor of America's most indefatigable mineral collectors, who sought for their treasures the world over. In this way also many of the rare species, hitherto lacking in the series were added, balancing, coordinating and making more complete the story of the earth's constituents.

Since the gift of the Bement Collection many additions of exceptional beauty and interest have been acquired by purchase from the Fund established in 1904 by Matilda IV. Bruce. The mineral collection which thus attained a high standard of merit has been augmented year by year through careful selection of the best available specimens of the more recently discovered species, varieties and occurrences.

In 1922 the Mineral Hall was completely remodeled architecturally through the generosity of Mr. George Fisher Baker, who chose this means of honoring the memory of his friend, and associate the late John Pierpont Morgan. Thus the Hall is now designated as the Morgan Memorial Hall of Minerals and Gems, and fittingly commemorates his great public service in rendering accessible to the people the contents of this treasure house of rare and beautiful fragments of our planet which he himself loved for their beauty and interest. 


\section{Chapter II}

\section{IVHAT IS A MINERAL}

WHEN we consider the various kinds of material that make up the world about us, we usually find that the familiar things,those that we know most about-are the animals and the plants. Yet because these organic things, which we call organisms, and of which we ourselves are a part, only exist on the surface of the earth, and in the water which covers part of this surface, they really form comparatively little of the mass of the earth on which we live. Underneath the grass roots begins the silent, immobile kingdom of the minerals. Extending to an unknown depth below us are miles upon miles of rocks all composed of minerals. Our knowledge of these substances which form the huge mass of the earth is limited to those of them which are to be found within a comparatively thin shell, ten miles in thickness and encircling the earth, which represents all we are able to see and study of the solid interior.

We have access to this part of the crust of the earth because the rocks have in many places been folded, then worn away until their edges are exposed, thus letting us who live on the exposed edges examine them to about the depth mentioned (ten miles). Of what, then is this "sample" of our planet made? And how can we learn the story of this silent realm of nature beneath our feet?

The researches of chemists tell us that everything to be found in the world is made up of combinations of less than a hundred different substances which are called elements, because, up to the present time, no one has been able to prove that they are themselves made up of simpler substances. These elements or 
ultimate substances, then, are the materials or "earth stuff" which nature has used to build up the vast structure of the world. They were probably all present in the mass of matter from which the planct was born, and they have combined and recombined to form natural compounds throughout the periods of its life. We know this because we have found many instances where a natural substance has been altered into quite a different substance through the action of natural forces. IVe have ample evidence that these natural combinations of world materials, to which we give the name of minerals, have been fused together as if in a melting pot and have emerged from the cooled solid mass as different combinations.

If we were to gather a handful of sand from the seashore and examine it, we would learn something about these minerals, because each of the tiny grains is nothing more or less than a very minute mineral specimen. Put them under a strong magnifying glass or a microscope of low power and we will find that we have before us a little mineral collection, limited in scope but still comprising perhaps half a dozen different kinds of minerals.

But each grain of sand has been broken from a rock by the action of the waves, so it is to the rocks that we must turn to learn more about the minerals that compose them. Let us take a piece of coarse grained granite, which is a very common rock and look at it carefully. We will find there several minerals that are obviously different from one another. There is a glassy mineral that has broken with a rough uneven surface resembling broken glass. This is one of the commonest of minerals and is called quartz. Then there is a salmon colored mineral, each grain of which has broken in flat shiny surfaces which all reflect back the light at once. This is one member of the large and important mineral group called the feldspars. Between the grains of quartz and feldspar will be found dark particles of a mineral quite different from the other two. This last is made up of thin sheets, or layers like the leaves of a book, and is a kind of mica. So we have found in our fragment of granite three important and 
widely distributed minerals, and are fairly started on our exploration of the mineral world.

But before we proceed further, let us consider a little more in detail the elements which combine to form the large and varied array of minerals known to science. There are 94 of these elements at present recognized by chemists, but of this number several are present only in the atmosphere, a large number are so rare that they may be practically disregarded as entering

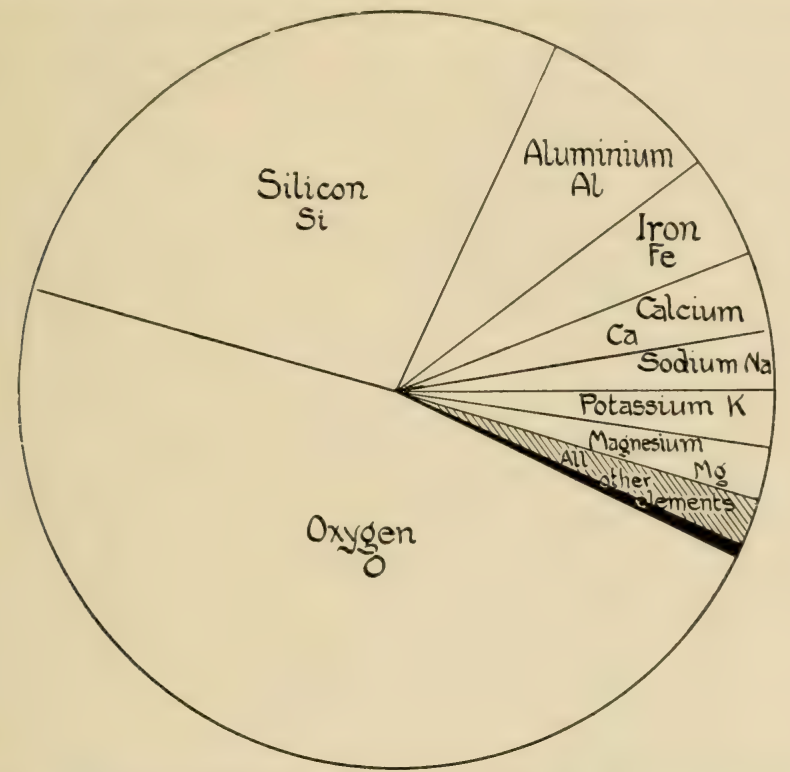

Fig. I. The Proportions of the Elements in the Crust of the Earth.

into the constitution of minerals to any appreciable degree, and of the remainder 20 are sufficiently abundant to make up $99 \frac{1}{2} \%$ of the earth's crust. Even among these 20 commoner elements there is a degree of rarity, for only 8 of the twenty furnish $97 \%$ of the material of the outer portion of the globe while the remaining $\mathrm{I} 2$ furnish the material for only $2 \frac{1}{2} \%$ of it. From this we would expect that the common minerals would be formed by combinations of the commoner elements, and 
this is true. The three minerals which we found in the fragment of granite were composed of elements from among the eight commonest earth forming substances. The diagram shown in Figure I gives the relative proportions of the 20 commoner elements, the names of which, in the order of their abundance are:-

\begin{aligned} x I & \multicolumn{1}{c}{ Element } \\ X2 & Silicon \\ 3 & Aluminum \\ 4 & Iron (Ferrum) \\ 5 & Calcium \\ 6 & Potassium (Kalium) \\ 7 & Sodium (Natrium) \\ 8 & Magnesium \\ 9 & Titanium \\ x 0 & Hydrogen \\ x I & Carbon \\ x 12 & Phosphorus \\ x 13 & Sulphur \\ I4 & Barium \\ I5 & Manganese \\ x16 & Chlorine \\ 17 & Strontium \\ x18 & Fluorine \\ 19 & Zirconium \\ 20 & Nickel \end{aligned}

Symbol of Abbreviation

$\mathrm{O}$

Si

Al

$\mathrm{Fe}$

$\mathrm{Ca}$

K

$\mathrm{Na}$

$\mathrm{Mg}$

$\mathrm{Ti}$

$\mathrm{H}$

C

$\mathrm{P}$

S

$\mathrm{Ba}$

Mn

Cl

$\mathrm{Sr}$

FI

$\mathrm{Zr}$

$\mathrm{Ni}$

In this list there are many names of substances that are unfamiliar to us. IV are acquainted with aluminum, iron, and nickel as very useful and important metals, and we know sulphur as a yellow substance that burns readily, and carbon as the black soot that forms inside of chimneys, and oxygen as the invisible gas that we breathe in the air and that keeps us alive. And if we consider we will realize that there is a great 
difference between the metals, aluminum, iron and nickel and such substances as oxygen, carbon and sulphur. We might even be inclined to think of oxygen as not a substance at all, because we can not see or feel it. But when we turn to our dictionaries we find that a substance is the material of which anything is made and since the earth is very nearly half made of oxygen, we can readily see that it is distinctly a substance. We then recognize that, even as far as our casual knowledge goes, metals like iron and nickel are different from oxygen, carbon, and sulphur. This difference is so essential that chemists have divided the elements into metallic and non-metallic elements. In the list of 20 elements, those which are marked with an $x$ are the non-metallic elements and those not so designated are the metallic ones. It is the non-metals among the elements which we should especially concern ourselves with, because in the combinations of one or more non-metals with one or more metals that, in general, go to form minerals, it is the non-metals which determine in what class the mineral is to be placed. Minerals are divided into Classes and Groups according to their chemical composition, that is, according to the elements which compose them, and the relation of these elements with one another. A mineral that is composed of the elements sulphur and iron is a sulpbide of iron and belongs in the Class of Sulphides, which includes the simple combinations of the element sulphur with the various metals.

Not only is the element oxygen by far the largest constituent of the materials of the earth, but it enters into the composition of a large proportion of the many different kinds of minerals. Combined with one or more of the metals, it forms an oxide. United with silicon, oxygen forms with the metallic elements the minerals belonging to the large and important group called the Silicates. Hydrogen and oxygen combine to produce water, which enters into the composition of a number of minerals. In this way we have hydrous oxides (oxides containing water), hydrous silicates, hydrous carbonates, hydrous phosphates and hydrous sulphates. 
The element carbon combines with oxygen and with the metallic elements to form Carbonates, a large and important section of the mineral kingdom.

Phosphorus and oxygen combine with other elements to form the series of minerals called the Phosphates, some of which are highly essential to us as the part of the soil which helps to make plants grow.

Sulphur is the basis of two classes of minerals. As we have already seen it enters alone into combination with metallic elements to form Sulphides, from which we derive many of our metallic ores; also combined with oxygen, it forms with other elements the Sulphates.

The elements chlorine and fluorine enter into the constitution of the Chlorides and the Fluorides, and are classed with Bromides and Iodides, compounds of the less common elements bromine and iodine, to make up the series of minerals called Halogens.

Thus we have a rough outline of the Mineral Classification which is essentially a chemical one, because the principal fact that we want to know about a mineral is what it is made of, that is, what chemical elements have come together to produce it.

In arranging minerals systematically, as is done with all large collections, the classification proceeds from the simpler to the more complex chemical compounds beginning with the elements that occur uncombined in nature.

\section{Scheme of Classification}

\footnotetext{
I Native Elements

II Sulphides, Selenides, Tellurides, Arsenides, Antimonides

III Sulpho-salts:-Sulpharsenites, Sulphantimonites, etc.

IV Haloids:-Chlorides, Bromides, Iodides, Fluorides

$\mathrm{V}$ Oxides

VI Carbonates

VII Silicates, Titanates

VIII Niobates, Tantalates
} 
IX Phosphates, Arsenates, Vanadates, Antimonates, Nitrates

X Borates, Uranates

XI Sulphates, Chromates, Tellurates

XII Tungstates, Molybdates

XIII Salts of Organic Acids:-Oxalates, Mellates

XIV Hydrocarbon Compounds

As to the number of different kinds of minerals, there have been discovered, up to the present time between thirteen and fourteen hundred, and this number is constantly being added to as new substances are being found in all parts of the world. Some of these are very rare, and are represented by only a handful of small fragments, while others are so common and so generously distributed as to form the bases of huge industries. But whether a mineral is so rare as to be found in only two or three pieces in a single very obscure spot, or so common as to be present in the very soil we walk over when we take a walk in the country, it belongs somewhere in the scheme of classification given above. It is a definite combination of certain of the chemical elements which compose the globe, these elements having been brought together without the instrumentality of living organisms. 


\section{Chapter III}

\section{NATURE'S MATHEMATICS}

IF WE were to observe a number of examples of minerals of different kinds which have been gathered together, that is to say if we were to inspect a Collection of Minerals, we would be impressed not so much by the beautiful colors which some of them display, as by the remarkably even and regular shapes which they have assumed. It would seem as though nature had moulded them into geometrical shapes and then polished the sides so that they glitter like a gem in a jeweler's show case.

Looking a little more closely at this singular tendency of minerals to assume regular shapes we will come upon a still more remarkable fact. We will notice that in the case of some one kind of a mineral (like the fluoride of calcium which is called fluorite) a particular shape (such as a cube) is characteristic of the mineral. And this discovery that fluoride of calcium almost always occurs in the form of cubes opens the way to two very significant questions:

1.-Does each kind of mineral have a characteristic shape, just as every animal or plant?

2.-If so, is this shape given to it by the chemical elements which compose it?

It took scientific men a long time in the early days of the development of mineralogy to find the answer to the first question, and it is only within very recent years that the second one has been really answered.

In the first place, it would seem that in most cases a mineral such as carbonate of calcium (calcite), did not have one particular shape which it always assumed. In point of fact this 
particular mineral has hundreds of shapes. But, and this is the essential fact, all of these bundreds of shapes are related by certain sery definite mathematical laws and conform to certain requirements of symmetry which may be recognized almost as easily as the symmetry of the three leaved clower. In other words calcite crystals always form in a systematic group of shapes.

We can, then, answer the first question in this way:Almost every mineral, together with most of the other chenical compounds, when allowed to solidify without interference from the outside, will produce a solid bounded by smooth, bright faces forming sharp well defined angles. This is due to an orderly cohesive attraction between particles of its matter and is known as crystallization. Crystallization is, in fact, the organizing or structure making principal of inorganic nature, producing definite forms for each species of inorganic matter as life does for each living species.

Let us then devote a little time to the consideration of this phenomenon of cohesion between particles of matter which we call crystallization. In the first place we should get a very definite idea of what is meant by "particles of matter." The phenomenon of crystallization is what we have learned to call a physical manifestation, and the force of cohesion between the particles of matter into which we are going to examine, is a physical force. Very early in the development of the science of physics men learned to speak of the units acted upon by a physical force as molecules. A rain drop falling through the air is made up of molecules of water loosely held together by the force of cohesion. We know nothing whatever about the shape of these molecules and not very much about their size, but on the latter point we are beginning to get a little more light. Lord Kelvin has stated that if we were to magnify the raindrop about which we have just been speaking, to the size of the earth, its molecules would have a size somewhat between that of an orange and a marble. So we are, at the very start, confronted with the idea that in picturing to ourselves these particles of matter, we must imagine them as almost infinitely small, so small 
in fact that they are far beyond the range of vision of even the most powerful microscope.

Another fact about the molecules that compose all kinds of matter is that they are never quite in contact with one another. This is apparent when we think of the mercury in the bulb of a thermometer. When the air is warm the space between its molecules is greater and the column of mercury rises. On the other hand when the weather gets cold the space between the molecules becomes smaller and the thermometer registers lower.

In every gas such as water vapor the space between the molecules is so large that its particles of matter have no cohesion, and in every liquid the corresponding space is reduced to a point where the molecules are held loosely together by cohesion so that they move freely and are not definitely linked one with another. But as soon as the space between the molecules is reduced to a certain point, a set of forces comes into play between them which link them together, and which link them together along certain definite lines of direction. It is as though the forces of cohesion which loosely bound together the molecules of a liquid, had, when that liquid became a solid been oriented along definite lines of attraction.

The molecules of every mineral, with a few rare exceptions ${ }^{1}$ possess this power of attracting to themselves other molecules of the same kind along definite directions of crystallizing force, which directions, as well as the relative intensities of the forces, are distinctive for the molecules of different kinds of substances. And they are capable under favorable conditions of building up orderly structures of these molecules, in much the same way that a brick layer builds bricks into a wall.

Let us follow the steps of what we may assume to be a favorable condition under which a substance becomes crystallized. Suppose we were to put a strong solution of common salt,

1 It is possible that these exceptions to the almost universal rule of crystallization in minerals are in reality not exceptions at all. The mineral turquoise was for a long time assumed to be without crystallization, that is anorplious, and it was only in 1911 that crystals of it were found and identified. 
(sodium chloride) in a flat dish, where it would have a large surface from which evaporation could take place, and allow it to evaporate until the diminishing quantity of water becomes so saturated with salt that it can no longer hold its burden of sodium chloride. We can imagine the tiny salt molecules, each with its set of crystallizing forces, reaching out for other mole-

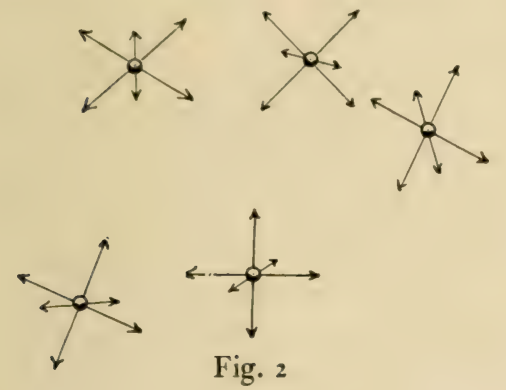

Fig. 2

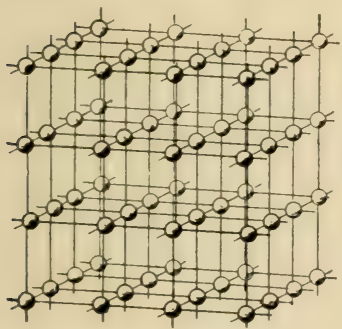

Fig. $3 b$

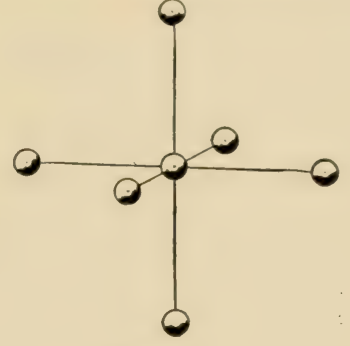

Fig. $3 a$

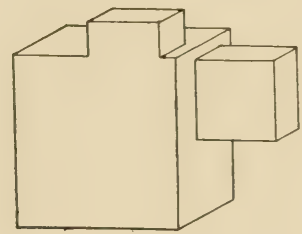

Fig. 4

Fig. 2. A diagram of freely moving Particles of a Crystallizing Substance.

Fig. 3a. Arrangement of Molecules in a Crystal of Common Salt.

Fig. $3 b$. The grouping of Crystal Particles in an Isometric Crystal.

Fig. 4. A group of Cubic Crystals of Common Salt.

cules of salt, much as a magnet reaches out its invisible force of attraction for a piece of iron. And just as the magnet can not exert its influence to attract the iron until it is approached near enough to it so the salt molecules continue to circulate in the solution, each continually reaching out in three rectangular directions of equal force, characteristic of the molecule of salt, but unable to pick up and hold any other particle of its own 
kind owing to the thinness of the solution. If we were able to look at these particles of matter through some super-microscope, thousands of times more powerful than any we have today, we might represent them in diagram in some such way as is shown in Figure 2. Of course the round shapes given them here do not mean that they are really round, they are merely assumed for convenience in representing them, and we have a number of reasons for supposing that they are not round. But the important fact is that each of them has a little group of crystallizing forces pulling equally in three directions at right angles to one another as we have represented in the diagram. But as the salt solution grows smaller in volume and more concentrated through evaporation, a point will be reached where some of the salt molecules will be able to attract and hold others along these lines of crystallizing force. As soon as this point is reached we find that the salt has begun to crystallize from the solution in little cubes. Each molecule of salt has attracted to itself six other molecules in the way indicated in Figure $3 a$, and a structure of molecules has been built up in the way indicated in Figure ${ }_{3} b$. As more molecules are added to this network of particles, when the solution becomes more concentrated by evaporation, the crystal grows in size until it becomes large enough for one to see. Perhaps two or more of them will unite, but always if these uniting crystals are free to move in the solution they will be joined together along the lines of the crystallizing forces, that is with their sides parallel, as we have suggested in Figure 4.

In this way we are able to see why common salt (sodium chloride) always crystallizes in cubes, the planes of which are at right angles to the directions of crystallizing force in its molecules operating with equal intensity and at right angles to one another. This is the principle upon which are produced the crystals of a number of minerals, such as Fluorite, Galena, and Pyrite which, as we can readily notice by examining them, form in cubes. ${ }^{1}$ But, on examining some of these cubic crystals, we

1 The reader may verify this statement by observing the series of these minerals in the cases of the Mineral Collection. 
will find that they are variously modified. In some (notably galena crystals) the corners of the cubes are cut off by other planes; others (notably fluorite crystals) have the edges of the cubes bevelled by other crystal faces.

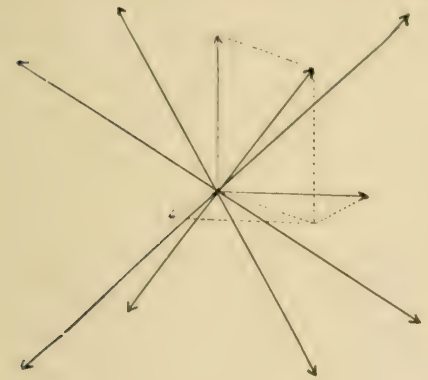

Fig. 5

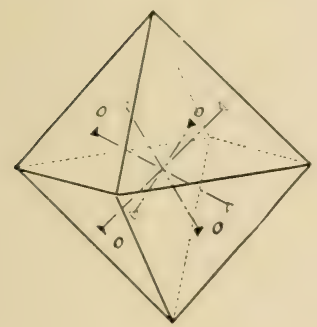

Fig. $6 b$

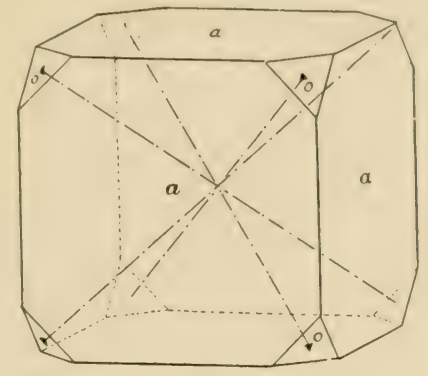

Fig. 7

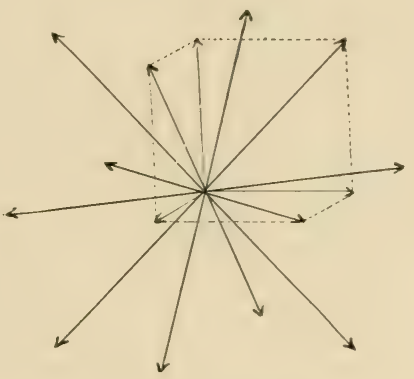

Fig. $6 a$

Fig. 5. The lines of Crystallizing Force resulting from combining the three directions of Force that operate to make a Cubic Crystal.

Fig. 6a. A Cube with the corners replaced by the faces of an Octahedron.

Fig. 6b. An Octahedral Crystal.

Fig. 7. The lines of Crystallizing Force resulting from combining two directions of Force that operate to make a Cubic Crystal.

Now in order to account for these modifying planes on cubic crystals, let us suppose that the crystallizing forces instead of each acting separately to make the faces of a cube, acted in combination, all three together. The resultant of each group of three directions of force will give us the new lines of force shown in 
Figure 5. These, producing crystal planes at right angles to their directions, result in the eight faces which replace the corners of the cube in Figure 6a. Frequently among minerals, whose molecules arrange themselves in cubic groupings the crystal form due to the combined directions of crystallizing force, indicated in Figure 5 is produced as an eight sided solid

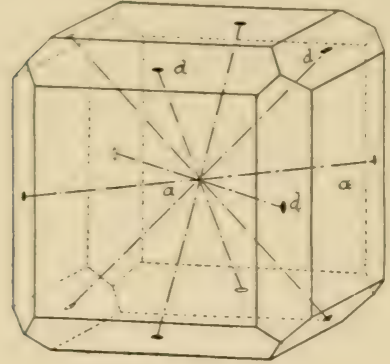

Fig. $8 a$

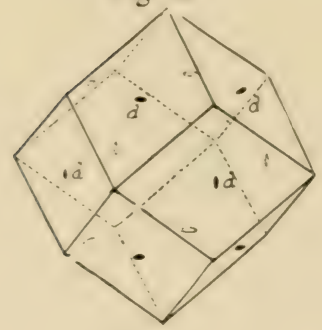

Fig. $8 b$

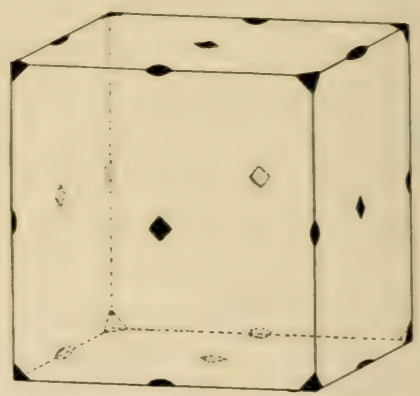

Fig. 9

Fig. 8. A Cube with the edges replaced by the faces of a Dodecahedron. Fig. $8 b$. A Dodecahedron.

Fig. 9. The symmetry of the Isometric System shown on a Cube.

called an octahedron, and shown in Figure $6 b$. It is erident that the planes of this crystal are the same as the triangular ones marked $o$ in Figure 6.، because, if we imagine these latter increased in proportionate size and the cubic faces (marked a) decreased in proportionate size we will ultimately come to the Figure $6 b$.

By a similar process of reasoning, if we combine two rec- 
tangular directions of crystallizing force in pairs as shown in Figure 7 , the erystal planes formed at right angles to them will replace the edges of a cube, as in $8 a$ and independently developed will give us the crystal form called the dodecahedron of Figure $8 b$. These three crystal forms, the cube, octahedron and dodecahedron, all produced by crystallizing forces of equal intensity at right angles to one another, belong to what is known as the lisometric system of erystallization, nor are they the only forms among Isometric crystals, for the crystallizing forces which have produced them are susceptible of combination between any two of themselves to produce other forms. These moreover combine with and modify one another until an assemblage of crystals, some of them highly complex, is built up among minerals having as the basis of their crystallizing tendency the three equal rectangular forces.

This has sometimes been called the cubic system because in it the crystal forming forces act primarily in the directions of the edges of a cube. All crystals formed in this way have, on account of their molecular grouping, certain inherent aspects of symmetry, just as our bodies with their right and left arms and legs, or a clover leaf with its three petals, have certain aspects of symmetry.

Let us consider a cube with this in mind and see for ourselves what these aspects of symmetry are. The cube shown in Figure 9 has in the center of every square face a point with respect to which all the surrounding edges and angles are repeated four times. The imaginary lines passing through the center of the cube and joining each pair of these points are called axes of 4 -fold, or tetragonal symmetry. In the same way, there emerges from the middle of every edge of the cube one end of an axis of 2 -fold or binary symmetry with respect to which all the parts of the cube, faces, edges and solid angles are repeated twice, or as we might say, they occur in pairs. Again every solid angle of the cube marks the position of one end of an axis of 3-fold or trigonal symmetry.

It is the presence of these four axes of trigonal symmetry, 
which in the cube are marked by the eight solid angles, that constitutes the distinguishing feature of every crystal belonging in the Isometric System, because although some of them may not show the perfect and complete symmetry of the cube, they all, even the most unsymmetrical ones, possess four axes around which their edges, faces and solid angles, howerer complex these latter may be, are repeated in 3 -fold aspect. ${ }^{1}$

Let us now consider the case of a substance whose molecules are bound together by crystallizing forces that operate in a slightly different way from those which form an isometric crystal. Let us suppose that these forces attract molecules of the same kind along the cubic directions of the isometric system, but while two of them are equal in intensity the third is either stronger or weaker than the other two. The resulting grouping of molecules when crystallization takes place will take either the form typified in Figure s o a or in Figure rob. In other words, the crystals built up by molecules of this kind will be of a type either like Figure i a $a$ or like Figure i $b$. Now by a series of steps exactly similar to those we used to develop the isometric forms of crystals, we can derelop from these types of molecule groupings, crystals which are different from isometric crystals in that they do not show the perfect symmetry of these latter, but are, as it were, longer or shorter in one direction.

It is the characteristic aspect of symmetry in crystals made up of this type of molecules which is the significant feature that distinguishes them from every other class, and places them in what is known as the Tetragonal System. We have seen that every isometric mineral belonging in a certain group of symmetry must crystallize in the same kind of forms. The cubes of galena are of the same shape as those of fluorite or those of a score of other minerals. The octahedrons of magnetite are like those of spinel or diamond. But, as now we are dealing with a

1 The reader is urged to make the test of this characteristic of isometric crystals upon the large group of wooden models of them installed in the Introductory Series, to the right of the entrance of the Morgan Memorial Hall. 


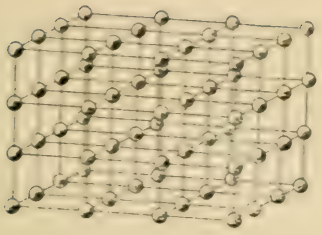

Fig. 10a

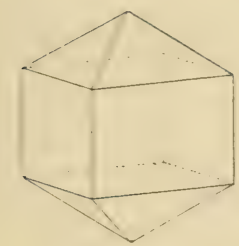

Fig. I $1 a$

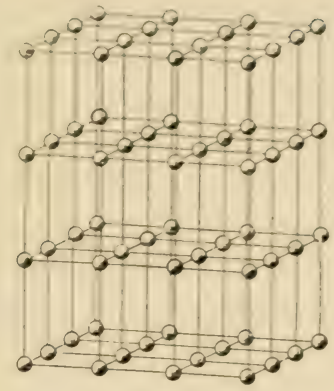

Fig. $10 b$

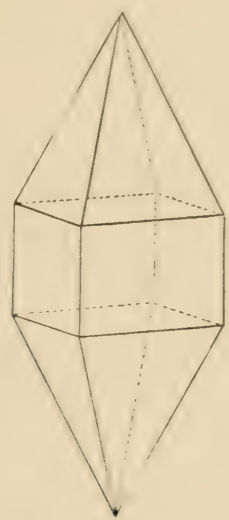

Fig. I $b$

Figs. Io $a$ and $10 b$. Groups of Crystal Particles that produce Tetragonal Crystals.

Figs. $11 a$ and $1 \mathrm{i} b$. Tetragonal Crystals that result from groupings shown in Figs. $10 a$ and $10 b$.

set of crystallizing forces in which one differs in intensity from the other two, we can readily see that the amount of its difference may vary for erery kind of tetragonal molecule. So in this, as well as in the succeeding systems erery mineral has its own distinctive group of crystal shapes, which differ from everything else in nature, and by means of which one may recognize 
a particular mineral by means of its crystals alone from among hundreds of others.

Let us then, assume as an example, a simple tetragonal crystal of the mineral zircon, which is a silicate of the element zirconium, and examine its symmetry. In Figure 12 two views of this crystal are giren; the upper one, which represents it as seen from above, is introduced to render the symmetry clearer. It is at once plain that this crystal has fewer points of symmetry than

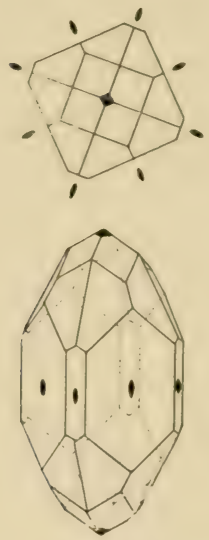

Fig. 12. A Crystal of Zircon showing the Symmetry of Tetragonal Crystals.

any in the isometric system. IVe have seen that every isometric crystal has four axes of trigonal symmetry, and in the most symmetrical group of this system every crystal has also three axes of tetragonal symmetry. But in crystals, such as the example of zircon shown in Figure $\mathrm{i} 2$, we find only one axis of tetragonal or 4 -fold symmetry and no 3 -fold symmetry axes. This, in general, is the distinguishing character of tetragonal crystals, chalcopyrite, a sulphide of iron and copper, constituting an exception among common minerals. With this exception then, we may say that tetragonal crystals are characterized by one axis of tetragonal symmetry and only one.

Molecules of substances belonging to another important system of crystallization have four directions of crystallizing 
force. Three of these form equal angles the one with the other, all three lying in the same plane, and are equal in intensity, but the third is at right angles to this plane and is greater or less in intensity than the other three. The assemblage of particles which results from the linking together of molecules actuated by these forces of attraction will take the forms typified in Figure $1_{3} a$ or $\mathrm{I}_{3} b$. In either case the resulting crystal will exhibit a symmetry in some respect like that of the tetragonal crystals, only in this instance, since there are three directions of equal force instead of two the axis of symmetry at right angles to them

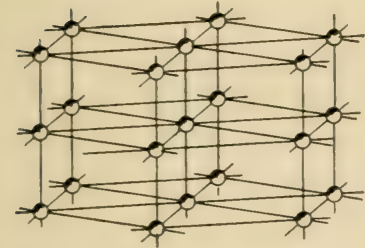

Fig. I $3 a$

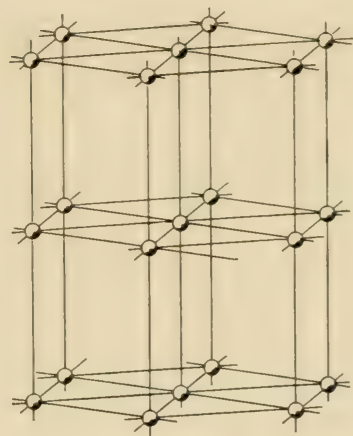

Fig. $13 b$

Figs. $1_{3} a$ and $1_{3} b$. Groupings of Crystal Particles that produce Hexagonal Crystals.

will be either a six-fold axis as in Figure 14 or a three-fold axis as in Figure 15. The former of these represents a crystal of beryl, a silicate of the rare element beryllium, and is a mineral of the Hexagonal System.

The crystal represented in Figure 15 is one commonly assumed by the mineral calcite, a carbonate of calcium, which crystallizes in a division of the Hexagonal System, known as the Trigonal or Rhombohedral Division.

Crystals of the Hexagonal Division are characterized by prisms and pyramids which are "six-sided," in other words, one axis of six-fold or hexagonal symmetry is essential to their de- 
velopment and is the distinguishing feature by which we may recognize them.

Crystals of the Rhombohedral or Trigonal Division, although often showing as part of their development a six-sided prism, always have their faces disposed in three-fold symmetry about their ends or terminations; and whether they are flat in aspect or slender and steep, like church spires, this three-fold arrangement of their planes is essential and characteristic.
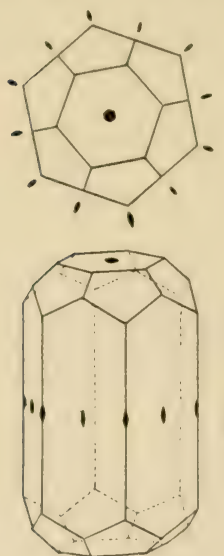

Fig. I4
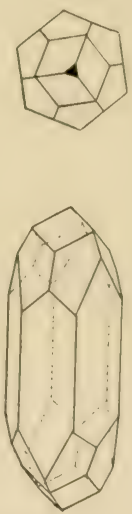

Fig. 15

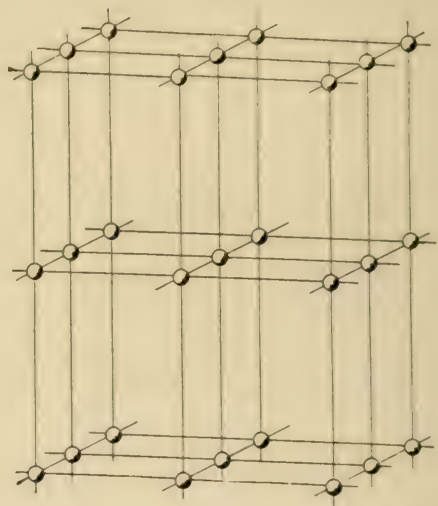

Fig. 16

Fig. 14. A Crystal of Beryl showing Hexagonal Symmetry.

Fig. 15. A Crystal of Calcite showing Trigonal Symmetry.

Fig. 16. A Grouping of Crystal Particles that produces an Orthorhombic Crystal.

A large and very important assemblage of crystallized substances range themselves in forms of a somewhat lower order of symmetry than any with which we have dealt hitherto. The molecules of such substances, like those of isometric or tetragonal crystals, have three directions of crystallizing force acting at right angles to one another, but with these molecules the intensity of these forces are all different. We can imagine such molecules responding to the impulse to crystallize by arranging themselves in some such way as is shown in Figure 16 , and 
assuming them to be molecules of the mineral barite, a sulphate of barium, the resulting crystal might take the form shown in Figure 17 .

Considering this crystal with regard to its symmetry, we will notice that, while we find here three axes of two-fold symmetry, corresponding to the three lines of crystallizing force, there is no aspect of symmetry higher than two-fold or binary symmetry. Such are the essential symmetry conditions of crystals belonging in the Orthorhombic System. Briefly stated they resolve themselves into the following general rule:crystals of the Orthorhombic System exhibit more than one axis of two-fold symmetry but no axis of higher symmetry.

In the foregoing pages we have taken up in turn the different kinds of crystals that are formed from molecules having three directions of crystallizing force acting at right angles with one another, and in isometric, tetragonal and orthorhombic crystals we have seen the effects produced respectively.

I. - By all three of these crystallizing forces acting with equal intensity (isometric crystals).

2.-By two of the crystallizing forces acting with equal intensity and the third with a greater or less intensity than the other two (tetragonal crystals).

3.-By no two of the three crystallizing forces acting with the same intensity (orthorhombic crystals).

Now it is quite evident that these three conditions of relative intensity between three crystallizing forces operating at right angles to one another represent all the variations possible under these conditions of direction, so that in order to further study the principles of symmetry under which molecules unite to form crystals we must assume that one or more of the directions of crystallizing force shall not be at right angles to the others.

Let us consider the case of a molecule in which two of the directions of crystallizing force are at right angles to each other and the third forms an angle with the plane of the other two. Molecules which are bound together by forces acting in this way might be represented in such a diagram as is shown in 
Figure 18 and produce crystals of the Monoclinic System, which is represented among minerals by a great many substances. A crystal of one of these, the mineral gypsum, a hydrated sulphate of calcium, is shown in Figure 19. It will be seen at once that such a crystal exhibits a symmetry of a lower

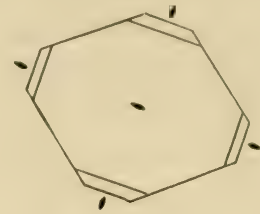

Fig. 17. A Crystal of Barite showing the Symmetry of Orthorhombic Crystals.

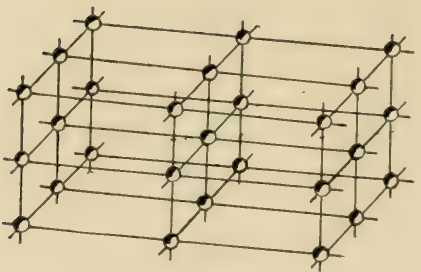

Fig. 18

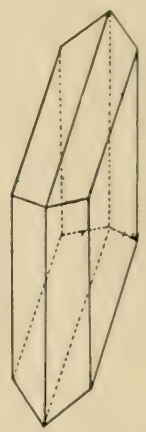

Fig. 19

Fig. 18. A Grouping of Crystal Particles that results in a Monoclinic Crystal.

Fig. 19. A Monoclinic Crystal Gypsum.

order than any which we have thus far discussed. Because the molecules that compose it are linked together by crystallizing forces which are no longer all acting in rectangular directions, its aspects of symmetry are reduced to a single plane of symmetry dividing it into symmetrical halves, just as our bodies are divided into right and left halves, and a single axis of two-fold symmetry at right angles to this plane. Either or both of these 
conditions of symmetry are essential to crystals of the Monoclinic System, and every monoclinic crystal exhibits at least one of them.

There is but one other way in which the forces which actuate molecules of matter to bind them together as crystals may act to produce crystals of essentially a different kind. If we assume the three directions of crystallizing force to be all oblique to one another molecules controlled by these forces might produce

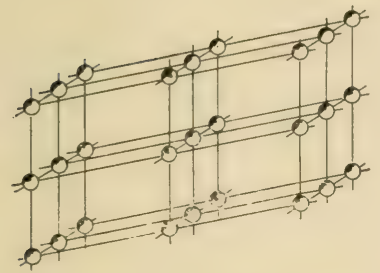

Fig. 20. Crystal Particles grouped in this way produce a Triclinic Crystal.
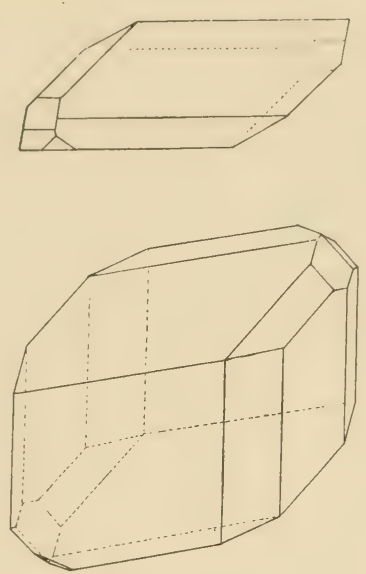

Fig. 21. A Triclinic Crystal of Axinite.

such a group of molecules as is shown in Figure 20 , and the resulting crystal will belong to the least symmetrical of all the systems of crystallization, the Triclinic System. The triclinic crystal shown in Figure 2 I represents an example of the mineral axinite, a boro-silicate of aluminum and calcium. Such a crystal has no axis or plane of symmetry, the lowest grade of symmetry assumed by any crystallized substance.

Throughout the realm of crystallized substances, a realm governed by laws as fixed and exact as those which hold the planets in their courses, we find each substance occupying its place in one of the six systems of crystallization which we have 
here outlined: So the bewilderingly complex multitude of forms arrange themselves into orderly groups, and when once we possess the key to the manner in which their particles are marshalled together, like soldiers on parade, we find that, like everything else in nature, they are governed by a few broad, far reaching principles. And as we penetrate deeper into the laws that govern these particles of matter, we find that the wealth of shapes which they assume is only one expression of the workings of these laws. Every minutest fragment of a crystallized substance bears witness of the way in which its molecules are arranged by the way in which it transmits light, and heat, and electricity. The glittering crystal of quartz which appeals to our eye as wonderful in the symmetrical disposition of its parts and the perfect exactitude of its angles is only the outward expression and result of an inner arrangement of its infinitesimal component particles, more wonderful and more significant even though we can not see them. 


\section{Chapter IV}

\section{THE MIMICRY OF MINERALS}

IVE SAW in the last chapter how the disposal of the facets which constitute the outward form of a crystal is governed by definite laws and how these laws operate to impose a definite and characteristic aspect of symmetry with respect to the disposal of these facets upon the crystal of a particular chemical substance. So we may have prisms of four or eight sides among the

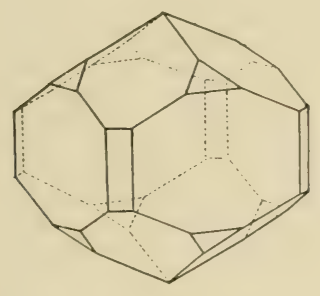

Fig. $22 a$

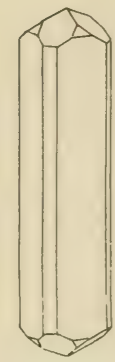

Fig. $22 b$

Figs. $22 a$ and $22 b$. Two Crystals of Rutile showing a variation in Crystal Habit.

crystals of a mineral that crystallizes in the tetragonal system. But there is nothing in the operation of the forces which produced such a prism to limit its relative length. In the growth of such a crystal its component particles might have added themselves to the nucleus in rows extending outward from the axis of 4 -fold symmetry which determines its system producing such a short stout shape as is shown in Figure $22 a$. Or, on the 
other hand, these same particles subjected to the same crystallizing fores may, under slightly different conditions, build up a crystal that is long and thin in the direction of the 4 -fold axis of symmetry, like Figure $22 \mathrm{~b}$. At present we know very little regarding the conditions of erystal formation which tend to produce these variations in the proportions of, as well as the diversity in form, among crystals of the same mineral. Certain conditions of heat and pressure certainly are responsible for some of them, and it is also reasonably certain that the presence of slight amounts of foreign matter in the crystallizing substance tends to vary the kind and number of forms. All of these variations we group under the term habit, and speak of a crystal as having a prismatic babit when the faces of the prisms are specially developed, or a pyranidal habit, when the relative size of the faces of the pyramids are so large as to predominate in the shape of the crystal. The crystal illustrated in Figure $6 a$ is of cubic habit and the one known in $6 b$ is octahedral in habit.

It is variation in crystal habit that produces such almost endless diversity among the crystals of mineral species. Some may be flat as a sheet of cardboard while others are drawn out to the proportions of a sewing needle or even a hair. Especially is this so among minerals that are both common and widely distributed. In the Atlas of the Crystal Forms of Minerals, compiled by Dr. Victor Goldschmidt ${ }^{1}$ the mineral calcite is illustrated by over 2500 figures, showing the remarkable diversity in crystal habit exhibited by this mineral.

A factor that plays a very important part in the development of crystals in the relative length of time consumed in their formation. Crystals formed by a slow process of building up of their molecules tend to become large and well developed, while on the other hand rapid action of the crystal forming forces produce small and ill developed crystal individuals. It is as though these forces require for their perfect operation a certain deliberation, and just as a regiment of soldiers scattered promiscuously orer a field need an appreciable time to come into

1 Victor Goldschmidt Atlas der Krystalliformen, 1913 Band II. 

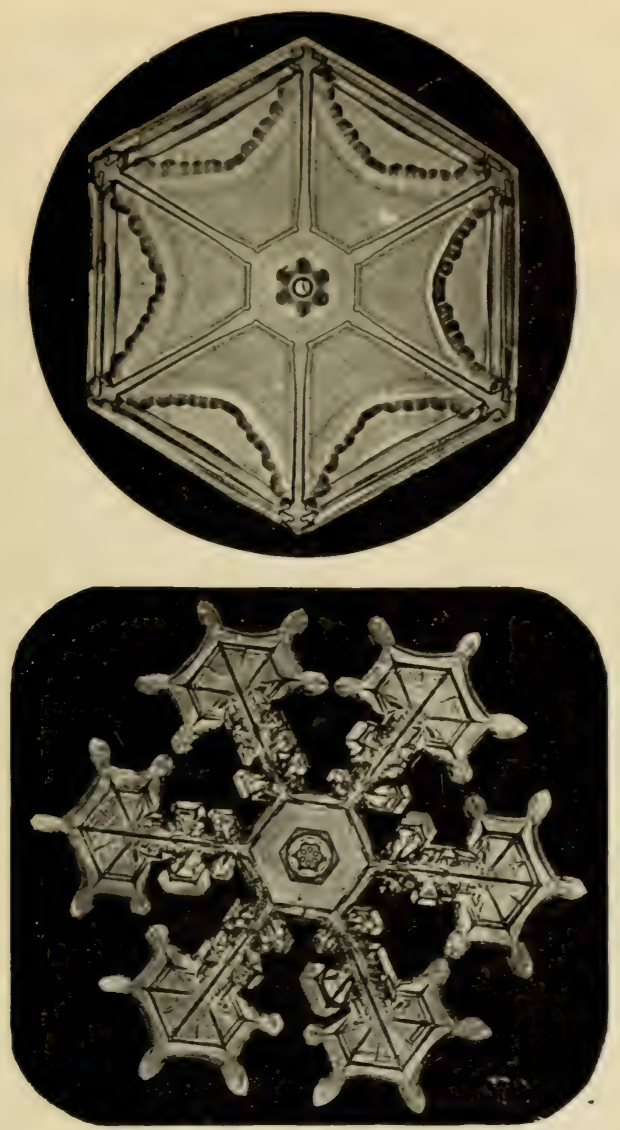

Fig. 23. The tiny six-sided plate (upper figure) which, under conditions of slow crystallization, is typical of snow, with a somewhat more rapid cooling of the air becomes the center of intricate, branching, and starlike forms of wonderful symmetry (lower figure).

formation, so the particles of matter that come together to form a crystal require time to effect the orderly arrangement which we find in highest perfection in large and well formed individuals. To such an extent is this so that we find, in the case of minerals that have formed very rapidly, no individual crystals at all, only a mass of mineral matter whose sole evidence of 
crystallization is revealed by its optical properties.

Between the perfectly formed crystal developed to ideal proportions and free from distortion, and such massive bodies which do not possess any outward token of crystallization, we find among minerals a wide range of examples of molecular

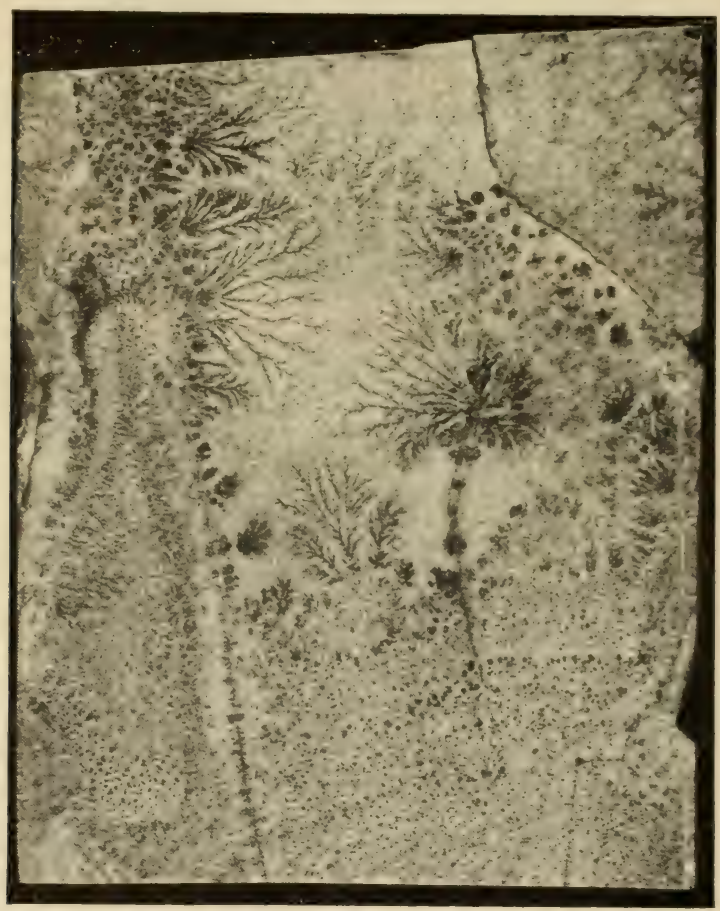

Crystalline Aggregate of the .Mineral Pyrolusite (Manganese Dioxide).This structure, which is called dendritic, is formed in the same way as window frost, which it closely resembles.

architecture which are known as crystalline aggregates. Many of these mimic the forms of animate nature, producing fanciful shapes of great diversity and beauty. Water, which is so common a substance that few of us realize that it is really a mineral, furnishes us with an admirable instance of the wealth of ex- 
quisite patterns produced by crystallization. Where water vapor is cooled slowly to just the point of freezing its molecules are drawn together to form little flat six-sided crystals familiar to anyone who has looked closely at snowflakes. With somewhat more rapid cooling of the air the minute nucleus of the

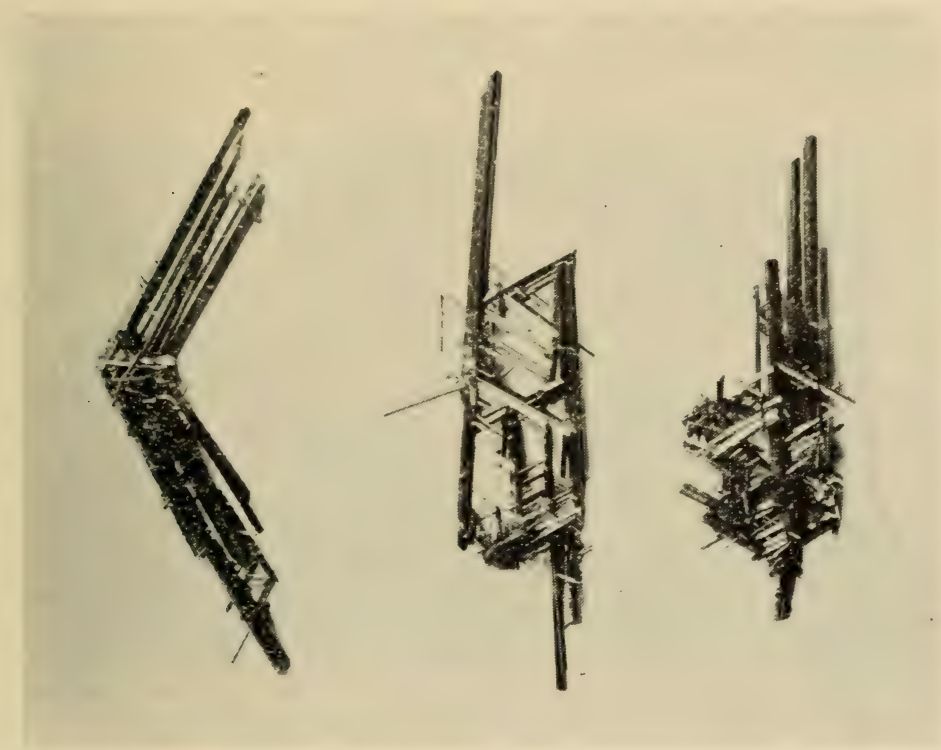

Long thin crystals of rutile (titanium dioxide), which group themselves in masses, suggesting the slender columns characteristic of certain types of architecture.

snow crystal becomes the center of intricate branching and starlike forms of wonderful symmetry, one of which is shown in Figure 23. Where water vapor consolidates on a cold sheet of glass, as a window pane, the water crystals grow much more rapidly and interlacing patterns of rods, produced by one tiny crystal forming against another, or branching, fernlike forms result. Lastly, where the dripping water is consolidated by the cold, the rounded shapes of icicles, resulting from the quick 
solidification of a liquid, give no outward evidence of the inward ordering of their molecules, although this arrangement is the same that has produced the snow crystal and the window frost. The knowledge of how window frost is produced enables us to understand the meaning of the so called dendritic structure, assumed by a number of minerals. Such minute and intimate crystal groupings as are to be seen in moss agate bear a very close resemblance to the delicate tracery of the vegetable world, and at first glance we are almost forced to the belief that they are in reality fossil plants. However, we have but to compare them with the designs that the touch of winter paints upon our window pane to realize their true nature.

Sometimes the long drawn out prisms of a mineral group themselves in masses joining one another like a bundle of sticks cr the slender fluted columns that distinguish some kinds of architecture. From the latter resemblance, this kind of grouping has been called columnar structure. Or again the long thin rods, which are in reality prismatic crystals, interlace to form a netlike structure with angular open spaces. This kind of structure may be seen in some varieties of the minerals rutile and cerussite.

Crystals seem to have a tendency to attach themselves to a support with the direction of their greatest length projecting outward. A crystal of slender prismatic habit will usually project out from the rock to which it is attached in much the same way that an iron filing sticks out from the magnet that attracts it, and if the crystal happens to be flat and plate-like it will very often be found attached by its edge. Needle-like or hair-like crystals attached to a projecting point will tend to radiate from this point as a center and will assume a structure like a tuft of hairs. Quite a number of minerals furnish examples of this grouping. Perhaps the most striking illustration is to be found in the radiating crystal aggregates of the mineral natrolite, which from a center thrust out their glistening white needles sometimes an inch and a half or more in all directions. As it usually happens that the length of these needle-like prisms is fairly constant, the outer surface of the group assumes the shape of a 
ball, the outline of which becomes more perfect as the radiating prisms that form it are more thickly grouped. An excellent instance of the perfect roundness assumed by these "mineral balls" will be found in the mineral wavellite, which assumes forms that remind us of the familiar fluffy seed balls of the dandelion. Occasionally the radiating structure has for its nucleus a single small fragment of a mineral, such as a fragment of quartz or a minute crystal, and the conditions are such that

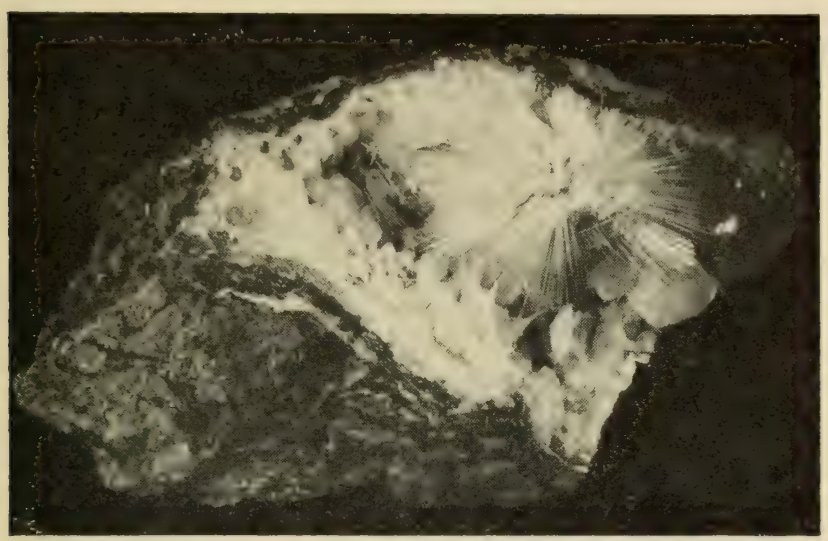

NATROLITE

Long slender silky needles of the mineral natrolite radiating from a central nucleus suggest a fluffy seed ball of the dandelion. Wavellite is another mineral that assumes forms of this type.

crystals are freely developed in all directions around this center. In this way the concretionary balls of the mineral pyrite are produced in slate, and when these are cut in sections through the centers they constitute the beautiful and remarkable objects that are known as pyrite "sunbursts."

The mineral bematite often crystallizes in flat hexagonal plates. Sometimes these plate-like crystals attach themselves to a projecting point in overlapping piles in much the same manner that the petals of a rose are attached to its calyx. The fanciful 
name of "iron roses" has been given to these groupings. When the plates are more thickly packed together a variety of curious and interesting crystal structures results, such as the crested aggregates of the mineral barite and the sheaf-like bundles of the mineral stilbite. The flat crystals of calamine, a silicate of

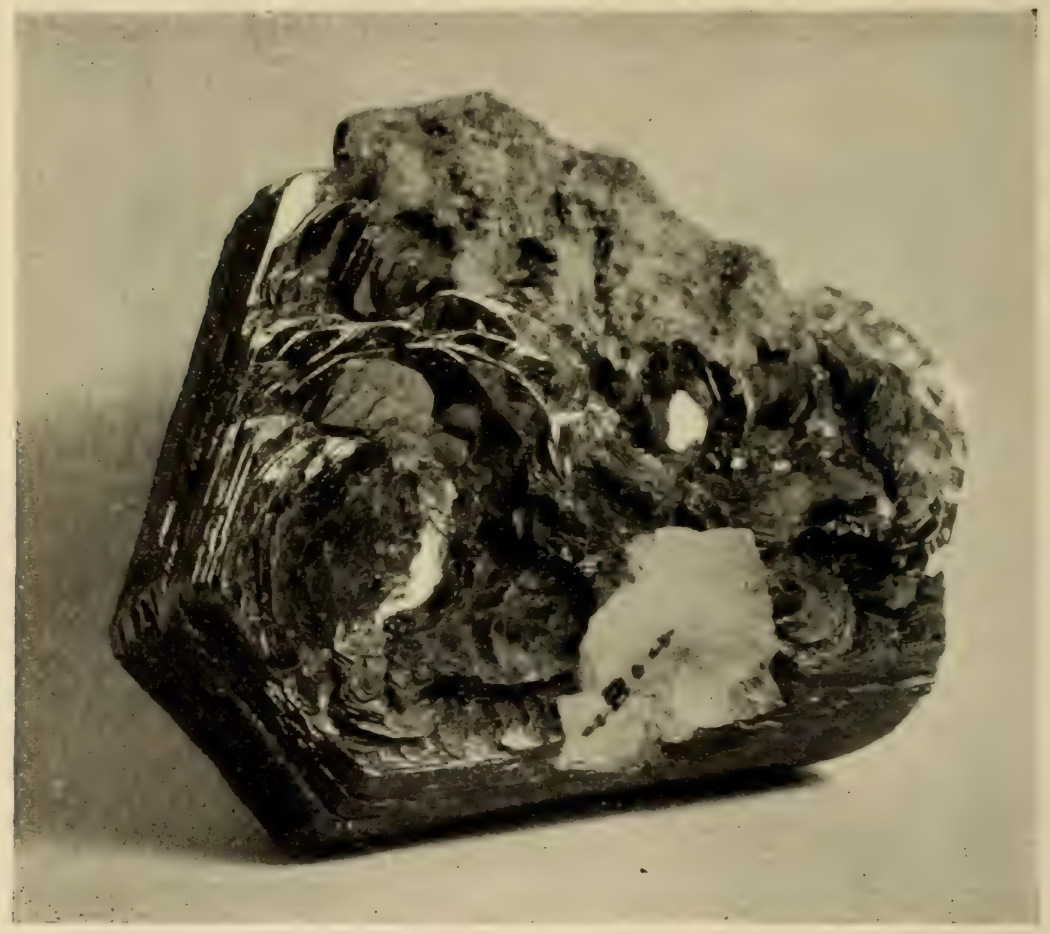

The flat platelike crystals of hematite sometimes bunch themselves in forms resembling the petals of a rose.

zinc, tend to group themselves in rounded ridges, notched at the crest where the angular edges of the crystals emerge from the group. From a fancied resemblance to the notched comb of a rooster, this grouping has been called "cockscomb" structure.

Frequently among minerals the crystal individuals are so crowded together that no single crystal has had a chance to 
develop its regular and characteristic outline, or to assume with its neighbors a characteristic group or aggregate. Such a structure made up of packed together crystal units may resemble when broken a lump of sugar or a mass of common table salt made solid by moisture. Because they are made up of masses of coarse or fine grains we call such structures massive and characterize them as "coarse granular" or "fine granular," the "grains" being each a tiny crystal without the outward form it would have had if it had been permitted a free and unobstructed growth.

We have in the foregoing pages touched upon some of the more significant examples of crystal structure and have endeavored to explain how nature operating through the inflexible laws of crystallization has out of inorganic matter fashioned the intricate shapes which often suggest the forms of life. We have, as it were, only opened the door of this fascinating maze of form and color a little way, and permitted you to merely glimpse the wonders that are within. To draw a comparison from the animate world, the relation between crystalline aggregates and the individual crystals that compose them is outwardly much the same as the relation between a compound flower and the separate flourets that make up its intricate form. And just as in the realm of plants we find countless shapes among compound flowers so in the mineral kingdom the varied forms assumed by groups of crystals continually excites our wonder and admiration. 


\section{Chapter V}

\section{WATER AS A MAKER OF MINERALS}

THE preceding chapters have given us a brief insight into answers to such questions as what minerals are and why they assume the remarkable and intricate shapes in which we find them. Let us now turn to the no less important consideration of some of the conditions governing the operation of the natural forces that have been at work since the beginning of time forming, breaking up and reforming minerals from the materials which constitute the earth. We can imagine the earth as a vast chemical laboratory in which at different places and under different conditions the chemical and physical reactions are operating today, as they have operated through the many ages of its history, to produce from the substance of the laboratory itself the many and varied compounds which comprise the mineral kingdom.

The alchemists, who in the middle ages occupied the place of the chemists and geologists of today, conceived these earth forces as "Elements," as elemental cosmic powers arranging, ordering and producing matter in nature's crucible. The elements of these early philosophers were Earth, Air, Fire and Water, forces which we now recognize as Heat, Pressure, Atmospheric Weathering and Water, and we are beginning to realize that the alchemists were fully justified in ascribing to them, however fantastically, supreme potency as natural forces.

Of this quartet of powerful earth-forming agencies, water is a very important and universal factor. Few of us realize to what degree water is present in everything that surrounds us. Everywhere, in the atmosphere, in the soil and in the rocks we can 
find evidence of the almost universal presence of moisture. If we were to bring an extremely cold piece of glass or metal, as a glass filled with ice, in contact with the air of a warm room it would immediately be corered with a thin film of water. If we were to crush what seems to be the dryest rock, and heat the powder to a red heat, it would yield a small amount of water. Below ground the presence of water is much more obvious. One of the first things that attracts our attention on descending the shaft of a mine is the constantly increasing trickle of water on the rocky sides of the excavation. One does not have to penetrate far below the surface before the volume of this underground water which filters through the crevices in the rocks that form the sides of the opening, has reached the size of a small brook.

This condition is in no respect confined to mines and caves, nor is it restricted to localities; in fact we have abundant proof that a large portion of the surface water which has fallen as rain and snow finds its way by percolation into the rocks and establishes a level of ground water. In other words we have a system of circulation of subterranean water no less real than our system of brooks, streams and rivers, but far more complicated, inasmuch as the ground water percolates rather than runs through the soil, loose conglomerate and cracks and fissures in the harder rocks.

But water does more than merely circulate through the fissures and interstices of the rocks. There is probably no substance which, under proper conditions, is not to some extent soluable in pure water. And this solvent power of water is very much increased by heat and pressure, as well as by the carbon dioxide which is absorbed in small amounts by rain water in its passage through the air. Even silica, a substance which we generally regard as very hard to dissolve, yields to the dissolving action of water under these conditions and is carried away in solution to be deposited elsewhere when the water of the underground system of circulation becomes overcharged with it. The hot springs of the Yellowstone afford excellent means of study- 
ing the mineralizing action of water bearing silica in solution and depositing it when the underground water is cooled and evaporation can take place around the point of outfliow of the spring. This is at once the simplest and most obvious instance of the way in which water operates to form minerals. We are forcibly reminded of the evaporating dish of brine depositing salt around its edges as the solution recedes.

Another very obvious and illuminating example of the way in which a mineral is formed by the action of water is furnished us in the icicle-like deposits of lime carbonate which we find in such caverns as the Mammoth Cave in Kentucky and Luray Cave in Virginia. These caverns are made by the dissolving action of underground water upon a limestone rock. Existing originally only as fissures through which the water circulated, the opening in the rock became gradually enlarged through the dissolving away of its sides until grottos of considerable size were produced. As the bulk of the underground water sought other channels the open spaces became caves into which water descending from the surface made its way through the small cracks and seams in the overlying limestone, always carrying with it on its journey lime carbonate dissolved from the rock which it traversed in its descent. Now as the water, forming in drops on the roof of a cavern, hung for a moment before dropping onto the floor, in this moment it gave up through evaporation a little of its dissolved lime carbonate. So for every drop of water falling from the roof onto the floor of the cave there was deposited on the spot from which it fell a tiny ring of lime carbonate, and the action was repeated on the floor of the cave at the spot that marked the place where the drop of water fell. Thus slender, hanging, pointed masses of Calcite and Aragonite, which are the minerals composed of lime carbonate deposited in this way, grew from the roof directly over somewhat more rounded masses of the same mineral deposited on the floor, producing the series of shapes so well known to us as icicles and formed by dripping and freezing water. As the pendent mass which is called a Stalactite grew in length and 
thickness its rate of growth became greater because there was more surface for the drop of water to traverse and consequenty more evaporation and more of its dissolved mineral to be set free. And the same of course is true of the lime carbonate mass that grew up from the floor and which is called a Stalagmite. It naturally follows that, if the growth of these two masses of lime carbonate is not interrupted, they will unite and merge into a column down which the water flows, continually increasing its size as more material is added.

One can readily see that stalactites and stalagmites, growing as they do by successive deposits of material, each of which is laid on the preceding one, will show on breaking or cutting them in two the concentric rings representing this growth much as an onion sliced in two exhibits the concentric layers of its growth. But there is this important difference:-an onion, like every other organic thing, grows from the inside, whereas stalactites and stalagmites, as well as every other mineral substance add material from the outside. Now let us suppose that the character of the solution of carbonate of lime that is building up our stalactite were to undergo a temporary change. It might for instance, carry a little iron rust in solution slightly coloring it red or brown. This change would be faithfully recorded in the forming stalactite which would at this point show a red or brown ring. In this way we get the beautiful and variegated colors that we find in slabs of Mexican onyx, which are in reality portions of huge stalactitic masses of carbonate of lime.

Calcite and Aragonite are by no means the only minerals that are formed by water, which pursuing its underground course, dissolves away portions of a rock and deposits them anew and perhaps as other compounds in some open space. There are many minerals that are commonly formed in this way and those of them that, by reason of their comparatively rapid deposition have not had a chance to form in definite crystals bear the stamp of their stalactitic origin in their smooth rounded outlines. In this way we have stalactites of marcasite, a sulphide of iron; of quartz, an oxide of silicon; of bematite, and limonite, oxides of 


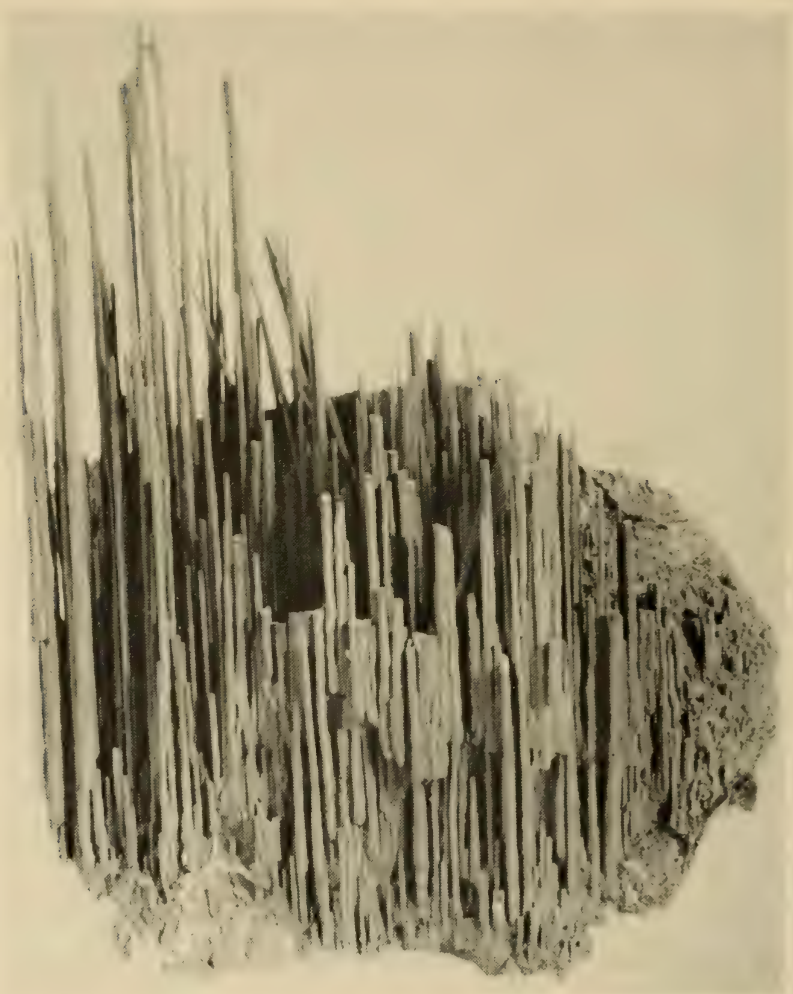

PSILOMELANE FROM ROSSBACH, NASSAU, GERMANY Panel N

Resembling, as it does, a miniature grotto, this group of slender shafts furnish a striking example of the stalactitic structure so common among water-formed minerals.

iron; a psilomelane, a hydrated oxide of manganese, of malachite, a carbonate of copper, and a number of other minerals. ${ }^{1}$

Nor is the character of the open space in the rocks in which water-formed stalactitic minerals are deposited by any means

${ }^{1}$ Excellent examples of stalactitic structure may be found in the General Mineral Collection under these species. The attention of the reader is also called to Case $\mathrm{S}$ of the wall series and to Case 29 containing stalactitic minerals deposited in caves. 
limited in size and shape. All of the forms of stalactites, staliggmites and columns which excite our wonder and admiration in such a cavern as the Mammoth Cave, may be faithfully reproduced in miniature in a fragment of rock so small that it can be easily held in the hand.

IVe are able to learn a great deal about the way in which water deposits its burden of dissolved mineral matter from a consideration of the geodes or mineral-lined cavities, composed of quartz, to be found in varying sizes in all collections of minerals. Geodes as they are found in the banks of some of the streams of Southeastern Iowa resemble rough, irregular cobblestones. If we were to break one open we might find it nearly filled with water, and would be no doubt somewhat puzzled as to how the water got there. The life history of such a quartz. geode reads something like this:-

A cavity in some soft rock, such as limestone, is eaten away by the dissolving action of the subterranean water much as the limestone cavern which we have described was fashioned, but on a much smaller scale. The underground water, which fills and circulates through such a cavity; in the course of time becomes saturated with silica that it has dissolved out of the rocks containing it, these rocks having been encountered in its previous travels underground. The cavity now becomes a receptacle for successive layers of stalactitic silica which the water, held temporarily as in a vessel, deposits on all sides, rounding the irregular walls of its container to a constantly increasing thickness as the silica solution is constantly renewed from its flowing source, and as the composition of the solution becomes slightly changed from time to time, the thickening layers of the deposited silica within the cavity record these changes in variegated agate. The process may go on until the cavity is completely filled with agate or chalcedony, or the silica depositing solutions may find a new channel leaving the opening only partly filled, or the building up of the interior lining may reach a point where the passage through which the solutions entered becomes completely blocked by silica, leaving 
some of the water, still containing silica in solution, sealed up in the cavity. In the latter case, the deposition of silica goes on within the cavity more slowly, and instead of rapidly deposited silica of the chalcedony phase there may be formed crystals of quart\%. These will continue to grow as long as there is enough dissolved silica in the imprisoned water to supply material for them.

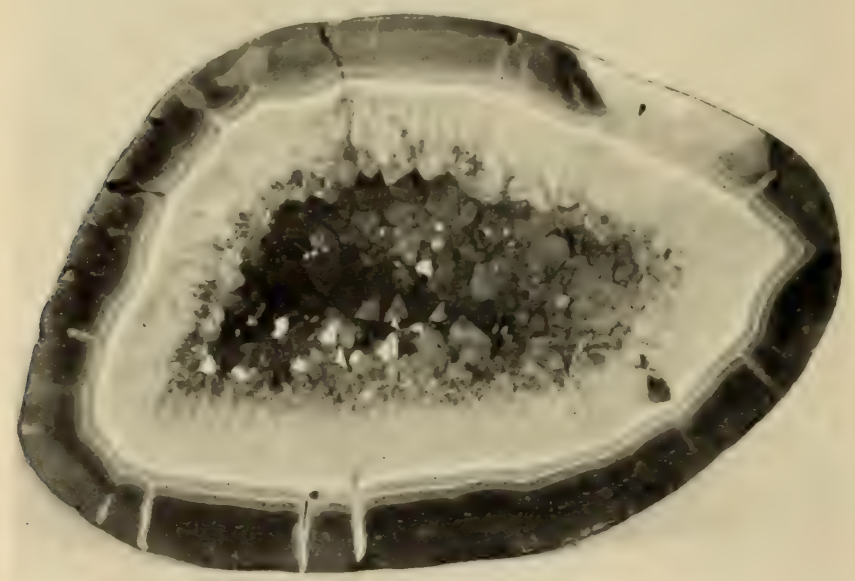

QUARTZ GEODE FROM URUGUAY

Panel L

The rock cavity which ultimately became this geode was incrusted with successive layers of agate, deposited from the silica dissolved in the water which circulated through it, and which finally, acting more slowly, added crystallized quartz in a final layer.

So we have the geode built up within a cavity or "vug" in its parent rock, and composed of harder and more resisting mineral matter than its surroundings. If, now, through the processes of erosion the rock containing the geode becomes the surface of the earth and is decomposed through the action of atmospheric weathering, this harder and more resistant mass of quartz will appear among the fragments resulting from rock decay as a 
more or less irregular but roughly rounded stonc. But if wc were to break open one of these odd shaped pebbles, we could read in the successive layers of its stony lining a complete history of the processes by which it came into existence.

In the foregoing illustration of the way in which water deposits mineral matter in the open spaces of the rocks, we have selected quartz for our example of a dissolved mineral, but such a choice is very far from being limited to one mineral. In fact the dissolving action of water is so universal a factor in mineral formation that it is directly responsible for the bringing into existence of a large and varied series of natural substances, which, because they were directly derived from other forms of earth material, we call secondary minerals.

We use the term "directly derived" because, strictly speaking, all minerals that we find now upon the earth must have passed through many changes, must have, during the evolution of the rocks of our planet, been melted, reformed and melted again in the early stages of rock formation. Nor is this process always as simple a one as the taking up of silica in solution and depositing it elsewhere as quartz. While mineral matter is in solution in the circulating underground waters chemical changes may take place in it, and it may emerge as a secondary mineral, or as several minerals, of different composition from the mineral or series of minerals which gave birth to them. The water that acts as an agent in this process of mineral building may itself become part of the secondary mineral as when iron oxide is taken up in solution and deposited as hydrated oxide of iron, the mineral limonite.

The process of mineral deposition may take place in the crevice or fissure which the underground water traverses, converting this opening in the rocks into a mineral vein.

Mineral veins furnish some of the best examples of secondary minerals deposited from water solutions. Not only are the materials dissolved from the rocks, which were encountered in the previous subterranean journey of these waters, here laid down, but there is often a chemical interaction between these 
substances in solution and the minerals which constitute the walls of the fissure itself. Such fundamental and often highly complex chemical changes which are greatly facilitated by the heat and pressure which frequently accompanies them, are responsible for the metallic sulphides, which, from an economic point of view, are the most important of the minerals formed in this way. It is in the open spaces which sometimes occur in the middle of a vein that the well formed crystals of such minerals as, pyrite, a sulphide of iron, galena, the sulphide of lead, and sphalerite, the sulphide of zinc, are brought into being. And as the succession of mineral solutions, some perhaps differently charged with dissolved matter, follow one another, there may be built up along the sides of the vein layers of two or more minerals. The Mliner, the Geologist and the Mineralogist examining these examples of nature's handiwork, after they have been unearthed by man's enterprise in digging into the earth's crust in his search for valuable and useful things, can tell by the way in which layer is superposed upon layer on the sides of a mineral vein, which was the first and which the last to be formed, and what were the chemical and physical processes which played so essential a part in their production. 


\section{Chapter VI}

\section{CHANGE, AND DECAY IN MINERALS}

AMONG the many wonders of the Yellowstone National Park there is a buried grove of stone trees. At one time in the history of the earth these trees actually grew, they were part of the ancient forest that covered that part of $W_{y}$ yoming. In some flood of a far distant geologic time they were buried under tons of sand and gravel, and then the process by which they were turned into quartz began. For that ever present agent of change-water-was at work here also. The water that circulated through the sand and gravel which covered these old trees and that penetrated into every part of their woody structure was heavily charged with silica in solution, and as the wood was removed particle by particle through decay its place was taken by silica. Thus gradually each tree became a mass of quartz, which while replacing the wood tissue, faithfully preserved the outline of every cell. The replacement of woody tissue by quartz gives us a good example with which to compare some of the less obvious changes in composition that have taken place among minerals. However hard and resistant to alteration a mineral may seem, most of them are by no means proof against the forces of change that are lying in wait to break down their substance and for it substitute something that is chemically different.

Particularly are these agents of alteration active and effective in what is known as the zone of alteration of the earth's crust which is the upper portion of the rocky skin of Mother Earth, and naturally the one with which we are most familiar. It is here that the circulating subterranean waters charged with oxygen 


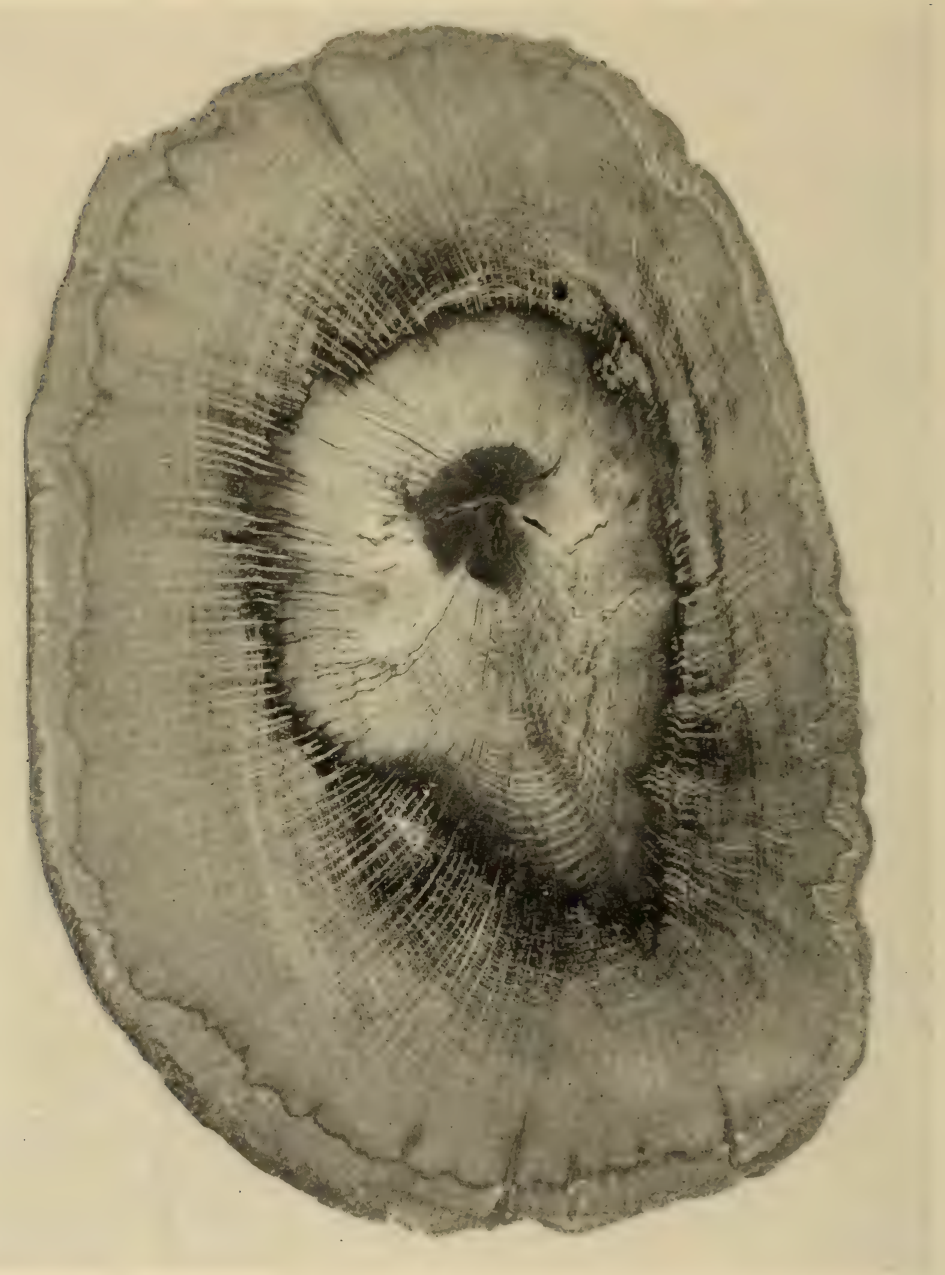

OPALIZED IVOOD FROM LINCOLN COUNTY, IDAHO Panel L

Particle by particle the woody tissue of this old tree has been replaced by silica. So perfect has been the process by which it has been transformed into opal that the bark, the rings of growth and the medullary rays are just as distinguished as though the tree were still composed of wood. 
and carbon dioxide operate to gradually remove by dissolving it away, the original mineral and to eventually substitute in the open space left in this way a new mineral of quite a different chemical composition and character. Thus we sometimes meet with instances where quartz has filled a cast left through the dissolving away of such a mineral as fuorite, the fluoride of calcium. Now fluorite ordinarily crystallizes in cubes, and quartz in terminated six-sided prisms; so we are faced with the apparent paradox of a mineral "stealing" as it were, a crystal form which does not belong to it. This substitution of one mineral for another is called a pseudomorph, and in the case we have just described the pseudomorph has been effected by infiltration.

A much more important kind of pseudomorph is one in which the chemical composition of the original mineral has been altered either by the loss or gain of some elements to produce its final composition, or through an exchange of constituents by which it both loses and gains something. In pseudomorphs of this character we can trace a real chemical relation between the original mineral and the one that has assumed its outward form. A crystal of cuprite, the oxide of copper may through the agency of water carrying carbon dioxide, have added to its composition carbon dioxide and water and become Malachite, a hydrated carbonate of copper. But you will observe that the copper of the original mineral is still present in its altered state, and moreover sometimes in such cases, a little of the original mineral is still present unaltered in the center of the pseudomorph. So, although the crystal form of this pseudomorph, an octahedron with the edges replaced by the planes of dodecahedron belongs to cuprite and not to malachite, we can more readily see how one has altered to the other, than we could if there were no chemical connection between the two. A good example of a pseudomorph that has been reproduced by a partial exchange of the constituents of the two minerals involved, is to be found in pyrite, an iron sulphide, which has altered to limonite, a hydrated oxide of iron. Here the cubic crystals of 
pyrite have given up their sulphur constituent and taken up oxygen in place of it. In a similar way limonite sometimes replaces the carbonate of iron in the rhombohedral crystals of siderite by the removal of the carbon dioxide and the addition of water.

In all pseudomorphs it is customary to speak of the new substance as a pseudomorph after the original mineral. Thus we have pseudomorphs of chlorite after garnet mainly through an addition of water or pyromorphite pseudomorphous after galena through the change of a lead sulphide to a lead phosphate with lead chloride.

Serpentine which is a very common and widely distributed mineral owes its origin entirely to the alteration of some one of a number of silicates containing magnesia. These have been changed by the action upon them of the ground water to hydrated silicates of magnesia. So it is that we have examples of serpentine in pseudomorphs after chrysolite, amphibole, pyroxene and chondrodite, of ten taking the easily recognizable crystal forms of these minerals, but more frequently forming in rock masses that only show their derivation under the microscope.

But important though they are in furnishing us with means of acquiring knowledge about the way in which minerals replace one another, pseudomorphs only constitute a small part of the great and varied changes that are constantly taking place in the kingdom of the minerals. Some of these we have already touched on in the preceding chapter in speaking of secondary minerals in general. There are, however, a very large group of secondary minerals which are so closely associated with the substances from which they are derived that, to borrow an expression from the realm of living things we may almost call them "parasitic." Such secondary minerals are formed from the partial or complete dissolving away of a previously formed mineral by actively decomposing solutions or vapors, and the subsequent depositing on or near it of a substance, composed partly of the elements of the original compound, and partly of those contributed by the reacting solution or vapor. To draw 
an illustration from commonplace things, this reaction is like the forming of the rust of iron oxide on a surface of iron that has been exposed to moisture and has added oxygen to its composition from the water that has come in contact with it. The sulphides of the metals are particularly subject to this kind of alteration, of ten changing to oxides or to some of the chemical compounds containing oxygen such as carbonates, silicates, phosphates or sulphates.

It is among these products of alteration that a great many of the rare members of the mineral family are to be found lurking in the little hollows and crevices of the commoner mineral from which they were derived or crusting its exposed surface in a thin film of microscopic crystals. In this way we learn to look for alteration minerals containing a particular metal such as lead among the lead sulphides of certain localities, and if in addition we have reason to suppose that other elements are present in the mineral rein we may expect to find them also represented in the series of minerals resulting from alteration. Thus certain spots on the earth's surface are often the resting places of unique and characteristic minerals present there because a combination of circumstances has brought together the component elements that unite to make them, and the physical forces which permit elements to combine in this way. 

PART TIVO 


\section{A TOLR OF THE WALL PANELS IN THE MORGAN MIMORIAL HALL}

\section{Chapter VII}

\section{ELEMENTS, SULPHIDFS AND HALOIDES}

THE wall panel assemblage of minerals in the Morgan Memorial Hall is designed as a key exhibit to the larger and more detailed collection which occupies the adjourning flat cases in the north and south sections of the Hall. ${ }^{1}$

The wall panels should be inspected in regular order beginning with Panel $\mathrm{A}$ at the left of the entrance.

We first encounter the elements, that is to say those minerals which are composed of a single elementary substance. This division of the minerals of the earth is a relatively small one because not by any means all of the elements which go to make up the mineral kingdom are found uncombined in the earth. Many of them have such a strong tendency to combine with others that nature, working unceasingly in her chemical laboratory, which is the earth, has never been able to find them alone long enough to make them into separate minerals.

As we saw in Chapter II, these primary substances fall into two groups; metals, which beside exhibiting the well known characteristics of luster and malleability that we associate with them, commonly play the part of the positive or basic element in a chemical combination of elements, and non-metals, which, on the other hand, are lacking in these characters and enact the role of the negative or acid part in chemical combinations.

1 This latter collection includes most of the mineral species known to science and is arranged in accordance with the System of Mineralogy introduced by the late James D. Dana and extended by Edward S. Dana in his Text Book of Mineralogy (1922 Edition).

For a detailed study of this series the visitor is urged to consult one of the text books to be found on the table in the middle of the Hall. 
Between these two groups are ranged a very limited number of substances which are less perfectly metallic in their physical characters and which chemically sometimes act as metals and sometimes as non-metals. These are the so-called semi-metals or metalloids.

In Panel A we find examples of the non-metallic elements in sulphur and carbon, the latter of which occurs in nature in two

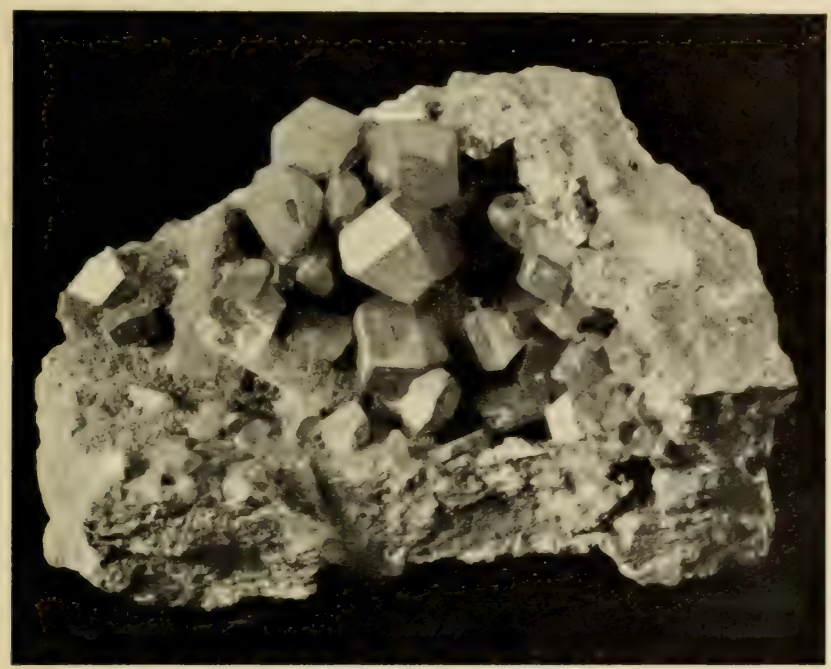

SULPHUR FROM CIANCIANA, ITALY

Panel A

A very familiar substance but in a form that is unfamiliar to most of us. These beautifully symmetrical crystals are, however, the true, characteristic form of Sulphur.

forms as the minerals Graphite and Diamond. Familiarity with the sulphur of commerce has taught us that this substance is brittle, with a resinous luster and a light yellow color, and so we find it in nature. We are however unprepared for the large and perfectly formed crystals that present such a striking feature of the suite of specimens from Sicily. These come from the extensive beds of sulphur in the neighborhood of Girgenti and 
Cianciana where they are found associated with gypsum, the sulphate of calcium, from the decomposition of which mineral they are derived.

It would be difficult to find two substances that present a greater contrast to the eye than Diamond and Graphite, and yet chemically they are alike, both are made of carbon and nothing else. It is the difference in the conditions under which these two kinds of carbon were formed that is responsible for the production of two minerals so widely different physically. Observation as well as experiment have shown that Diamonds are formed in the midst of molten masses of rock under great heat and pressure. The origin of Graphite is much more obscure, and, in at least some instances, we are inclined to attribute the beginning of this form of carbon to the decay of organisms.

Two examples of semi-metals will also be found in Panel A, Antimony and Bismuth, and extending our tour a little to include Case I (facing Panel A) we will find Arsenic the other important semi-metal which occurs uncombined in nature. All of these resemble metals at first glance, in that they have a decided metallic luster. They are however unlike metals in that they are brittle rather than malleable. ${ }^{1}$ In Panel B we find the native metals, and here again the inspection of the wall panel exhibit should be supplemented by a reference to Case I which contains a complete series of this group of minerals. Gold, Silver, and Copper are very familiar to us and we should encounter no difficulty in connecting the beautiful crystallized examples of the well known metals with the articles made from them that have since very early times been part of our culture. It may seem strange that such a common metal as Iron should be of rare occurrence in its uncombined state in the earth, but when we consider how easily this element enters into chemical union with others we readily see how the earth's iron, as far as our knowledge goes, is almost entirely made up of minerals representing these combinations. In this statement we must lay

1 We speak of a mineral as malleable when slices cut off from it may be flattened by hammering them. 


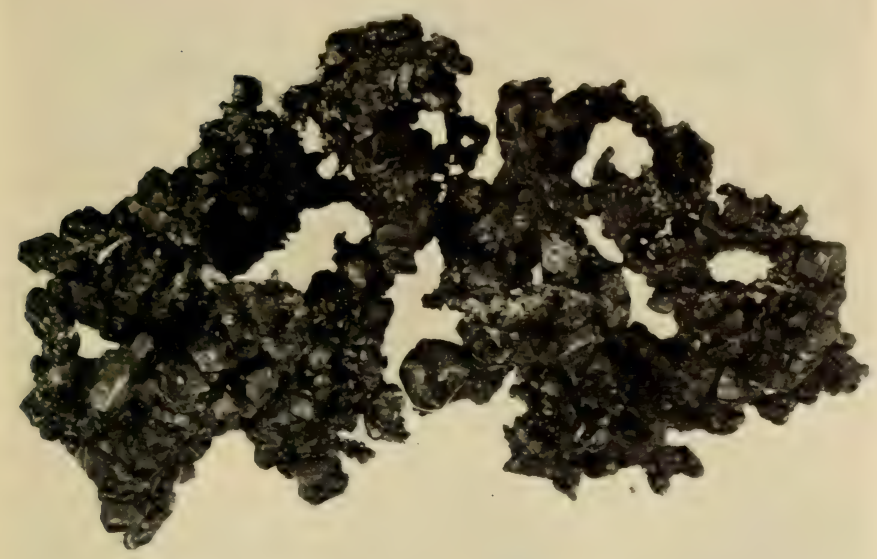

COPPER FROM LAKE SUPERIOR, MICHIGAN Panel A

Copper as it occurs in nature often consists of close aggregates of crystals grouped in branching forms, like the twigs of a tree, or some kind of seaveed.

stress on the expression "the earth's iron," because metallic iron forms a considerable part of the matter that comes to us from outer space in the form of meteorites. Here of course the iron has had little chance to unite with oxygen since oxygen is lacking in those remote spaces, and so the first step in the forming of an oxide, or a carbonate, or a phosphate of iron is rendered impossible.

The explanation of the rarity of native iron in the rocks of the earth furnishes us also with an explanation of why there are so few native elements. As we proceed on our excursion into the mineral kingdom we will encounter combinations involving many elements which are only known to us in nature through 


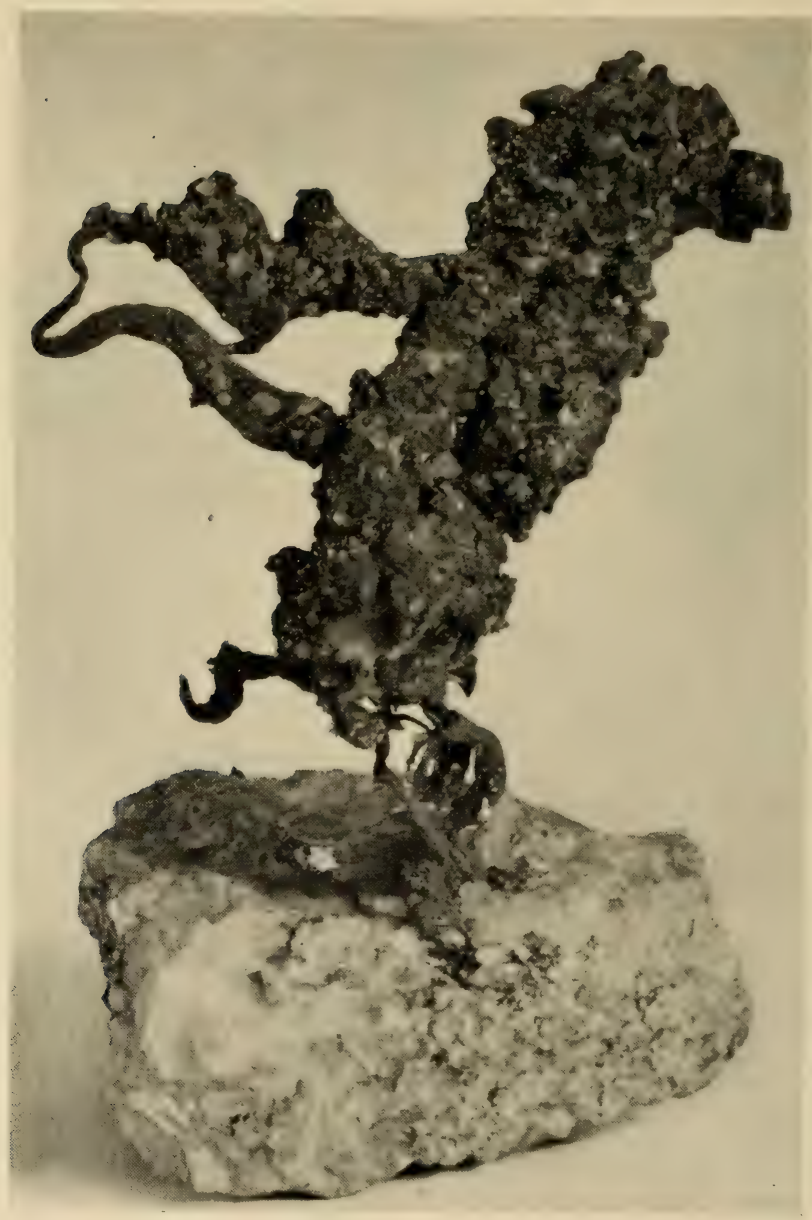

\section{SILVER FROM KONGSBERG, NORWAY} Panel B

In nature this well known metal forms in aggregates of crystals, producing twisted and wire-like shapes. 
these combinations, and so, although we are well started on our journey when we have become acquainted with some of the elements from which minerals are formed, we must expect to encounter many more non-metals, semi-metals and metals before we have finished our brief survey of the world's minerals.

The next class of minerals, that of the Sulphides, Arsenides and Antimonides of the Semi-Metals and Metals is a very much larger and more important one and includes the characteristic minerals of the metallic veins from which most of our useful metals are derived. In Panels B and $C$ will be found some of the combinations of sulphur with the semi-metals and as we might expect we find at the beginning of this series sulphides of arsenic and a sulphide of antimony. There are two forms in which sulphur and arsenic combine in nature which gives us the two minerals Realgar and Orpiment. Of these Realgar contains the greater amount of arsenic and is always found in orange-red crystals and masses as will be seen from the specimens in Panel B. Orpiment is a somewhat scaly mineral of a brilliant lemon yellow color. Both Realgar and Orpiment were formerly much used for the pigments which they furnished on being ground, but artificial arsenic sulphides have now largely replaced them.

The large and handsome groups of Stibnite crystals in Panel C well illustrate this sulphide of the semi-metal antimony. Stibnite is sometimes called antimony glance and is a very widely distributed mineral. The slender orthorhombic prisms in which it usually crystallizes have the remarkable property of developing under pressure a tendency to bend. This is not an ordinary bending such as can be effected with a brass rod but a slipping of the particles of matter along one of the planes in which they are more closely grouped. ${ }^{1}$ In several of the specimens of Stibnite from Japan in Panel C this molecular slipping can be noted on some of the large crystals. Stibnite, beside being the chief source of antimony, is quite extensively used in the manufacture of safety matches, percussion caps, fireworks and rubber goods.

${ }^{1}$ Figure 16 illustrates the structure of an orthorhombic crystal and shows how the molecules are crowded together in certain layers. 


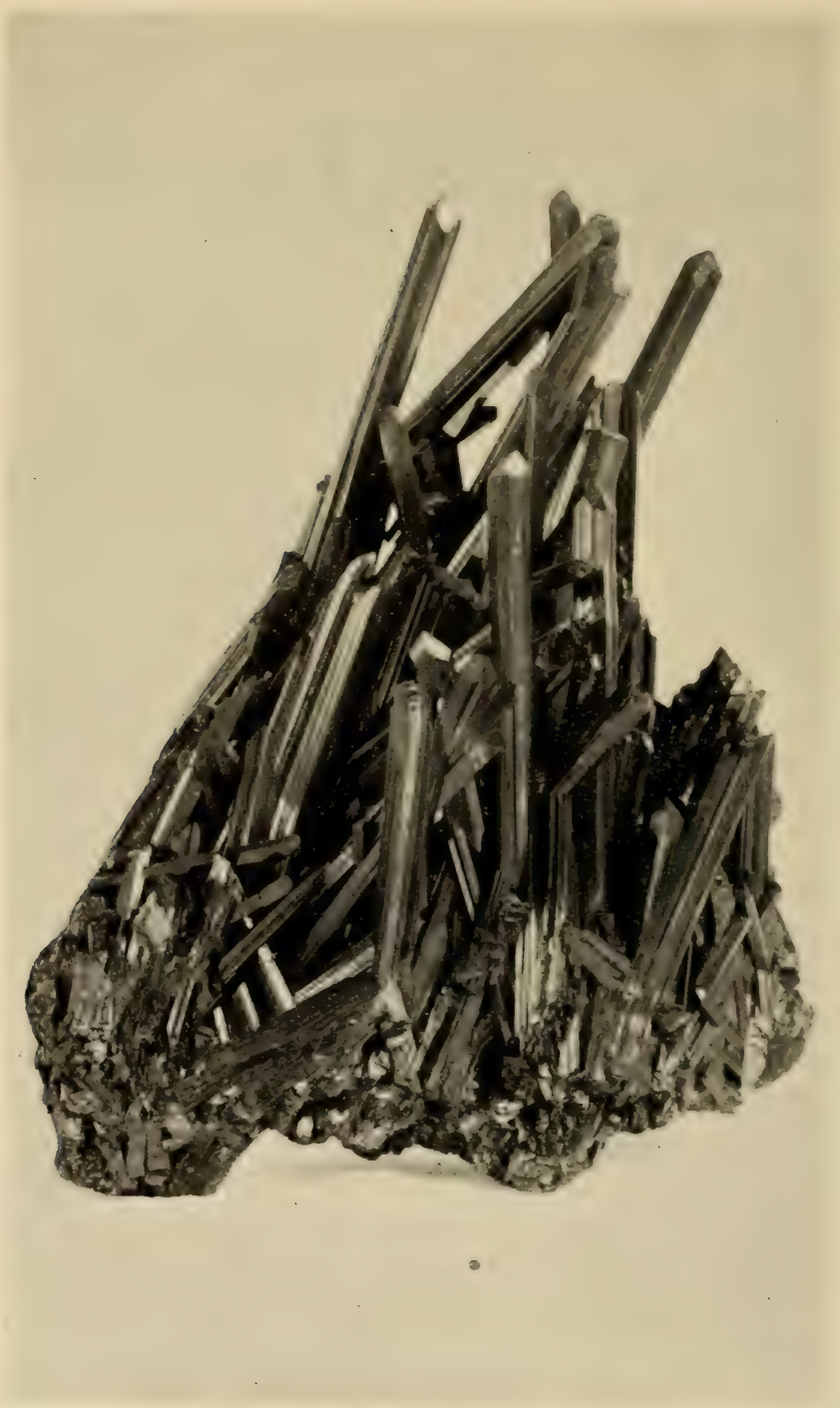

STIBNITE FROM INYO, JAPAN

Panel C

The long slender prisms of stibnite are in reality groups made up of many crystals joined in parallel position. 
Molybdenite is another sulphide of the semi-metals, the base with which the sulphur unites in this case being molybdenium. Molybdenite and Graphite have much the same appearance, they both have a metallic luster and are both of a lead-gray color. The color of Molybdenite, however, is faintly tinged with blue, which slight difference helps us to distinguish the two minerals from each other.

The sulphides of the metallic elements embrace a very large and varied series of minerals. Most of these are vein minerals which have been formed by supersaturated mineral solutions rising in some rock fissure and depositing the mineral matter dissolved in them on the side of the fissure which thus becomes a vein. Thus we have sulphur and more rarely selenium and tellurium, elements related to sulphur and acting chemically much as sulphur does, entering into combination with the metals silver, copper, lead, mercury, iron, zinc, manganese, nickel and cobalt, as well as some of the rare metals such as cadmium, and thallium. But, as we have seen, the semi-metals antimony and arsenic sometimes act as non-metals combining with the metallic elements, so the scope of the sulphide class of minerals is increased by the additions of a number of antimonides and arsenides, substances composed of antimony combined with a metal or arsenic combined with a metal. Nor are these combinations always confined to a single metallic element; sometimes two and more rarely three metals enter into combination with sulphur, antimony or arsenic or combinations of them, giving rise to minerals of quite complex compositions and producing a great many rare and obscure species. On these ramifications of the sulphide class of minerals we will not dwell, although most of them may be seen in Cases 2 and 3 of the Main Collection, but confine ourselves to the commoner and more important sulphides of the key exhibit.

Galena, the sulphide of lead, is shown in Panels C and D. One is at once impressed with the very characteristic cubic crystals of this mineral which, taken with the gray metallic color it always assumes, renders its recognition comparatively easy. 


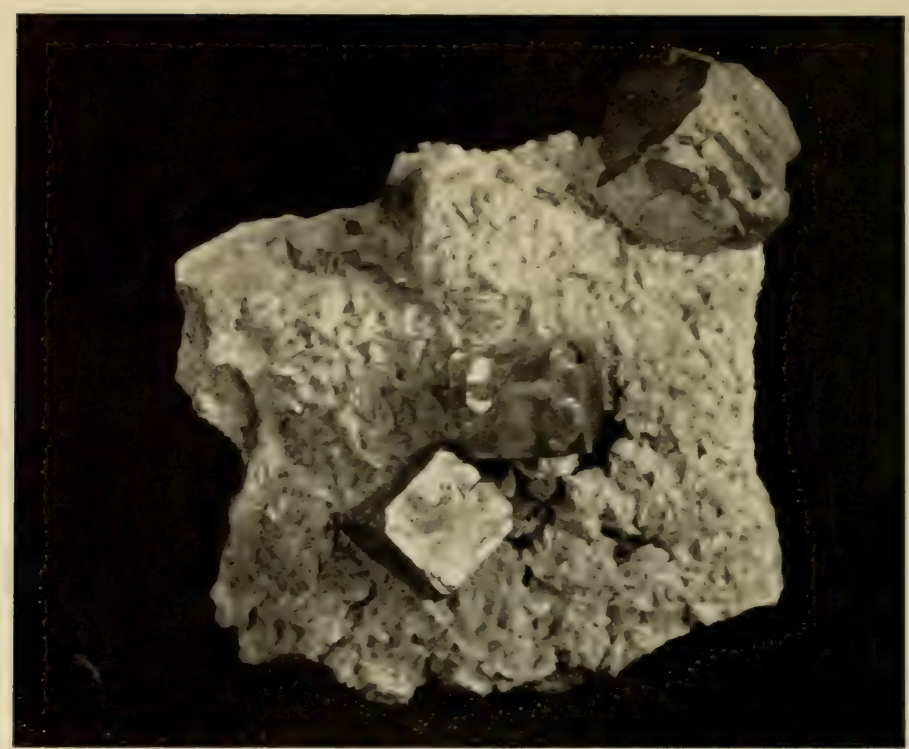

GALENA ON DOLOMITE FROM JOPLIN, MISSOLRI Panel D

The sides of this mineral vein were lined with dolomite upon which, at a somewhat later time in the rein derelopment, cubic crystals of galena were formed.

And where crystals are absent the strong tendency of galena to break parallel to cubic planes constitutes a valuable help to its identification. Galena, or as it is sometimes called "lead glance," is one of the commonest of the sulphides and the chief source of the world's production of lead. It is found in almost every country and where the rocks have been fissured and "mineralized" veins of galena are by no means rare. Often these carry some silver as a sort of impurity in the sulphide of lead and more infrequently a little gold as well.

Sphalerite, the sulphide of zinc, has sereral other names; it is often called "blende" or "zinc blende" while the darker colored varieties are sometimes called by miners "black jack." Although 
sphalerite is frequently found in crystals of the isometric system, these are not always easy to classify. But, like galena, sphalerite has a very easy cleavage, that is a tendency to break parallel to certain planes of its crystal structure, and, whereas in galena we found a right angular cleavage, in sphalerite the cleavage planes form oblique angles. This characteristic together with its luster, which is not metallic but similar to resin, constitutes an important fact to note as it helps us to recognize sphalerite at sight. Sphalerite and Galena are very often found together in veins and seem to be in close relation on the side of their origin as well as on that of their chemical composition. A large proportion of the world's zinc is extracted from Sphalerite which thus takes high rank as a useful metallic ore.

In Panel $\mathrm{E}$ will be found examples of Cinnabar, the sulphide of mercury, which also has a non-metallic luster. The hexagonal crystals of cinnabar are relatively rare and it is commonly met with in granular or earthy masses always of a reddish color which is often very brilliant. Formerly Cinnabar was ground for the pigment called vermilion but its chief use is the extraction from it of the metal mercury, of which it is the only important source.

In Chalcopyrite, specimens of which are to be found in Panel E, we meet with an example of a double sulphide of iron and copper. The common name for chalcopyrite is "copper pyrites." This is a brass-yellow metallic mineral often occurring in tetragonal crystals but more commonly in crystalline masses. Its brassy color which is our best means of distinguishing it has sometimes led to its being mistaken for gold by people ignorant of the true color of the more uncommon and valuable mineral. Chalcopyrite is a mineral of wide distribution in veins and open spaces in the rocks where it is not infrequently found in the near neighborhood of galena and sphalerite. It is the principal source of the valuable metal copper.

Pyrite, or as it is popularly called "iron pyrites" is a sulphide of iron and is the commonest and most widely distributed of any mineral among the sulphides. Its isometric crystals, usually in 
the form of cubes, are to be encountered in almost every kind of rock formation. Cubes, however, are by no means the only form assumed by this mineral; modifying planes on the alternate cube edges and on the cube corners produce highly intricate and beautiful crystals, many of which may be seen on specimens in

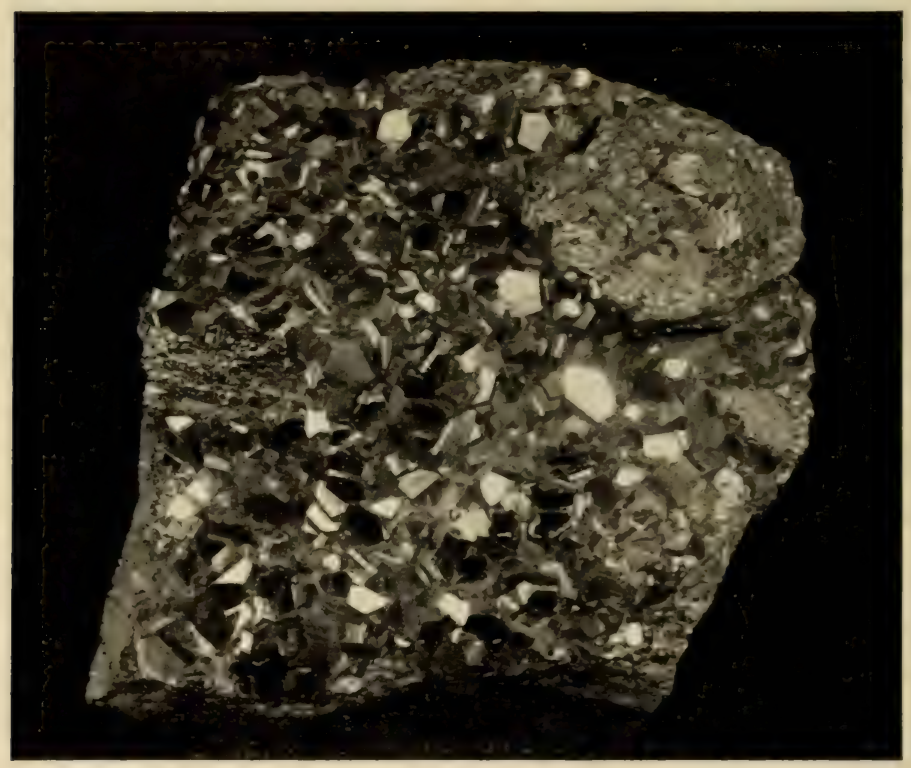

PYRITE FROM BINGHAM, UTAH

Panel E

A mineralizing solution depositing iron sulphide slowly and evenly as operated to produce these large, brilliant and finely developed crystals of pyrite.

Panel E. ${ }^{1}$ Py rite has been sometimes called "fools gold" because, like chalcopyrite, it is often mistaken for gold, its brilliant metallic luster and pale brass-yellow color, although lighter than that of chalcopyrite, gives some reason for this popular mistake. Where large deposits of pyrite occur these are often

1 In order to better understand these modified erystals consult the series of wooden models in Case $25 \mathrm{~B}$. 
worked for the production of sulphuric acid and sometimes small quantities of gold and copper are recovered from the more impure varieties. There is, however, no way of extracting the iron from Pyrite economically and generally speaking it has no value as a metallic ore.

Another iron sulphide, Marcasite, or white iron pyrites, will be found in Panels E and F. Marcasite has the same chemical composition as Pyrite but forms orthorhombic instead of isometric crystals, thus giving us a good example of what is called dimorphism among minerals. Of the two, Marcasite appears to be a less stable sulphide of iron than Pyrite; it is more liable to decompose under the action of water, and is in general formed by the cooler circulating water near the surface of the earth. These latter conditions lead to the formation of Stalactites of Marcasite, several of which, striking in size and shape, are among the specimens in Panel F. In color Marcasite is of a paler yellow than Pyrite, although this difference is slight. It is used for its sulphur constituent in the manufacture of sulphuric acid.

Related to the sulphides both from the point of view of their chemistry and of their origin are the minerals known as the sulpho-salts, combinations of sulphur and antimony, arsenic or bismuth with one or more of the metals which in general include copper, silver and lead. A much larger proportion of these sulpharsenides and sulphantimonides are rare minerals than is the case with the sulphides. Several, however, are of sufficient importance to take their places in the key exhibit in Panel F, and most of the remaining species are to be found in the more complete series in Cases 3 and 4 .

Two important minerals of this class are a sulphantimonite of silver, Proustite, and a sulpharsenide of silver, Pyrargyrite. They are commonly grouped together by miners under the term ruby silver ore because in thin silvers both minerals show a strong red color by transmitted light. Pyrargyrite is sometimes called dark ruby silver ore and Proustite light ruby silver ore. Both crystallize in the hexagonal system in crystals which are almost identical in form, so that the chief means of distinguish- 


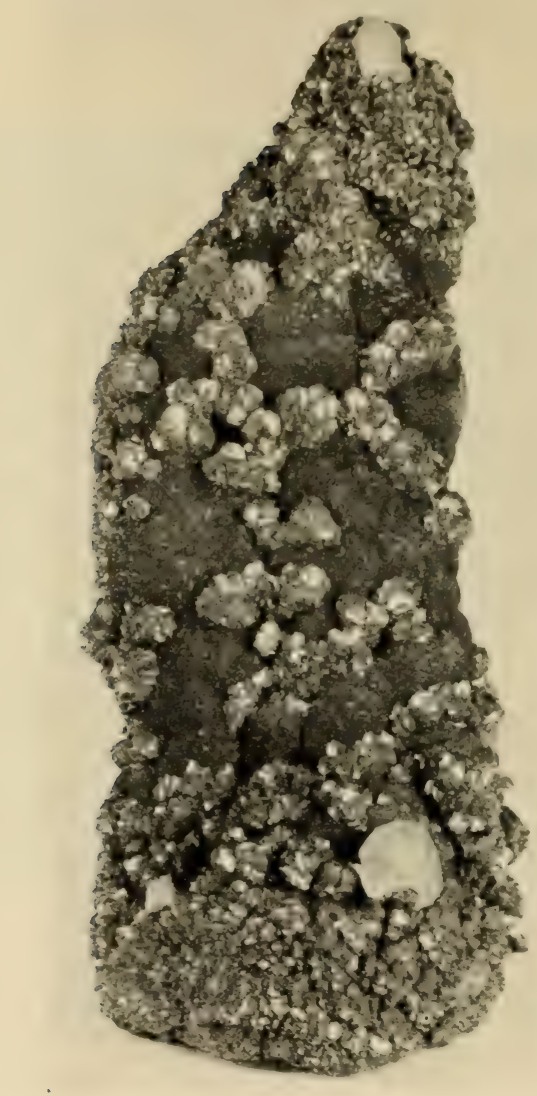

MARCASITE FROM GALENA, ILLINOIS

Panel F

In the formation of this stalactite of marcasite, the mineralizing solutions depositing iron sulphide were operating with greater rapidity than they would have done had they produced pyrite, and so this more quickly formed and more unstable iron sulphide was formed. 
ing them apart is by the luster which is more metallic in the case of Pyrargyrite. The fine red color of Proustite is made very much darker by long exposure to the light, so that the specimens of it in Case 3 are kept under cover. Both Pyrargyrite and Proustite are mined for silver in Mexico, Chile and the silver bearing regions of the western United States.

Tetrahedrite, a sulphantimonite of copper, is also known as gray copper ore because of its gray metallic color which is best seen in massive specimens. Tetrahedrite is very commonly found associated with Chalcopyrite, the latter mineral often coating or encrusting the isometric crystals of the sulphantimonite. These crystals are invariably developed as modified tetrahedrons, and it is from this crystal habit that the mineral gets its name. Tetrahedrite is often mined with its associate chalcopyrite for copper. Polybasite is another sulphantimonite of silver, having a higher percentage of silver than Pyrargyrite. The crystals although really monoclinic look very much like orthorhombic ones. In other respects it looks very much like Pyrargyrite and as it is found in association with the latter mineral it is often mined with it for silver.

A group of non-metals which are so closely related chemically that we may almost say that they constitute a family among the elements are those which are of ten called the balogen elements. They include chlorine, bromine, iodine and fluorine. None of them occur native, that is, uncombined in nature and when isolated in the laboratory all except bromine are gaseous at ordinary temperatures; bromine under these conditions is a liquid.

The halogen elements combine in nature with a number of the metals to form chlorides, bromides, iodides and fluorides, thus constituting a branch of the mineral classification which, although small as to the number of species, includes several common and important minerals.

The first of these is very well known to us as common salt or rock salt, which is the chloride of sodium, and the mineral name for which is Halite. The process by which Halite has been 
formed in nature can be repeated in miniature by allowing a solution of common salt dissolved in water to evaporate in a shallow dish until the disappearing water has left its load of dissolved salt as a layer at the bottom of the dish. The beds of Halite, which are found among the rocks of all ages represent

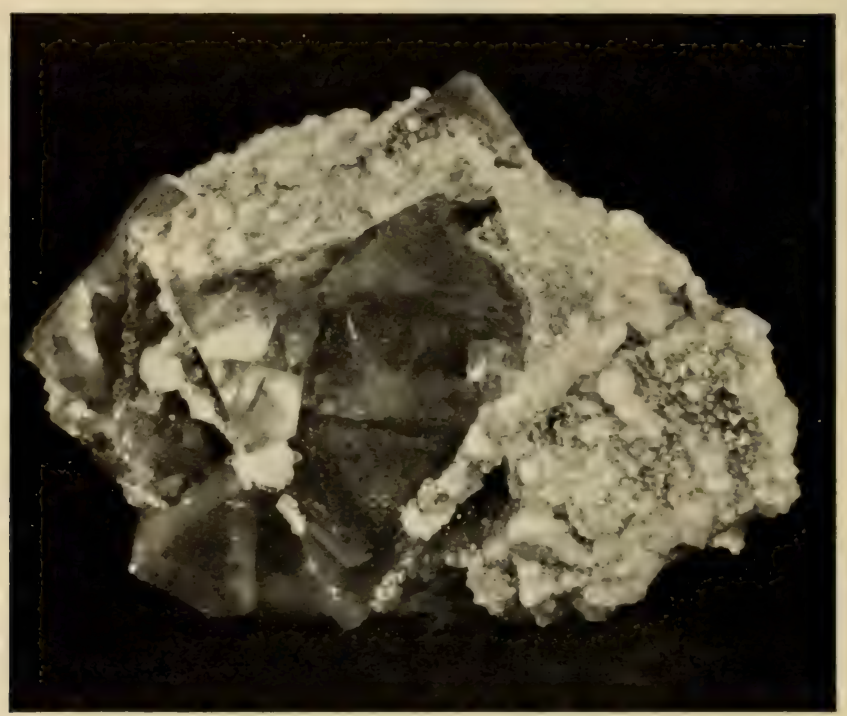

\section{FLUORITE ENCRUSTED WITH QUARTZ FROM CUMBERLAND, ENGLAND}

Panel G

Quartz is usually the last mineral to be deposited from a mineral-forming solution, and, as in this instance, it often forms as a crystalline crust over a mineral that has been previously crystallized from the solution.

the deposits of chloride of sodium left by the gradual evaporation from bodies of water which have in times past, been cut off from the main body of the ocean. This process is still taking place in many parts of the world, so we have here a mineral which is forming, as it were, under our eyes. Halite is usually either clear and transparent or white in color, but sometimes impurities impart to it various colors such as yellow, red, brown, 
blue or even purple, and frequently, as the character of the brine solution forming it has altered from time to time, layers of color following the outlines of the growing cubic crystals accentuate these changes.

Fluorite, which is also called fluor spar or fluor, is the fluoride of calcium. It is a very common and widely distributed mineral, and one which may be easily recognized by its isometric crystals, which take the form of cubes or more infrequently of octahedrons. The large series displayed in Panel G shows the great range of color which is one of the chief characters of this mineral. These differences of color are produced by slight variations in its composition, due to impurities, such as iron and manganese. It is noteworthy in this connection that, although the color varies through many shades, the prevailing form of the crystals is fairly constant. As we saw in the case of Halite bandings of color show slight changes to have taken place in the composition of the mineral-forming solutions while the crystals were in process of formation. Fluorite is to a large extent a vein mineral, and is often found associated with the metallic sulphides, particularly with Galena and Sphalerite. It is used as a flux in some metallurgical processes, and in the production of opalescent glass and of hydrofluoric acid. 


\section{Chapter VIII}

\section{OXIDES}

OF ALL the elements present in that part of the earth's crust which we are able to study, oxygen is the most abundant and the most universally present. Moreover it is one of the most active among the elements, entering into the composition of over $75 \%$ of all the minerals known to science. It is the natural chemical compounds, in which oxygen plays so prominent a part, that we now encounter in our brief survey of the kingdom of the minerals.

As we would naturally suppose, the simplest of these, and consequently the ones which would come first in the mineral classification, are the combinations of oxygen along with one or more of the other elements, combinations to which we give the name Oxides. Next to oxygen both in abundance and in importance as a constituent of minerals is ranked the element silicon and it is the mineral Quartz, the oxide of silicon, that we find at the beginning of the class of the oxides in Case H.

Quartz is the commonest and most widely distributed of all minerals, and is to be found in almost every kind of rock formed under a great variety of conditions. The scope and diversity of these conditions find expression in the many varieties of this unique and ubiquitous mineral. Its clear, glassy, six-sided crystals, to which the name of "rock crystal" has been given, are often of very great size. These are composed of pure oxide of silicon unmixed with even the slight amount of the foreign matter that tint the colored varieties.

Quartz, whether produced from a mineral charged solution or from a mass of fused semi-fluid mineral matter, is usually the 
last mineral to be formed. It is to this fact that we attribute the number of perfectly formed minerals that are to be found enclosed in some kinds of clear quartz. These have been produced by the mineral-forming solution at a relatively early

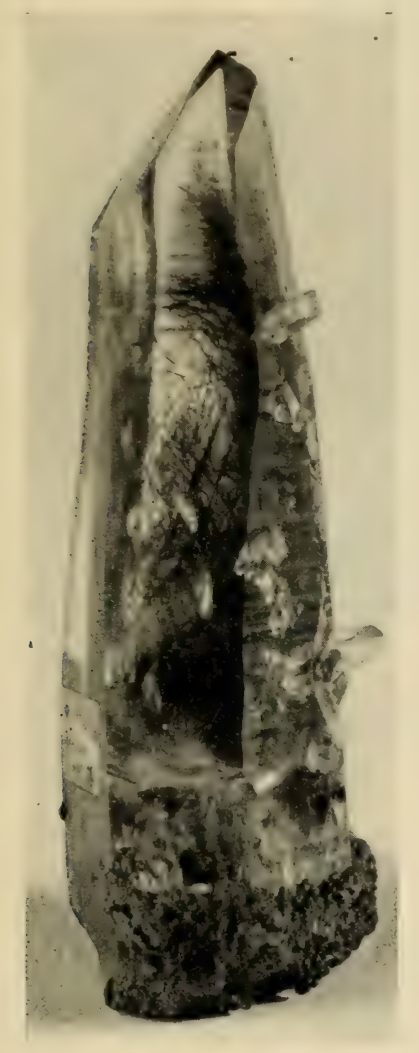

QUARTZ FROM

ST. GOTTHARD,

SWITZERLAND

Panel I

The slender, hairlike crystals of actinolite that are so clearly visible inside this quartz crystal were formed first; later in the process of mineral formation silica in the form of crystallized quartz was deposited around and completely enclosed them.

stage of its action, and later pure oxide of silica was formed around them, just as we often find weeds and grass enclosed in the ice of a frozen pond. Thus we have quartz enclosing crystals of tourmaline and rutile, or the moss-like aggregates of manganese oxide or chlorite which constitute moss-agate. 
Since the process by which quartz crystals grow by the addition of particles of matter from the outside is a slow one, we find a number of striking evidences that their formation is not always a continuous and uninterrupted one. A slight change in, or the temporary arresting of the action of the quartz depositing solution may produce a "phantom" representing the crystal at one stage of its development within the completed crystal. Or at some point in the growth of the quartz crystal some other mineral, such as mica, may have been produced, coating the pointed end of the crystal, and, when the quartz deposition has been resumed, forming a layer which admits of the two sections of quartz being separated. "Capped quartz" showing two or more repetitions of this process are often encountered. ${ }^{1}$

The presence of small amounts of impurities give rise to several colored varieties of quartz. The smoky brown variety which is known as Smoky Quartz probably owes its color to organic matter. Often the intensity of this coloration is so deep as to be almost black, as will be noted in some of the specimens from Switzerland in Panel I.

A pink quartz of more or less deep color is called Rose Quartz, and, in this case, the coloring matter may be titanium oxide. Rose Quartz is seldom found in distinct crystals. The best known among the varieties of colored quartz is Amethyst, which is said to be colored by manganese. A magnificent series of Amethyst crystals are displayed in Panel K.

The crystallized varieties of quartz which we have dealt with up to this point have resulted from a slow process of silica (oxide of silicon) deposition. IVe come now to the massive varieties which were formed from a solution depositing silica more rapidly. These massive kinds of quartz appear to have been deposited in every instance by water solutions. They never form crystals, and the evidence which we have so far been able to gather as to their internal structure leads us to regard them

${ }^{1}$ Examples of "phantom quartz" and "capped quartz" will be found in Case 5 . 


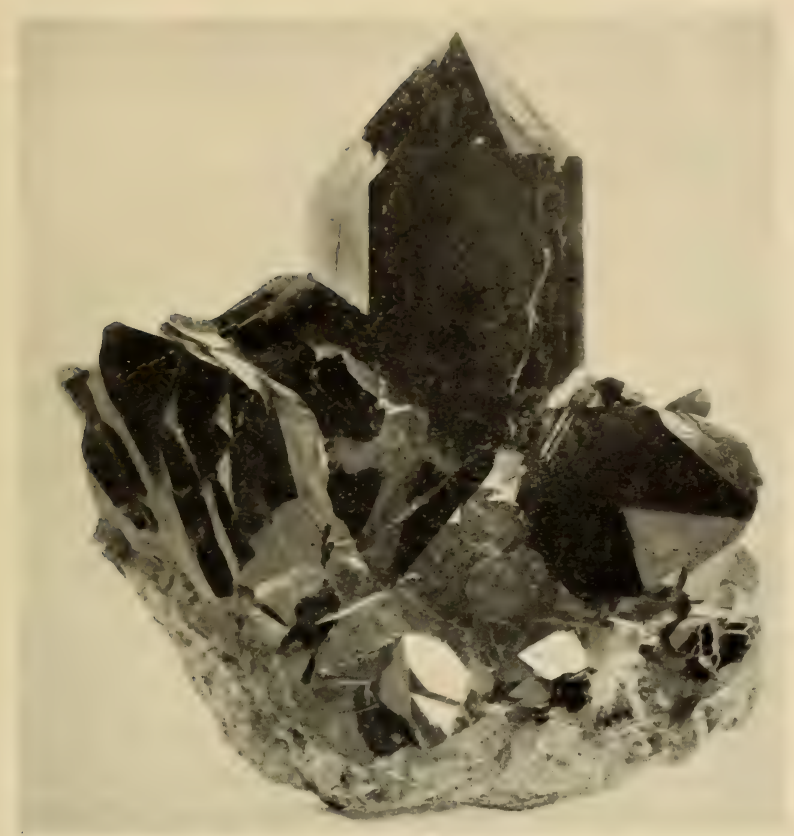

SMOKY QUARTZ FROM ST. GOTTHARD, SIITTZERLAND Panel I

The smoky brown or black color of this kind of quartz is largely due to included organic matter.

as only imperfectly crystalline. Chalcedony, which is a translucent waxy variety of quartz, is always found in stalactitic shapes, resembling icicles or the rounded masses of ice deposited from dripping and freezing water. In this way Chalcedony fills the cavities in decomposed igneous rock and is of frequent occurrence as the lining of geodes. The agate geodes in Panel L are lined with successive layers of chalcedony, differently colored as the silica solution producing them changed slightly in respect to the amount and character of the dissolved material which furnished the coloring matter. With considerable amounts of iron or clay or both in the quartz-forming water 
we have the opaque quart\% varieties known as jasper, while carbonaceous matter deposited with the silica gives rise to flint. Under certain conditions the woody tissues of trees have been permeated by waters which were heavily charged with silica. The result of this is that, after a time, jasper or agate is deposited in place of the wood cells, the tissue being replaced by quartz as fast as it decays, until the tree or fragment of a tree becomes "petrified." The replacement of woody tissue by jasper is called jasperized wood.

Oxide of silicon which contains a varying percentage of water constitutes the mineral Opal, remarkable as one of the very few natural substances which show no trace of crystallization. Like Chalcedony, Opal is essentially a water deposited mineral occurring in bands or layers as well as in stalactitic masses. Beside the precious variety with which we are mostly familiar, there are many kinds and colors of opal from the colorless transparent phase, which resembles drops of water, to the porous white material deposited around hot springs and geysers, which is often powdery in consistency. Opal replaces the tissue of wood in the same way that quartz does, sometimes furnishing most striking reproductions of the cellular structure. Some of these will be found in Panel L.

The oxides of the semi-metals include a small number of rare and unimportant minerals. One of these Senarmontite, the oxide of Antimony, is represented by a single specimen in Panel M. The oxides of the metallic elements, on the other hand, embrace a considerable number of common and important minerals.

Cuprite, the oxide of copper, is also called red copper ore, because its characteristic color is a rich ruby red. The isometric crystals of cuprite are simple modifications of cubes and octahedrons and are very easily identified. In the variety called Chalcotrichite the cubic crystals are so greatly elongated in one direction that they assume the dimensions of hairs. These, matted together in large numbers, give to the surface an appearance of crimson plush.

Cuprite, although not always in itself an important ore or 
copper, is often present in the upper layers of large veins and ore bodies consisting of copper sulphides. Several specimens are shown in Panel M.

An oxide of aluminum (sesquioxide of aluminum), the mineral Corundum, will be found in Panel M. Perhaps the mest unique characteristic of Corundum, is its great hardness, a property in which it is only exceeded by Diamond. The crystals are usually some modification of a steep hexagonal pyramid or less often a six-sided prism. When perfectly pure Corundum is clear and colorless, but this condition is seldom attained in nature; small amounts of the other metallic oxides, present as impurities, act as strong coloring agents, and produce the brilliantly colored gem varieties which run a gamut of colors from the red of ruby to the blue of sappbire. ${ }^{1}$ When not transparent, a color frequently assumed by corundum is a grayish blue. A mixture of corundum with foreign matter, such as iron ore, is known as emery, and is in much demand as an abrasive material.

A much commoner oxide is the sesquioxide of iron, Hematite, known also as specular iron ore. Hematite is a very widely distributed mineral, formed under varying conditions in a number of places, and in consequence, presenting several quite widely different varieties. When formed in crystals, these have the symmetry of the rhombohedral division of the hexagonal system, occurring in stout individuals with a prominent axis of trigonal symmetry, and are sometimes reduced to the proportions of a tabular habit. The luster of crystallized Hematite is brilliantly metallic as is well shown by the examples from Elba, Italy in Panel M. Aggregates of crystals result in a number of interesting groupings, such as the rosettes of flat crystals from Switzerland, and the radiating masses which pass by insensible graduations to the rounded, kidney-shaped forms, magnificent specimens of which from Cumberland, England are exhibited in Panel M. The red, earthy varieties are known as "red hema-

1 A very complete series of the gem varieties of Corundum will be found in Cases II and III of the Gem Stone series. 


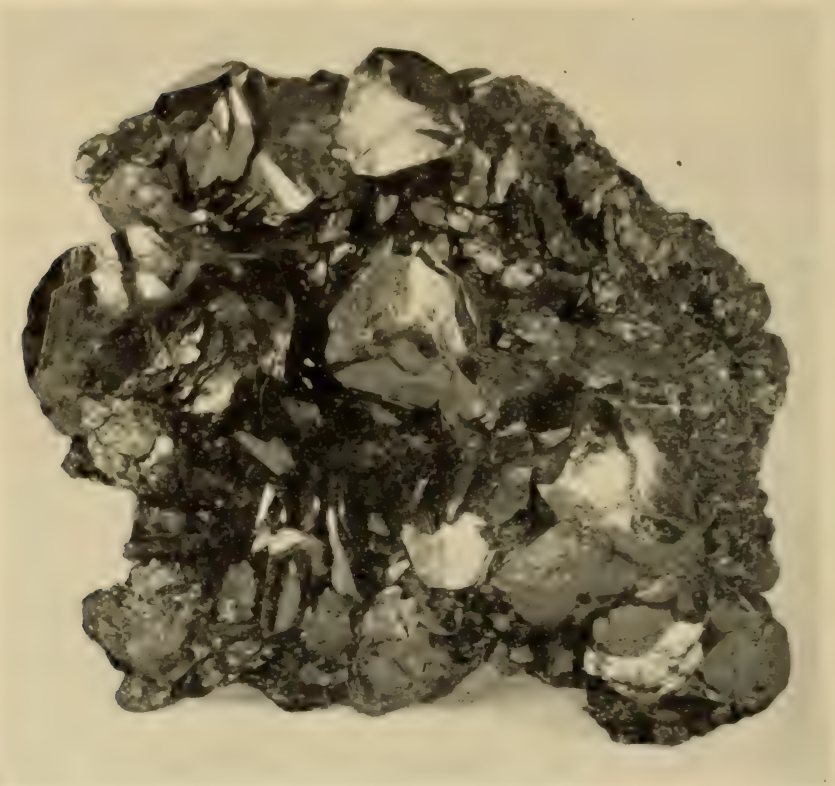

HEMATITE FROM RIO, ELBA, ITALY

Panel M

The brilliant metallic crystals of this common oxide of iron show the threefold arrangement of faces that is characteristic of their crystal symmetry.

tite" and exists as extensive beds in number of places. Hematite is the chief source of the world's iron and as such is one of our most useful and important minerals.

Another common combination of oxygen and iron is the mineral Magnetite, so named because it will attract a magnet. The isometric crystals of Magnetite commonly take the form of octahedrons, which fact, combined with its strong magnetism, makes the recognition of this mineral comparatively easy. It is extensively mined for iron.

Closely related to Magnetite is the mineral Franklinite, a combination of oxygen with the metals iron, manganese and zinc. Octahedral crystals are also characteristic of this mineral which is found at Franklin, New Jersey, and which has been 
named after that place. It is used with other Franklin minerals for the production of zinc, and for an alloy of iron and manganese known as spiegeleisen.

In the same group with magnetite and franklinite is the mineral Spinel, a combination of oxygen with magnesium and aluminium. Like the last two minerals, spinel crystallizes in octahedrons, often of considerable sizc. There are several colored varieties of spinel that are sufficiently transparent to be used for gem stones (see Gem Case VII).

Rutile, in Panel $\mathbf{N}$, which is also sometimes called nigrine, is a dioxide of titanium. It is a mineral of commoner occurrence than is generally supposed, its long thin crystals being not infrequently met with in the rocks of Manhattan Island. Rutile affords a fine example of a mineral that crystallizes in the tetragonal system, the large and well formed crystals being frequently almost diagrammatic in the symmetry of their development. The luster of Rutile is in most cases brilliantly metallic and the color black. Because, however, the slender crystals and thin plates show a deep red color by transmitted light, there is, in many instances, a reddish tinge transmitted to the larger masses. Rutile is the chief source of the various titanium compounds used in the arts.

The hydrous oxides contained in Panel $\mathrm{N}$ are metallic oxides into the composition of which enters a definite proportion of water. These are essentially minerals of the upper layers of the earth's crust, where the free circulation of the ground water plays the most prominent part in their formation. From the secondary nature of such a mode of origin we may expect to find stalactitic structures and pseudomorphs very much in evidence among the minerals of this group, and the series in Panel N shows a number of striking examples of both of these manifestations of the work of water as a former of minerals.

Manganite, the hydrated sesquioxide of manganese, is notable for its grouping of orthorhombic crystals in bundles like the pipes of an organ. These are black or gray with a submetallic luster. More rarely stalactitic forms occur. 


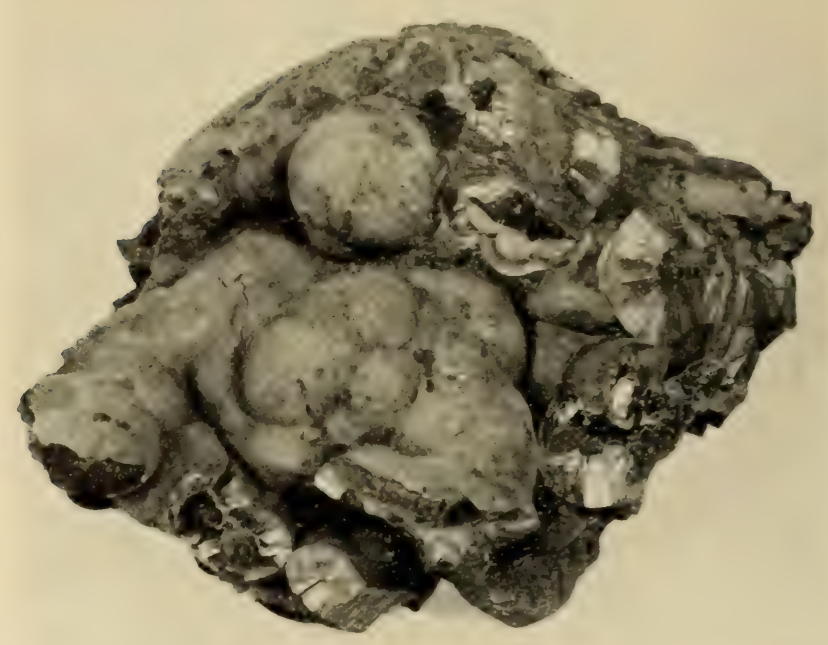

GOETHITE FROM NEGAUNEE, MICHIGAN Panel $\mathrm{N}$

The rounded surfaces and concentric structure of this example of a hydrous oxide, bears witness of the prominent part that water has played in its formation.

There are several hydrated sesquioxides of iron, three of which are here included among the commoner minerals. These are Goethite, Limonite and Turgite. They are sometimes grouped together under the somewhat misleading name of "brown hematite."

Goethite is usually characterized by radiating orthorhombic crystals with an adamantine luster and a black to brown color. These may be developed on such a minute scale as to produce drusy and velvety surfaces where the mineral takes on stalactitic forms.

Limonite is the commonest of the hydrated iron oxides. 
Unlike Goethite it never crystallizes although it often, as a pseudomorph, takes the form of other minerals. This is because Limonite always forms as a result of the alteration of other iron minerals. Stalactitic forms are both frequent and very characteristic. A loose, earthy Limonite mixed with more or less clay, is formed as bog ore by the action of streams which carry iron in solution, and which deposits it as oxide in marshy places. The more compact kinds of Limonite show a black, varnishlike surface and a radiating structure. The less compact varieties have a dull luster and are brown or vellow in color.

Limonite is a very abundant but low grade ore of iron, which, with the present market values of that metal, can be profitably worked only under the most advantageous conditions.

Psilomelane combines in its composition oxygen and manganese with water; it is practically never found in a pure state and hence the composition is somewhat in doubt. Like Limonite, it never forms in crystals but always in rounded, stalactitic masses of a sooty black to steel gray color.

It is a common but an impure ore of manganese which, owing to its abundance, and to the fact that it is commonly associated with other manganese minerals such as manganite, is a considerable source of manganese. 


\section{Chapter IX}

\section{CARBONATES}

OXYGEN not only enters into simple combinations with the various metals and semi-metals to form oxides, but it also unites with certain other non-metals such as carbon, silicon and sulphur to produce, with one or more metallic oxides, compounds which are called oxygen salts. The first group of these that we encounter is the carbonates, the composition of which is based upon the combination of carbon dioxide with one or more metallic oxides. These are, without exception, minerals formed in the part of the earth's crust nearest the surface, where the circulating ground water, so largely instrumental in their production, is ever present in the rocks. They are conspicuous minerals in metallic veins, where they have been deposited next to such metallic sulphides as Galena and Sphalerite, and they are very often to be found as secondary minerals that have been derived from the dissolving of older ones.

The most important mineral in this class is Calcite, a carbonate of calcium, often called "common spar." This is nearly as common a mineral as Quartz and, like the latter, includes many varieties produced by the varied conditions governing their formation. Calcite is remarkable for the great number of forms assumed by its crystals. Since these were first studied there have been recorded over 2500 different kinds of Calcite crystals, an amazing and bewildering array. The suite of specimens in Panels O, P, and Q shows a few of many forms in which crystals of Calcite occur, and observing them we will notice the grouping of crystal faces in sets of three, which is the earmark of the system in which Calcite crystallizes. 


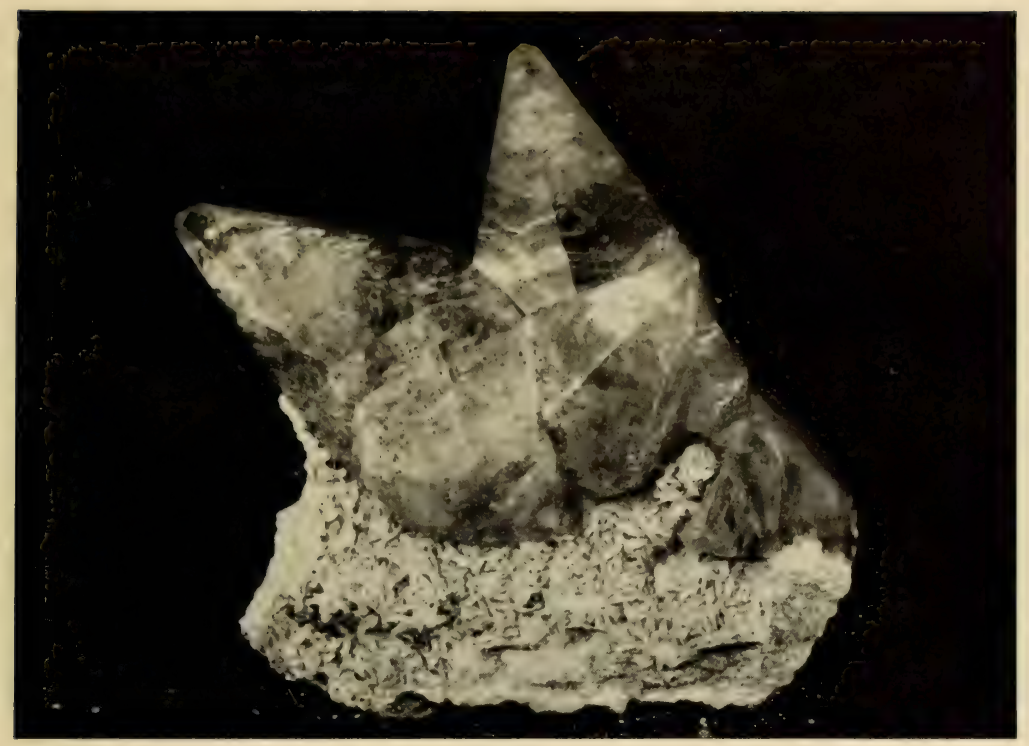

CALCITE FROM JOPLIN, MISSOURI

Panel P

The crystals of calcite assume a great variety of forms, of which these shapes, that look like church spires with three-fold symmetry, are quite common ones.

Here we will find rhombohedrons, each of which looks like a cube stood up on one corner, and either pressed together to resemble a flattened cube or drawn out so that the corner is more pointed than that of a cube would be. A very common crystal form with calcite is the scalenohedron which suggests a double six-sided pyramid, of which the faces that form the apices are not all equally inclined to one another but adjacent angles are unequal while alternate angles are equal. What would then be the base line of a double pyramid is, under these conditions, a zigzag instead of a continuous broken line, and the symmetry of the faces grouped about the apex is not six-sided but three- 


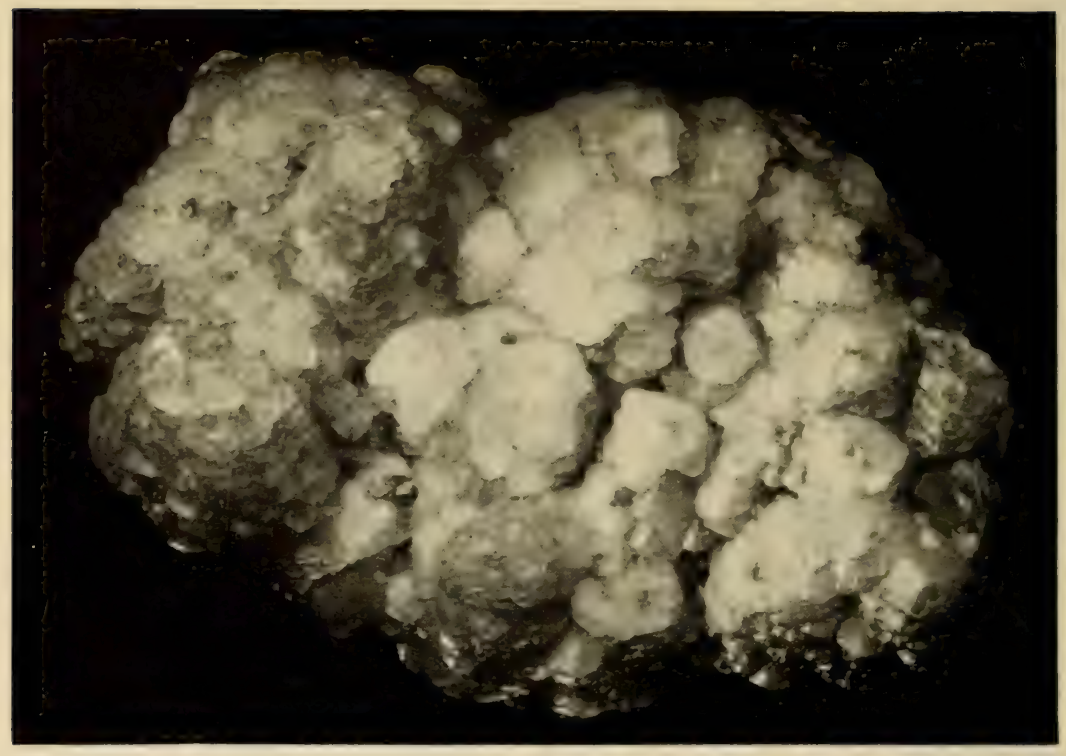

\section{CALCITE FROM CUMBERLAND, ENGLAND Panel $\mathrm{P}$}

A very common shape to be found among the many in which calcite crystallizes is that of the flat rhombohedron, which, like all the crystals of this mineral, has three-fold symmetry. In this example hundreds of these flat rhombohedrons have grown one upon the other in parallel groups.

sided. ${ }^{1}$ Calcite has a very characteristic and easy cleavage in three directions parallel to the faces of a rhombohedron, and this property furnishes a ready way to identify it in fractured and massive pieces, where the crystals can not be distinguished. As one would expect from a mineral so widely distributed through out the earth's crust, and which owes its origin to water which has traversed and accumulated matter from such a variety of rocks, Calcite is colored by small amounts of various

1 A good idea of the complexity of the crystals of calcite, their relation to one another, and the broad principle of symetry that binds them together may be gathered from the series of wooden models in Case ${ }_{25} \mathrm{E}$. 
oxides in a number of shades; white, however, is by far the commonest color and some of the handsomest and best developed crystals are clear and colorless, indicating carbonate of calcium free from any impurity. The clearest kind of calcite is called "Iceland spar" and is valued as a material from which the parts of certain forms of optical instruments are made. This use depends upon the property of refracting rays of light in two directions that is possessed by calcite to an unique degrec. Objects viewed in certain directions through pieces of clear Calcite appear double.

The massive varieties of Calcite emphasize the derivation of this mineral from watery solutions depositing calcium carbonate. A loose porous form is deposited around the opening of calcareous hot springs and is known as tufa. This is quite analogous to the geyserite variety of oxide of silicon described under opal. Dripping calcareous water deposits calcium carbonate, in the form of stalactites and stalagmites in caverns, and travertine is produced in much the same way.

Rock masses of Calcite, constituting the massive varieties limestone and marble, have many uses in the arts, but, as these fall under the heading of economic geology, they are dealt with and illustrated elsewhere. Calcite stands at the head of a group of carbonates closely related chemically and crystallizing in closely similar forms of the rhombohedral division of the hexagonal system. Such a group of minerals is said to be an isomorphous group. In the isomorphous group of which Calcite is the typical mineral, the elements calcium, magnesium, iron, manganese and zinc constitute the metallic bases, and, as is the case with all such groups, they tend to replace one another producing intermediate compounds of varying composition. For instance, between the carbonate of calcium and magnesium, Dolomite, and the carbonate of iron, Siderite, there is a carbonate of calcium, magnesium and iron, Ankerite, in which some of the magnesium is replaced by iron.

Dolomite is often called pearl spar because in some varieties the luster is pearly. The rhombohedrons of Dolomite tend to 
group themselies in crystal aggregates that are nearly, but not quite, parallel, producing curved composite faces which are very characteristic. Most of the marble used for building stone is massive Dolomite.

Siderite, the carbonate of iron, is also known as "spathic iron ore," the word spathic being derived from "spar," an old, indefinite term for a mineral with a bright non-metallic luster. Crystal aggregates of Siderite resemble those of Dolomite, but are invariably some shade of brown, and, like the other carbonates of the Calcite group, Siderite has an oblique cleavage in three directions. It is but little used as an ore of iron because in general the high cost of production prevents the iron being extracted from it with profit. It is not then as an ore mineral that Siderite claims our interest, but rather, because like Dolomite. it is frequently associated with the lead and zinc sulphides in mineral veins.

Rhodochrosite, the carbonate of manganese, is so named on account of its fine rose-red color. In everything but color it has a marked resemblance to Siderite as will be seen by comparing specimens of the two minerals in Panel R. With this species rounded stalactitic forms are much commoner than is the case with Dolomite. Although in itself of little or no commercial importance, Rhodochrosite is interesting from the fact that it is often found associated with the sulphides of lead, copper and silver, as well as with other manganese minerals.

Smithsonite, the carbonate of zinc, is even more strongly characterized by stalactitic forms than is Rhodochrosite. When crystals occur they are rhombohedral and similar to those of the other members of the group, but crystallized Smithsonite is of relatively rare occurrence. Usually the mineral is found in rounded masses, giving evidence of its secondary origin from water carrying zinc carbonate in solution; and in crystalline crusts and druses. Sometimes porous, honercombed masses occur, to which the appropriate and descriptive name "dry bone ore" has been given. Although the usual color of Smithsonite is some shade of light brown, varieties of many highly attractive 


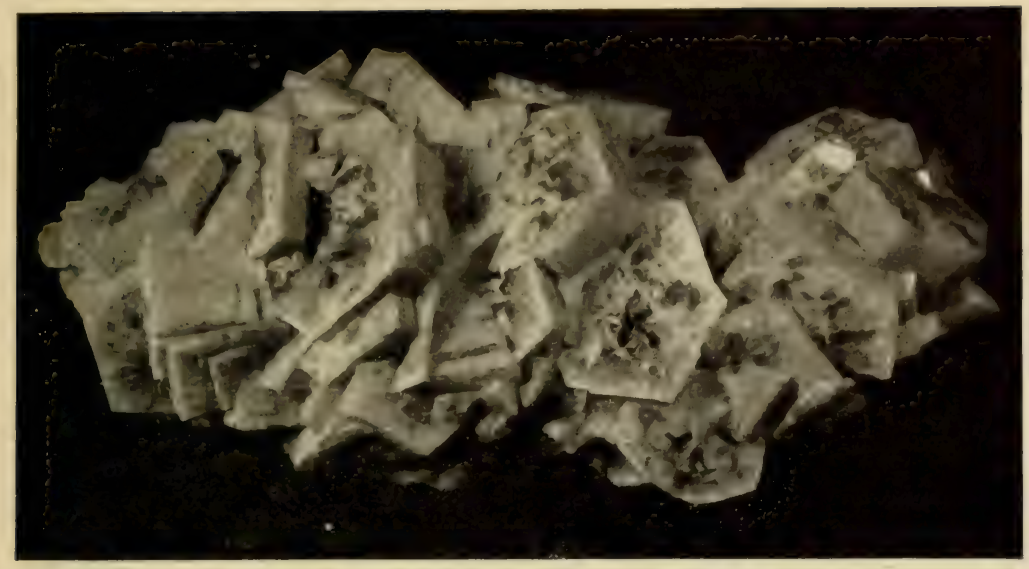

ARAGONITE FROM CIANCIANA, ITALY

\section{Panel R}

Aragonite is the form of calcium carbonate that forms in orthorhombic crystals. These sometimes, as in this example, look like hexagonal prisms, but are in reality each a twinned group of three orthorhombic crystals.

colors, such as blue, green and yellow occur, a fine example being shown in Panel R.

Smithsonite most frequently accompanies other zinc minerals, notably Sphalerite, from which it is commonly derived by the action of carbonate water in the upper portions of mineral veins. It was named in honor of James Smithson, the founder of the Smithsonian Institute of Washington.

Calcium carbonate affords another instance of dimorphism, one example of which has already come to our notice in the iron sulphides, Pyrite and Marcasite. Of the two forms of calcium carbonate, the hexagonal one, Calcite, has already been discussed at length. There remains the calcium carbonate that crystallizes in orthorhombic forms, the mineral Aragonite.

Aragonite is a much less common mineral than Calcite and seems to represent a less stable phase of carbonate of calcium, just as Marcasite is less common and less stable than Pyrite. Also we have reason to think that hot carbonated water tends to 


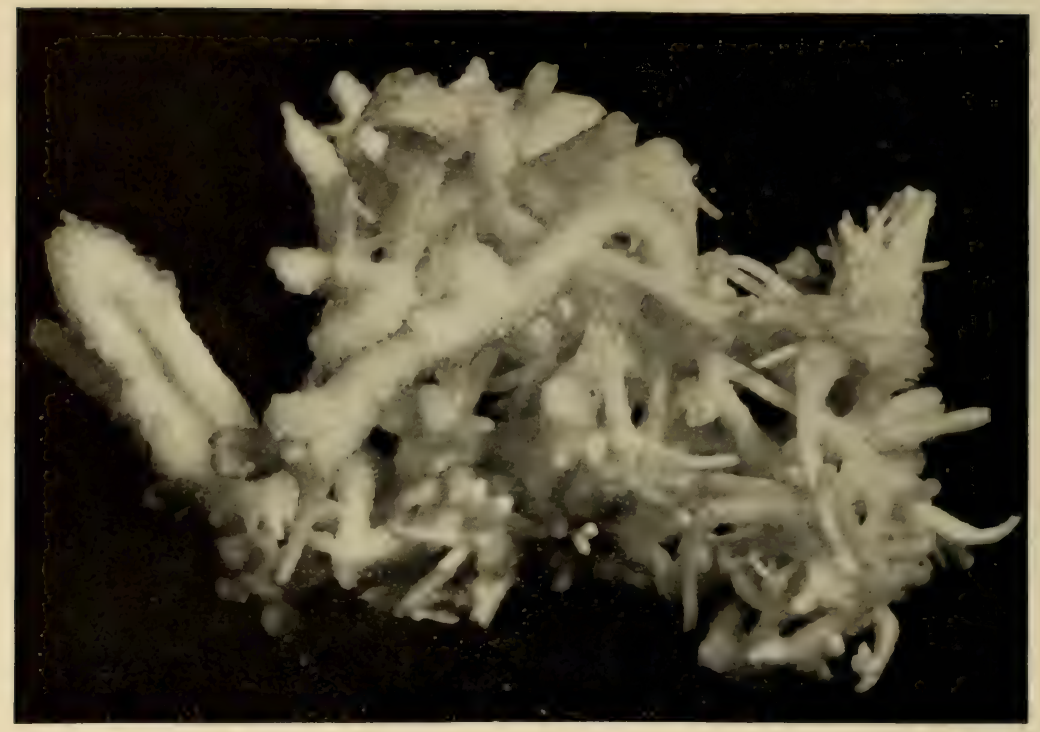

ARAGONITE FROM CHIHUAHUA, MEXICO

Case 29

A stalactitic deposit of calcium carbonate that has been called Flossferri (flower of iron) because it is often to be found in deposits of iron ore.

deposit Aragonite from a saturated solution, whereas cold carbonated water will form Calcite.

Crystals of Aragonite often develop in sharp pointed forms like spines grouped in tufts. Also regular twinned groupings that look very much like six-sided prisms are frequent in some places. These would mislead us into supposing that Aragonite was hexagonal instead of orthorhombic unless we noticed that the sides of each grouping are not quite flat, but show a slight indenting; also the flat tops of the crystals are striated or grooved in three directions. Both these considerations show that what seems to be a hexagonal prism is really a group of three orthorhombic crystals, grown together according to a regular twin law. Sometimes the crystals of Aragonite are grouped in columnar organ-pipe fashion like those we saw under Manganite. 
The prevailing color of Aragonite is white, which, however, shades to violet, yellow and pale green in some varieties. Massive varieties are hard to distinguish from Calcite as they ordinarily assume the same kinds of stalactitic forms.

Aragonite is frequently found associated with Gypsum, the sulphate of calcium, as in the large specimens from Girgenti, Italy, in Panel R. A massive variety called Flos ferri (flower of iron) is to be found in some iron ore deposits, taking the form of loosely interwoven, stalactitic masses, resembling tangled white cord or some kinds of coral. Some fine examples of Flos ferri are shown in Case 29.

Cerussite, the carbonate of lead, is sometimes called "white lead ore" because it has the same composition as the artificial white lead used for paint. Cerussite is related to Aragonite in much the same way that the minerals of the group containing Dolomite, Siderite and Rhodochrosite are related to Calcite. Its crystals resemble Aragonite in form but it has a silky, or sometimes an adamantine, luster which is quite distinctive. Characteristic also are the siender, interlaced, prismatic crystals which pass into aggregates of silky fibers and masses like some kinds of pulled candy. In color Cerussite is almost always white or gray.

Cerussite is always a secondary mineral, occurring in close association with other lead minerals, notably Galena, from which it is frequently derived. It is quite common and widely distributed, and is found in most regions where lead ores abound. Although not as rich in lead as Galena, Cerussite has a considerable use as a source of that metal.

There are two copper carbonates represented by common minerals to be found in Panel T, both of which are conspicuous and easily recognized by their color.

Malachite is popularly known as the green carbonate of copper, because of its fine grass green shade. Distinct crystals are rare, but close crystalline aggregates of silky fibers are both common and characteristic. These may occur incrusting other minerals or as radiaring masses given rounded surfaces. Stalac- 


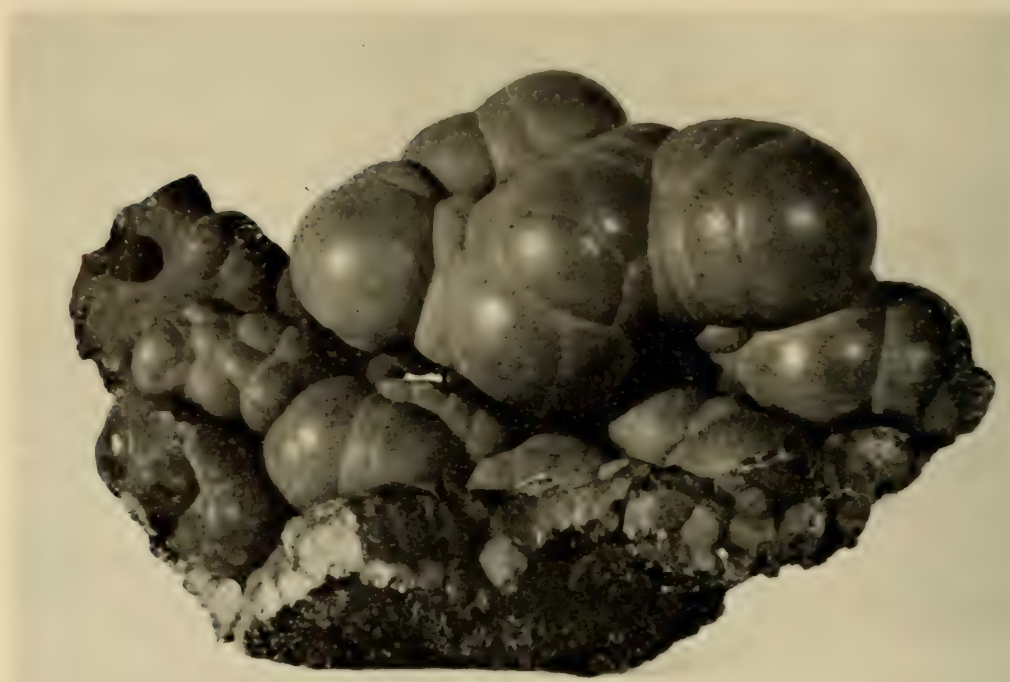

MALACHITE FROM AMBRIZ, AFRICA Panel T

Rounded masses such as these, indicate stalactitic structure formed by layer upon layer of water-deposited mineral matter.

titic forms are very common with this mineral, and bands of light and dark green, similar to the bands formed of agate, are often met with. Such stalactitic banding sometimes occurs in Malachite which has a texture sufficiently firm to admit of its being polished, as in the specimen from Siberia in Panel $\mathrm{T}$, in which case an attractive ornamental stone is cut from it.

Malachite is formed by the action of carbonated water on the sulphides in the upper portion of a copper vein. When present in any appreciable quantity, it indicates the possible existence of Chalcopyrite, or the less common copper sulphides lower down in the vein.

Malachite sometimes forms pseudomorphs after other copper minerals, such as the replacement of Cuprite by Malachite, in 
which the latter mineral assumes the isometric crystal shapes of the former. Azurite, as its name indicates, is the blue carbonate of copper, which, in distinction from its near relative Malachite, is almost always found in crystals of the monoclinic system. The crystals often occur in druses and are of great beauty. Azurite is deposited as a secondary mineral in much the same way as Malachite, and is found in close association with it. The two minerals differ very little in chemical composition, Malachite having a slightly higher percentage of copper than Azurite. Both are important copper ores. 


\section{Chapter X}

\section{SILICATES}

JUST as carbon and oxygen combine with metallic oxides to produce the carbonates among minerals, so we have the very abundant elements silica and oxygen uniting to form the basis of the large and important class of the silicates. In general, these are the minerals that constitute what are known as the crystalline rocks, such as granite, gneiss and diabase, rocks which give evidence of having been formed under conditions of great heat and pressure. We have abundant reason for assuming that the rock-forming matter under such conditions was in a state of fusion, and that the molten rock constituted an actual solution of which the constituents were mutually dissolved one in another, like a mixture of water and alcohol. It is quite evident that under such circumstances the elements that were contained in the fluid mass, which was to solidify into a crystalline rock, had ample opportunity to unite into a variety of compounds, in the same way and subject to the same reactions as the constituents of any other chemical solution.

Now, in order to form a better idea of the principal combinations of elements which we are about to encounter in our survey of the minerals that make up the silicates, let us refer again to Figure 1 on page 12 and refresh our mental picture of what elements are most plentiful in the crystalline rocks. As we have already seen, oxygen is by far the most abundant of the elements, and unites freely with almost all of the others. Thus we have silica, from a combination of oxygen and silicon; alumina, from a combination of oxygen and aluminum; ferrous and ferric oxides of iron, from a combination of oxygen and iron; 
lime from the combination of oxygen and calcium; potash from a combination of oxygen and potassium; soda, from a combination of oxygen and sodium; and magnesia, from a combination of oxygen and magnesium. These oxygen combinations are indicated in diagram in Figure 23, the subscript numbers attached to the symbol of an element indicating that two or more atoms of that element enters into the combination. The Class of the Silicates, which include nearly 28 per cent of all the mineral species known, are combinations of silica with one or more of

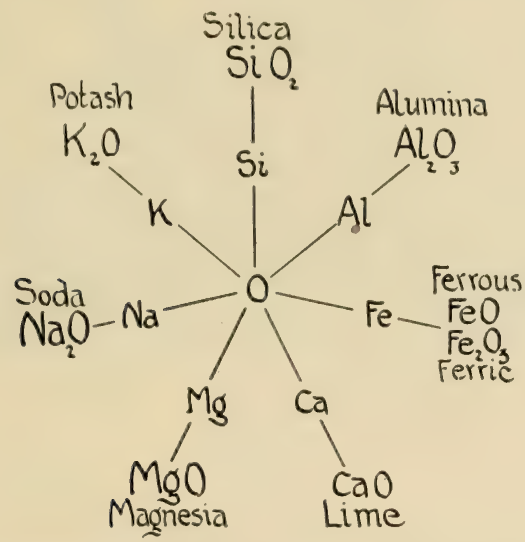

Fig. 23. Diagram showing the Common Mineral-forming Oxides.

the above oxides, to the number of which, as of more rare occurrence, should be added lithia (oxide of lithium), oxide of titanium, oxide of zirconium and oxide of manganese, as well as oxides of copper and zinc which are sometimes locally present in the neighborhood of ore deposits. Some of the silicates contain water, forming a division of hydrous Silicates corresponding to the Hydrous Oxides and Hydrous Carbonates which we have already encountered. Also, several species such as datolite and tourmaline contain the relatively rare element boron. But as a basis to which, in general, the composition of the Silicates may be referred, a diagram such as Figure 24 will be found of 
service. For instance Albite, a mineral of the Feldspar Group, is a soda-alumina silicate, and its composition may be written $\mathrm{Na}_{2} \mathrm{O} . \mathrm{Al}_{2} \mathrm{O}_{3} .6 \mathrm{SiO} .2$; Diopside, a member of the Pyroxene group, is a lime-magnesia silicate, having for its composition $\mathrm{CaO} . \mathrm{MgO}_{2} \mathrm{SiO}_{2}$; and Almandite one of the Garnet Group is a ferrous-alumina silicate, with the composition ${ }_{3} \mathrm{FeO} \cdot \mathrm{Al}_{2} \mathrm{O}_{3} \cdot 3$ $\mathrm{SiO}_{2}$.

In Panel $\mathrm{U}$ will be found examples of the Feldspar Group which for many reasons are ranked as first in importance among the Silicates. As rock-forming material, they are the most

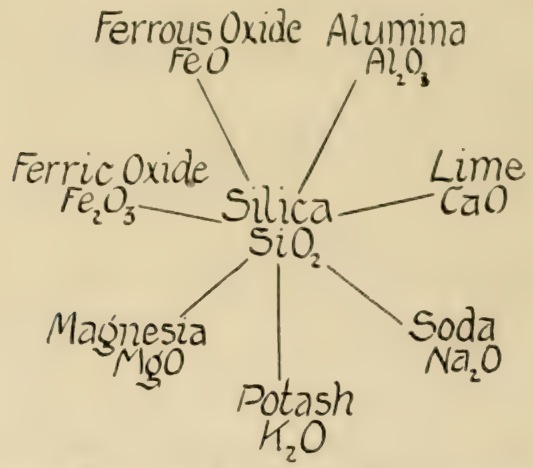

Fig. 24. Diagram to illustrate the General Composition of the Silicates.

abundant of all the minerals which enter into the constitution of the earth, forming nearly 60 per cent of the matter contained in the igneous rocks. The mineral ingredients of such a familiar thing as the soil that supports vegetation are largely furnished by the decomposition of the feldspar from the underlying rocks. The feldspars are composed of silica, alumina and one or more of the metallic oxides, which in the commoner species include potash, lime and soda.

Orthoclase and Microcline are potash feldspars, rather closely related, although Orthoclase is a monoclinic and Microcline a triclinic mineral.

Orthoclase is derived from two Greek words meaning "right 


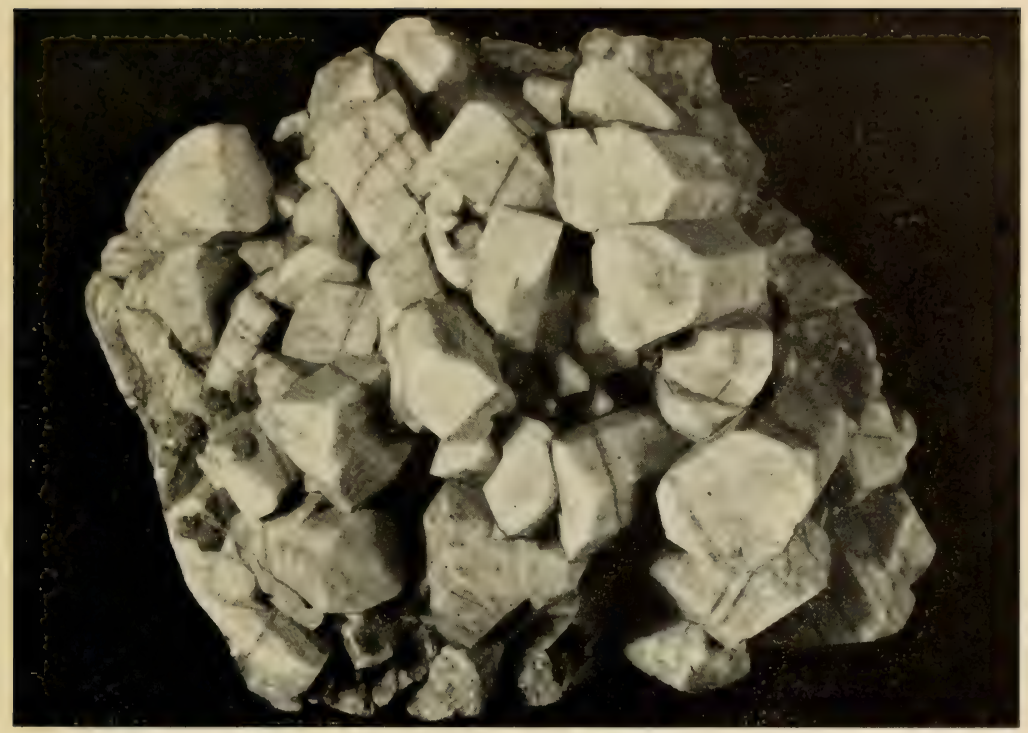

MICROCLINE FROM CRYSTAL PARK, COLORADO Panel V

A group of triclinic crystals which illustrates the usual crystal habit of orthoclase and microcline.

fracture," and refers to the right-angled cleavage, which is a conspicuous and distinctive characteristic of both this mineral and Microcline. A colorless or white glassy kind of Orthoclase is called Adularia, and occurs in crystals which are quite different in appearance from the thick prisms of the ordinary varieties of both Orthoclase and Microcline. These latter varieties are so nearly alike in crystallization and occurrence that it is very difficult to distinguish them from each other. A variety of microcline, called Amazon Stone, is apple-green in color and readily distinguishable from other feldspars. Both Orthoclase and Microcline are common minerals and the principal ingredients of granite, gneiss and other crystalline rocks. They are used in the manufacture of porcelain and china, both as constitu- 
ents of the body of the ware and also to produce the glaze.

The isomorphous group of feldspars called the plagioclases are mixtures of the soda feldspar Albite and the lime feldspar Anorthite, ranging in composition between these two extremes. Thus we have the soda-lime feldspars Oligoclase, Andesine and Labradorite, marking definite proportions of the Albite and Anorthite molecules.

Albite is a white glassy mineral forming in triclinic crystals which are usually flat and plate-like and which often have a pearly luster. The marked tendency to form twin crystals, which is common to all the feldspars, is especially conspicuous in the case of albite, the crystals of which almost invariably exhibit the grooves and reentering angles which are the indications of twinning. All the feldspars, but especially the plagioclases, show in certain varieties a play of color known as iridescence. This is supposed to be due to extremely small and regularly spaced cavities in the interior of the mineral, which break up the light through interference and refract it back as some prismatic color, which in the case of Labradorite is commonly bluish or greenish.

In Panel $\mathrm{V}$ we find a group of Silicates that are more closely allied to one another than the feldspars and are included under the name of Pyroxene. These are sometimes regarded as distinct mineral species and classed together under the designation of the Monoclinic Pyroxenes, because they all crystallize in forms of the monoclinic system, whereas there are also orthorhombic and triclinic minerals included in the Pyroxene Group. Following the precedent of Dana, however, we will regard these monoclinic minerals, that crystallize in the same kind of crystal forms, as subspecies of the mineral Pyroxene. These are silicates of lime with one or more of the metallic oxides, magnesia, ferrous oxide, ferric oxide and alumina, the rarer sub-species also containing manganese and zinc.

The name Pyroxene records a misconception, being derived from two Greek words which signify "a stranger to the domain of fire," whereas this mineral is one of the most important of 


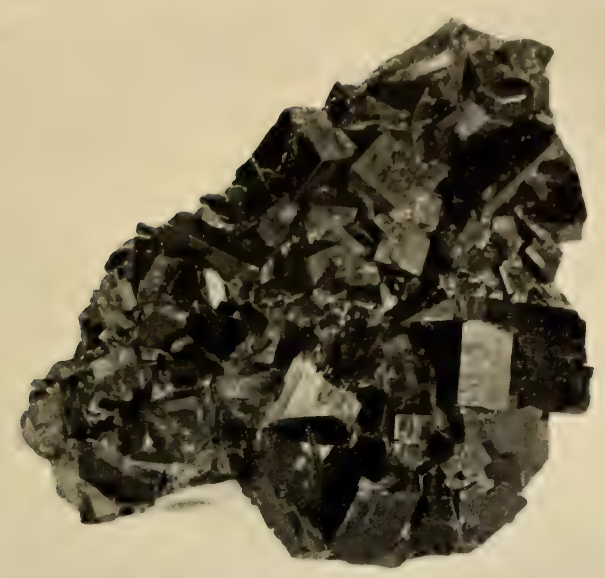

PYROXENE FROM NORDMARK, SWEDEN Panel V

The prismatic crystals of this rock-forming mineral are usually rectangular or eight-sided in cross-section with angles that are nearly equal.

those formed in melted rock masses, and ranks next to the feldspars as a constituent of igneous rocks.

Diopside is a lime-magnesia Pyroxene crystallizing in prismatic forms which present a square or octagonal cross section, and which are often, but not always, some shade of green in color. The best crystallized examples of it are usually to be found at points where an igneous rock while in process of solidification has come in contact with a crystalline limestone. Such junctures of rocks in the formative stage are called "contact zones," and furnish favorable conditions for the crystallization of minerals from mineral material furnished by both of the rocks in contact. One can compare this action to two chemical solutions that have been brought into contact so as to react upon one another. Augite, another subspecies under Pyroxene, is more complex in composition than Diopside, being a limemagnesia silicate also containing alumina, ferrous and ferric 
oxides. In color it is generally darker than Diopside, the varieties containing a high percentage of iron being black; as the iron constituent decreases in amount we have varieties that are dark green to light green or even grayish or white, but these are rare and the Pyroxenes that are called Augite are generally black or nearly so.

Besides being found as a chief constituent in such rocks as diabases and gabbros, Augite is often encountered in the cavities of lava.

Spodumene is a silicate of alumina and the rarer oxide lithia, related to Pyroxene, and, although differing sufficiently from the latter mineral to constitute a separate species, is included in the Pyroxene Group. It occurs in monoclinic crystals which are sometimes of considerable size as will be seen from the specimen from the Black Hills of $\mathbf{I}$ yoming in Panel $\mathrm{V}$. Spodumene has the property of splitting into broad, smooth plates parallel to one of its crystal faces. So prominent is this characteristic that it constitutes one of the means by which the commoner kinds of this mineral may be recognized at sight. The color of Spodumene is mostly an opaque white, but transparent colored varieties of various shades of green, pink and purple are also found and are sometimes cut for semiprecious stones. ${ }^{1}$

Rhodonite, which is a silicate of manganese, is a mineral of the Pyroxene Group that is quite readily recognizable on account of its unusual and characteristic color. Its triclinic crystals are flesh red to rose-pink, colors which are imparted to it by the manganese. On account of these attractive tints Rhodonite is sometimes used as an ornamental stone, the Russian variety being particularly rich in color.

The minerals of the Amphibole Group, specimens of which will be found in Panel V, present a striking similarity to the Pyroxenes both from the point of view of their chemical constitution and that of their playing an important part in the formation of many of the igneous rocks. Like the Pyroxene

1 For a series of the gem stones cut from Spodumene see Case XXIII of the Gem Stone Series. 
Group, they are silicates of various combinations of the rockforming metallic oxides in which lime, magnesia and ferrous iron are the most prominent. Amphibole, which is a monoclinic member of the group, corresponding to Pyroxene of the Pyroxene Group, is an abundant constituent of such important building stone rocks as granites, syenites and diorites, occupy-

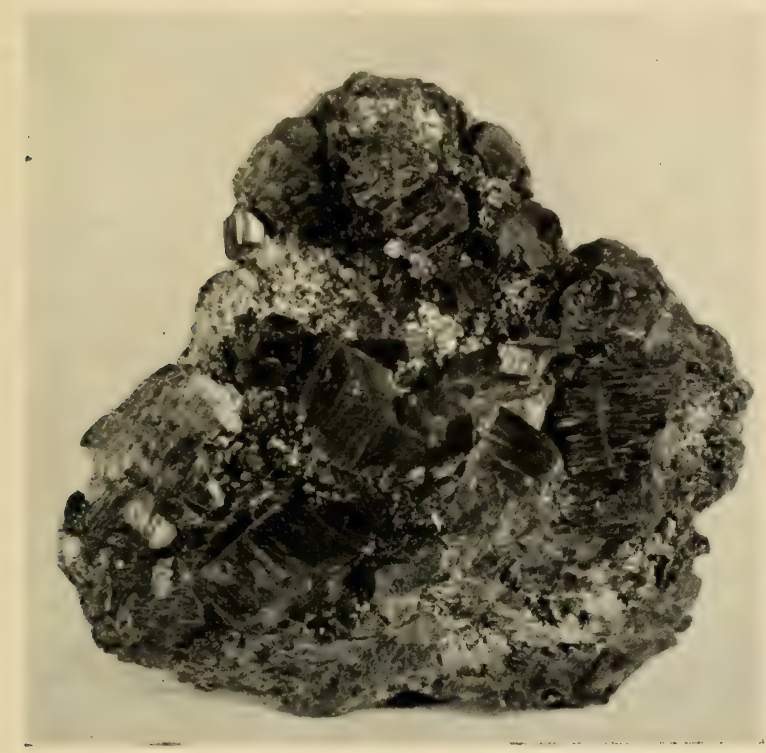

AMPHIBOLE FROM ST. LAIVRENCE COUNTY, NEWV YORK Panel V

A group of hornblende crystals, whose fibrous, black appearance is both striking and characteristic.

ing a place in their mineral make up which is analogous to that of Pyroxene in such rocks as diabases and gabbros.

The subspecies under Amphibole correspond chemically to those of Pyroxene, the difference between the two species consisting of a variation in the arrangement of their molecules resulting in different forms of crystals, although both minerals crystallize in the Monoclinic System.

Tremolite is a lime-magnesia amphibole ranging in color 
from white to dark gray. It is to be found in many crystalline magnesium limestones, particularly in those portions of them which are adjacent to masses of igneous rocks, corresponding in its mode of occurrence with the lime magnesia Pyroxene, Diopside. Tremolite is characterized by a silky luster the "grain" of which runs parallel to the edges of the prism.

Actinolite is also a lime-magnesia Amphibole with some of the magnesia replaced by ferrous iron. In color this Amphibole ranges from grayish green to bright green, the deeper green color corresponding to the higher percentage of iron. Some important varieties of Actinolite are Nepbrite, which includes the commoner kinds of jade, and Asbestos, a variety consisting of white, gray or green fibers which are easily separated, and can be woven into fabrics. Actinolite is found in such rocks as crystalline schists, some of which are mainly composed of it, and talc and serpentine rocks.

A very common rock-forming Amphibole is the aluminous subspecies Hornblende, which contains in addition to alumina, lime, magnesia and iron. Hornblende, containing as it does a higher percentage of iron, is darker in color than the other Amphiboles, the commoner kinds being black. These latter are present in many kinds of granites, gneisses and in some schists, the Hornblende crystals in these instances being developed in long thin prisms.

An excellent way of differentiating between Pyroxene and Amphibole is to note the angle made by the prominent prism faces of the crystals, which in Pyroxene is very close to a right angle, and in Amphibole usually presents an acute rhombic section. Both Pyroxene and Amphibole include a considerable number of more or less obscure and rare subspecies most of which will be found in Case 12 of the main Series. 


\section{Chapter XI}

\section{SILICATES (Continued)}

IN CHAPTER $X$ we considered briefly the silicates which enter as essential minerals into the constitution of the eruptive rocks. We come now in our tour of the wall panels to some silicate minerals, which, although common in these rocks, are present rather as accessory minerals than as the chiet constituents of them. Like the Feldspars, the Pyroxenes and the Amphiboles they are, for the most part, composed of combinations of the silicate forming oxides shown in diagram in Figure 24 , page 104, but, as we would naturally expect, there have also been locally present in some of the fused mixtures of these oxides, smaller amounts of oxides of the rarer elements, and these entering into combination with silica and the other oxides of the silicate-making group produce such minerals as Beryl, Zircon and Tourmaline.

Beryl, which is a silicate of beryllium, is represented in Panel $\mathbf{V}$ by a number of specimens. It is a fairly common mineral in granites which are characterized by large and coarse crystals, and which are called pegmatites. Beryl forms very characteristic crystals, in which the predominating form is a hexagonal prism. Quartz, which also forms in hexagonal prisms, and which might sometimes be mistaken for Beryl, always presents a pointed termination, whereas Beryl, when terminated crystals can be observed, shows a flat basal plane at right angles to the prism.

As with most of the common silicates, Beryl occurs in a number of colors and degrees of transparency. It is found in pale shades of green, blue and yellow, merging into white. These colors characterize the common varieties; the rarer 
varieties, many of which are cut into gem stones, include Emerald, a brilliant grass-green Beryl, Aquamarine, which is a transparent variety, light blue to light green in color, and Morganite, named for Mr. J. Pierpont Morgan, which is rose color. ${ }^{1}$

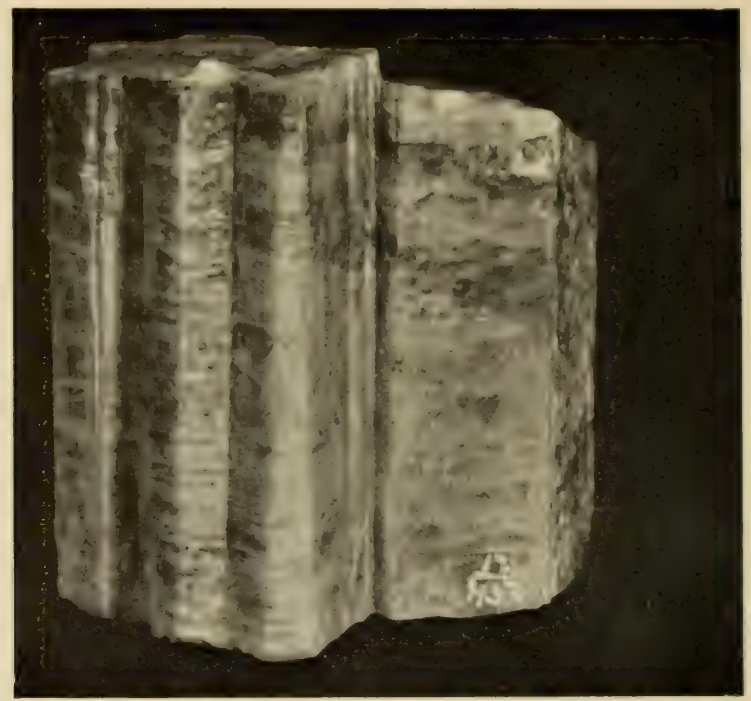

\section{BERYL FROM PORTLAND, CONNECTICUT Panel V}

The columnar grouping of these hexagonal prisms is very characteristic of beryl. Sometimes the crystals are of enormous size.

In Panel IV will be found the very widely distributed silicate, Garnet, which, like the minerals Pyroxene and Amphibole, comprises a number of subspecies. These vary in composition, being mainly combinations of silica with the oxides alumina, lime, magnesia, and iron. The crystals of Garnet are easily recognized, being simple combinations of two or three isometric forms, which are usually very free from distortion. There are

1 A splendid series of these Beryl gems will be found in Cases IV and $\mathrm{V}^{\top}$ of the Gem Stone Series. 
two sub-species that include most of the common occurrences of garnet; Almandite and Andradite.

Almandite is an iron-alumina garnet which is usually deep red to black in color. Besides including many of the common varieties of garnet, this sub-species furnishes some of the transparent garnets that are cut for gems. It is the garnet that is most frequently found in mica schists and in other metamorphic rocks.

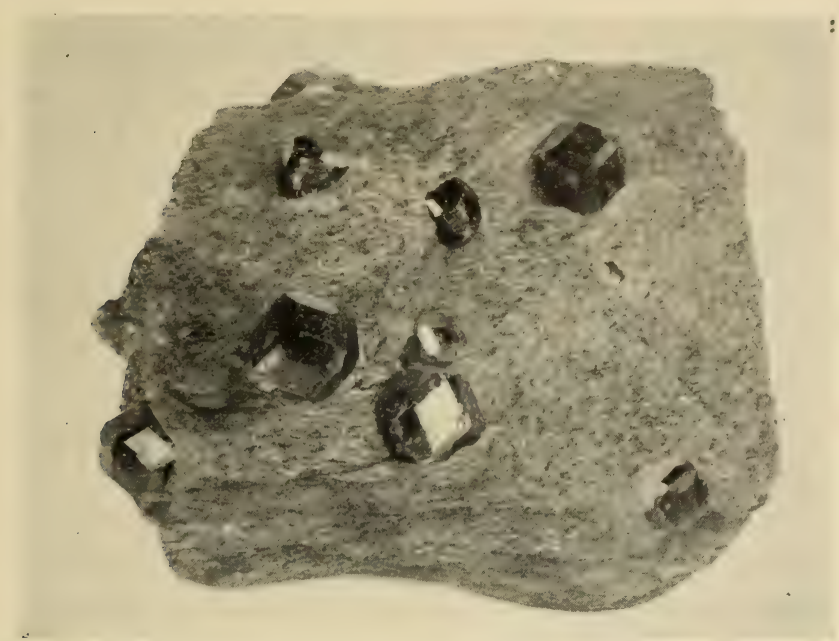

GARNET IN MICA SCHIST FROM STICKEEN RIVER, ALASKA Panel W

These finely developed crystals are excellent examples of the perfect symmetry of the isometric system.

Andradite, or common garnet, is a sub-species containing lime and ferric iron. The partial replacement of these oxides by alumina, ferrous iron, magnesia and manganese gives rise to a considerable variation in the color, various shades of yellow, green, red, brown and black being represented among its many varieties. Andradite is much more widely distributed than the other garnets, occurring in rocks of many types, especially 
in crystalline limestones. Pseudomorphs of such minerals as Chlorite and Serpentine after Garnet are not at all infrequent.

In addition to the gem uses to which transparent varieties of Garnet are put, massive deposits are sometimes ground to furnish an abrasive sand which is characterized by sharp cutting edges.

Willemite is a silicate of zinc in which, in the variety Troostite, a considerable part of the zinc is replaced by manganese. It is a mineral which is only locally important, the only place where it is found in notable quantities being Franklin, N. J. Willemite crystallizes in forms of hexagonal symmetry. When pure it is greenish yellow to apple-green in color, but the presence of manganese in increasing amounts imparts to it a grayish to fleshred color. Willemite is mined for zinc at the Franklin locality.

Another metallic silicate that is of relatively little importance except in certain localities is Dioptase, a silicate of Copper. This mineral may be readily recognized by its hexagonal crystals and its brilliant emerald green color. It is rare except in certain copper deposits, where it is mined with other ores.

A group of minerals that are accessory constituents of some of the igneous and metamorphic rocks are the Scapolites, an isomorphous group of alumina silicates, into the composition of which there also enters combinations of the oxides soda and lime. Thus, they have a certain chemical analogy to the Plagioclase Group of the feldspars, forming like them a series of isomorphous mixtures, the two end numbers of which are a lime-alumina silicate and a soda-alumina silicate, the latter in this instance containing a little chlorine. The minerals of the Scapolite Group crystallize in similar forms of the tetragonal system.

Wernerite, which is also called common scapolite, is the most widely distributed mineral of this group. It is an alumina-limesoda silicate of various proportions of these oxides, the composition of the different varieties covering a number of isomorphous mixtures of the two end members of the series. The crystals are prismatic in habit, the prisms having eight-sided cross sections 
and low pyramidal terminations. They are commonly coarse and thick, often with rounded edges and angles, and with a characteristic fibrous appearance on the cleavage surface when broken.

In color Wernerite is usually some neutral tint of gray, dull green or white, or sometimes bluish or reddish. It is found mostly in metamorphic rocks, and, like some kinds of pyroxene and amphibole, is abundant in crystalline limestone near the contact with granite or other igneous rocks.

Zircon is a silicate of the rare element zirconium, and is a fairly common accessory rock mineral. It is usually found in small, isolated tetragonal crystals of square prismatic habit. These are very distinctive, and supply a ready means of recognizing this mineral, even when, as often happens, only a part of them can be seen protruding from the rock. The luster and color of Zircon are also quite characteristic, the former being adamantine, with the oily sheen of an uncut diamond, and the latter usually some shade of brown, reddish or gray.

Zircon is among the earliest of the minerals to crystallize from a cooling molten rock mass, a fact that may be recognized in the field by the way in which the latter formed quartz and feldspar of a granite tend to crystallize in radiating "bunches" from a nucleus formed by an isolated Zircon crystal.

Transparent varieties of Zircon are used for gem stones. It also furnishes a source of the zirconium oxides used in making incandescent gas mantles.

Topaz is a silicate of alumina which also contains some of the halogen element fluorine. It forms orthorhombic crystals which are commonly prismatic in habit and are often highly complex. The luster is vitreous like quartz which might sometimes be confused with the colorless, massive kinds of Topaz, were it not for the fact that the latter mineral shows a very marked cleavage at right angles to the prism faces, producing cleavage surfaces of great brilliancy. The color of Topaz covers quite a wide range of delicate tints from white through various shades of yellow, green, blue and even reddish. Although Topaz is 
commonly found in such igneous rocks as granite and rhyolite, it is present in veins and cavities in these rocks where we have reason to suppose it was deposited through the action of hot vapors after the rock mass had crystallized. Many of the transparent varieties of topaz are cut to furnish the well known semiprecious gem stones which are known among the jewelers as "precious topaz." 1

Two silicates of alumina are among the mineral species shown in Panel IV, Andalusite and Cyanite. Both are somewhat uncommon accessory minerals in metamorphic rocks, particularly in gneiss and mica schist. Andalusite, named from Andalusia, Spain, where it was first found, occurs in coarse, orthorhombic crystals nearly square in cross section. Sometimes the crystals are roughly rounded and contain carbonaceous inclusions arranged along the lines of the crystal structure, which show, on being broken or cut across, symmetrical figures in black and white. Such a variety is called Chiastolite, derived from the Greek word meaning "arranged diagonally." The color of Andalusite varies from white or light gray through light green or violet to rose-red or flesh-red.

Cyanite, which is sometimes also called disthene, is found in long bladelike, triclinic crystals and in aggregates of these that often bear a resemblance to bundles of knife blades. The color is usually, but not always, a grayish blue. Cyanite occurs in gneiss and mica schist.

Datolite, specimens of which are shown in Panel X, is a silicate of lime containing boron and a small amount of water. The monoclinic crystals in which it forms are often highly complex and difficult to orient. In general characteristics, and in the mode of its occurrence in pockets in basaltic rocks, datolite very much resembles the minerals of the Zeolite Group, which will be described in the next chapter, and is often closely associated with these minerals. It is almost always clear and glassy or white in color, although sometimes colored a faint green, yellow or

1 A fine series of these Topaz gems will be found in Case VI of the Gem Stone Series. 


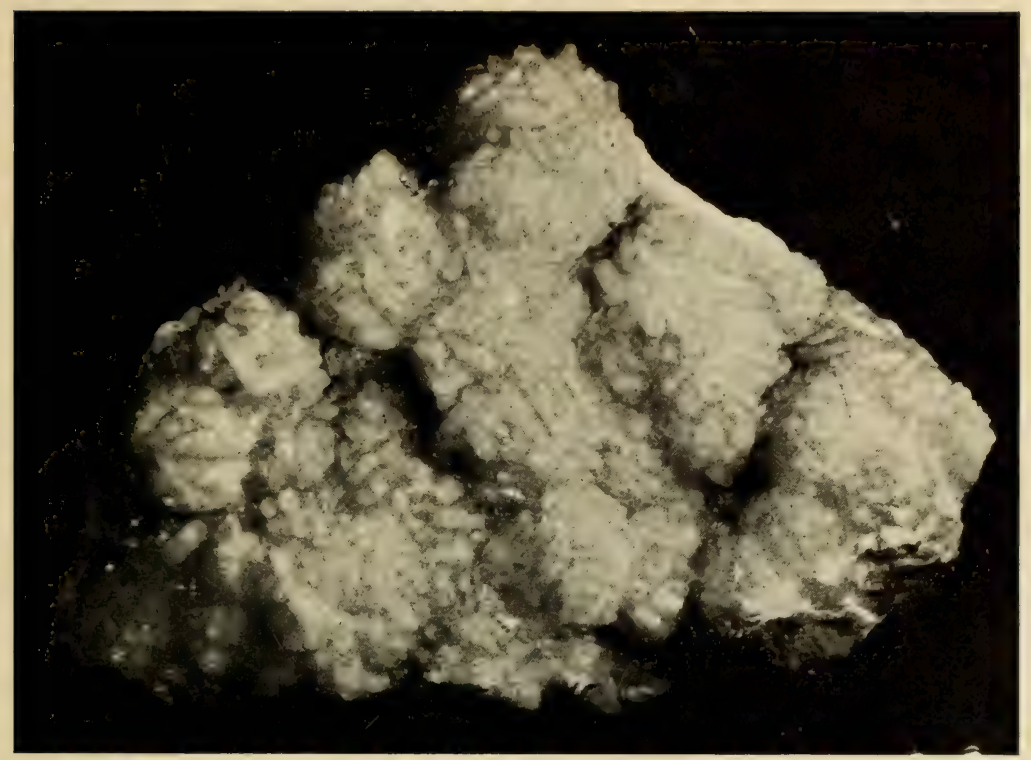

CALAMINE FROM OGDENSBURG, NEW JERSEY Panel X

The flat orthorhombic crystals of this mineral are often joined in radiating groups, forming rounded, notched ridges like cockscombs.

pink. Datolite is essentially a secondary mineral, having been deposited in veins and cavities by solutions in circulating water.

In Epidote, specimens of which are shown in Panel $W$, we meet a common accessory mineral found in many of the metamorphic rocks. Epidote is a silicate of lime, alumina and iron, with a small amount of water. Unlike most of the minerals that we have hitherto encountered, Epidote has a characteristic color. This is a pistachio green which ranges through several shades from light to nearly black, but is always distinguishable. The crystals of Epidote which are monoclinic have usually a very marked prismatic habit, the prisms being long and slender, and developed at right angles to the plane of symmetry. In other words they are borizontal rather than vertical prisms with 
respect to the way in which we usually orient monoclinic crystals. So pronounced is this prismatic habit that we often find Epidote in long needle-like crystals grouped in divergent masses.

Epidote frequently occurs in the contact area between crystalline limestone and granite, and in such metamorphic rocks as gneiss, and mica schist.

Prehnite, which is a lime-alumina silicate with some water, occurs as a secondary mineral in veins and cavities in such eruptive rocks as basalts and diabases in very much the same way, and commonly associated with Datolite and the minerals of the Zeolite group. It is very seldom found in distinct crystals but forms in rounded crystalline aggregates.

The color of Prehnite is sufficiently distinctive to be of use in recognizing it. It is commonly a light apple green, which is sometimes shaded to yellowish green and more rarely gray or white. Among the few silicate minerals that constitute ores of the useful metals is Calamine, a silicate of zinc containing a little water. Its orthorhombic crystals have a strong tendency to join one another in radiated groups which form rounded, notched ridges, a crystal grouping which has been called "cockscomb structure" because it resembles the comb of a rooster. Calamine is usually colorless or white, but slight amounts of impurities impart to it delicate shades of blue, green, yellow or brown, these colors being particularly characteristic of the massive, stalactitic varieties.

Calamine is essentially a secondary mineral and usually accompanies Smithsonite, the zinc carbonate, in the oxidized zone of zinc deposits. It is mined with other zinc ores.

In Panel X will also be found several specimens of Tourmaline, another name for which is Schorl. This is a common accessory mineral in many of the crystalline rocks, such as granite, gneiss, mica schist, and crystalline limestone. It is a complex silicate of boron and alumina with small but appreciable amounts of the other common silicate-forming oxides in various combinations. Such a wide range of chemical compo- 


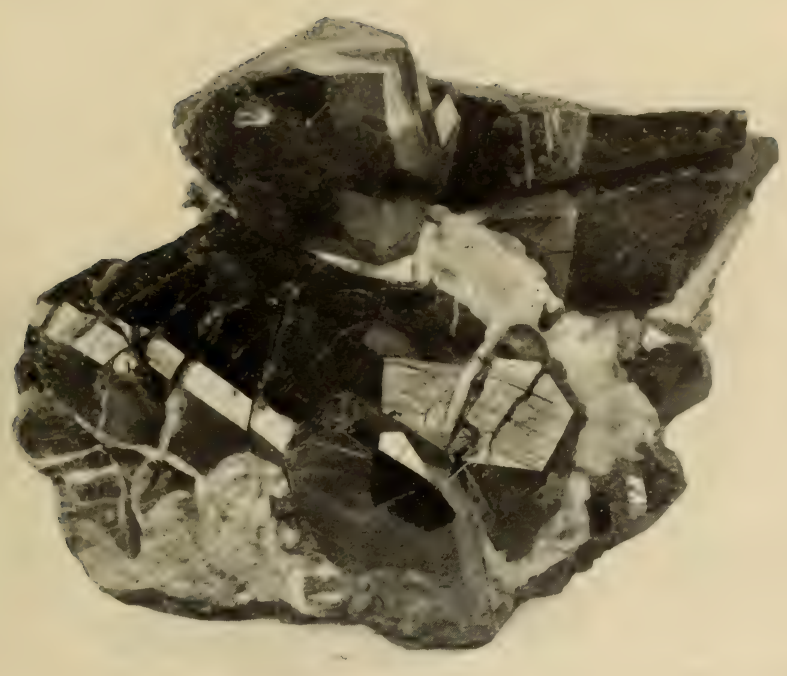

TOURMALINE FROM GOUVERNEUR, NEW YORK Panel X

Very characteristic of this mineral are the roughly triangular prisms to be seen in this example.

sition give rise to a number of varieties which differ much in color and transparency from the commoner opaque black Tourmaline, which contains a good deal of iron, through brown kinds rich in magnesia, to green blue and red transparent varieties. Tourmaline crystallizes in rhombohedral forms of the hexagonal system, the crystals being terminated by different forms on the two ends. The crystals of Tourmaline are prismatic in habit, sometimes short and thick, but more often long and slender with grooves or striations parallel to their edges. They are to be distinguished from those of other common minerals by the characteristic of always presenting a somewhat triangular cross section.

Staurolite is a silicate of iron and alumina in which magnesia 
and sometimes manganese replace part of the ferrous iron. It is a somewhat uncommon accessory mineral in such metamorphic rocks as gneiss and mica schist, where it is often associated with Garnet, Cyanite and Tourmaline. Staurolite may be recognized by its orthorhombic crystals, which are of prismatic habit and are often twinned, producing forms that are shaped like crosses. These are dark brown, or gray to black in color. 


\section{Chapter XII}

\section{SILICATES (Continued)}

THE hydrous silicates contained in Panels $\mathrm{Y}$ and $\mathrm{Z}$ are minerals of the Silicate Class into the composition of which water enters in appreciable amounts. This may have happened in several ways. In the instance of the group of hydrous silicates known as the Zeolites, which will be found in Panel Y, the water which they contain is called water of crystallization. This is a term used to describe the chemical relation of certain molecules of water, which are so loosely bound to the other elements that compose a mineral that it is possible to drive them off by subjecting the mineral to a relatively low degree of heat. This rapid expulsion of water from the fusing mineral produces a violent bubbling or boiling of the fused mass, and is the reason for naming the group Zeolites, which means in Greek "boiling stones."

The Zeolites are all of secondary origin, being deposited from water solutions which have dissolved the minerals composing them out of the rocks which these solutions have previously traversed. The dissolved minerals which furnished the material entering into their composition were mostly feldspars, and, since the feldspars are alumina silicates with lime and soda, so the Zeolites are hydrated alumina silicates with either lime or soda or both.

Zeolites are usually found in seams and cavities of igneous rocks, such as basalt or diabase, or as they are loosely called "trap rocks"; they are less frequently found in granite and gneiss.

Apophyllite, a hydrous silicate of potash and lime, while not 
strictly a zeolite, is usually included with these minerals on account of the secondary character of its formation, and its frequent association with zeolites in basaltic rocks. Apophyllite occurs in tetragonal crystals of rather simple combinations of forms and not complicated by twinning. These are ordinarily colorless or white, or less frequently pink or greenish. On the basal plane, which lies at right angles to the prism faces, a pearly luster due to internal opalescent reflections, and often likened to the eye of a fish, is sometimes noticeable. Some fine specimens of Apophyllite will be found in Panel Y.

Stilbite is a hydrous soda-lime-alumina silicate of the Zeolite Group, and is one of the commonest of the Zeolites. It occurs in monoclinic crystals, which, however, show such a marked tendency to form aggregates that distinct crystals are seldom met with. The forms assumed by the crystal aggregates, however, are quite distinctive, sheaflike, globular and radiated groupings of crystals being frequent. The tabular sides of these aggregates show a pearly luster, which, contrasting with the otherwise vitreous luster, is also a good distinguishing character. White is the usual color, although brown, yellow and even red stilbite may be seen in a large suite of specimens.

A less common Zeolite than Stilbite is Chabazite, a hydrated soda-lime-alumina silicate in which the proportion of the oxides differs from that of Stilbite. The crystallization also differs, for Chabazite occurs in rhombohedral crystals with nearly square faces, which give to them somewhat the aspect of cubes. These faces, however, are commonly grooved with fine lines parallel to the edges in trigonal symmetry, and are often broken by the protuberance of an angle of a twinned rhombohedron. The color of Chabazite is white or various shades of flesh-red.

Analcite is a hydrous soda-alumina silicate and is one of the commoner zeolites. It occurs in isometric crystals of great simplicity, these usually taking the form of trapezohedrons, like some of the crystals of garnet. They are commonly colorless or white like other zeolites, or faintly colored greenish or red.

One of the most attractive of this group of minerals is Natro- 


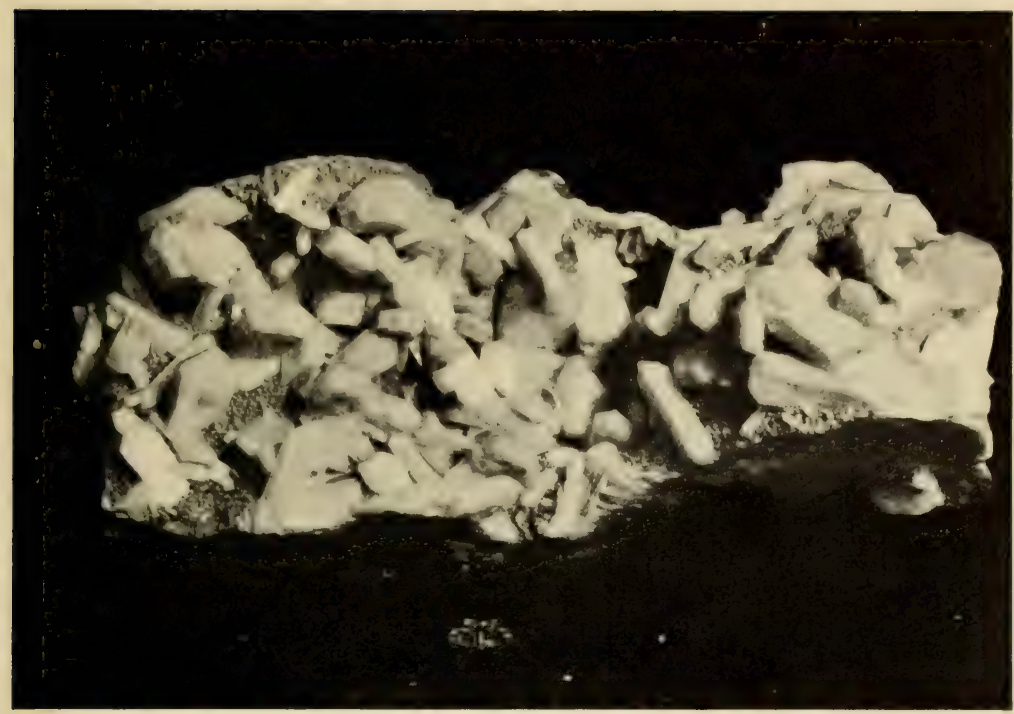

STILBITE FROM ICELAND

Panel Y

The strong tendency to form in crystal aggregates, which is a marked characteristic of this mineral, gives rise to these sheaflike forms.

lite, a hydrous soda-alumina silicate. The slender, orthorhombic prisms of Natrolite are nearly square in cross section, and might easily be mistaken for tetragonal crystals. They are commonly grouped in radiating and interlacing aggregates, sometimes resembling clusters of organ pipes; or the finer hair-like crystals form concentric tufts, outlined in striking contrast against the dark basaltic ground mass to which they are attached. Clear transparent crystals are much more frequent with Natrolite than with other Zeolites, although the usual colors of the group, white, greenish and reddish, are by no means lacking.

The Mica Group of minerals, specimens of which will be found in Panel Y, are, like the Zeolites, hydrous silicates. They differ, however, from the latter group in that the water involved in their composition is water of constitution and more inti- 
mately bound to the other elements composing them than the water of crystallization, so essential a characteristic of the Zeolites. This difference is a far reaching and significant one, and carries us to the fundamental difference which characterizes the formation of the two groups. As we have seen, the Zeolites are all of them secondary minerals, deposited by circulating water that held them in solution, and out of which they crystallized when the conditions were favorable to crystallization. The water involved in their chemical composition was, consequently, a part of that which formerly held dissolved the material composing them. The micas, on the other hand, are either essential or accessory minerals of the igneous and metamorphic rocks, formed under similar conditions of heat and pressure as those that produced the Feldspars, Pyroxenes and Garnets. The water that they contain was present in the fused plastic mass of matter from which they separated when the elements which constituted them came together, and was, in fact, part of the solid solution from which they were derived. Unlike the water contained in the Zeolites, this cannot be driven off at relatively low temperatures, but only yields to a red heat. The outstanding character of the Mica Group is a marked tendency to split into thin flexible plates.

Muscovite, the commonest of the micas, is a hydrous silicate of potash and alumina, or, since all the micas are alumina silicates, we may call it a potash mica. It has also been called white mica and isinglass. As a rock mineral, muscovite is an essential constituent of a large and important series of rocks, including granites, gneisses and mica schist. Its crystals are monoclinic, prismatic or tabular in habit, and cleave with the greatest ease into rhombic or hexagonal plates. It is quite common to find these tabular crystals grouped in globular or plumose forms, or as thin scales disseminated through the rocks. The largest crystals occur in dykes and veins in pegmatite rocks. The broad thin plates which may be readily split from them are used for doors of furnaces and stoves, and for the insulating material in dynamos and other electric appliances. Muscovite has a pearly 


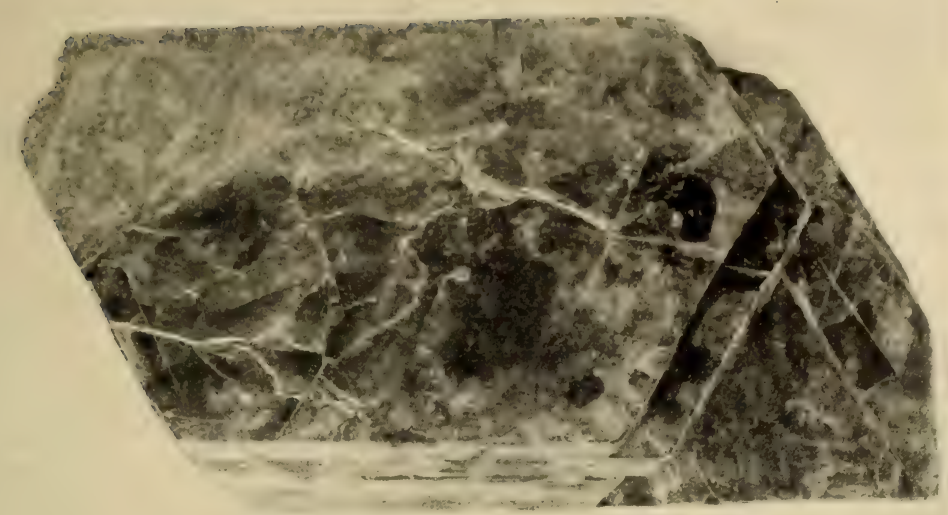

MUSCOVITE FROM AMELIA COURT HOUSE, VIRGINIA Panel Y

Like all the micas, this mineral forms in rhombic or six-sided crystals which split very easily into extremely thin plates.

luster on the cleavage planes and is usually gray, light brown, green or yellow in color.

Biotite, or black mica, is a potash-magnesia-iron mica, in which the amount of iron varies considerably with the different varieties. The monoclinic crystals in which it occurs as like those of muscovite, but are notably darker in color, the common varieties being dark green to black. The luster also differs from the pearly sheen of Muscovite, and in the darker kinds is submetallic. Biotite is also an important rock mineral of wide distribution, and occurs as a common constituent in many igneous rocks, such as most granites and many of the syenites and diorites. In small flakes, Biotite is present in many common rocks and soils. It is less frequently found in large sheets than is Muscovite.

A mineral of the Mica Group that resembles Muscovite is 
Phlogopite, a magnesia mica with some iron and fluorine. It is especially associated with crystalline limestone, being often found in the contact zones where igneous intrusive rocks adjoin beds of dolomite limestone. The color, which is the chief means of distinguishing it from the other micas in the field, is commonly yellowish brown to brownish red, and it frequently shows a metallic copper red on the cleavage surfaces. The chief use to which it is put is as an insulating material in electrical work.

The division of the Hydrous Silicates includes another very common mineral, which will be found in Panel $\mathrm{Z}$. This is Serpentine, a hydrous magnesia silicate with some of the magnesium replaced by iron. Serpentine is essentially a secondary mineral, always resulting from the alteration of some other iron magnesia silicate which formerly occupied the same position in the rocks. The mineral that is most frequently changed into Serpentine is Chrysolite, but there are also many instances of serpentine having been derived from pyroxene and amphibole. Serpentine never occurs in crystals of its own characteristic form, although, from the nature of its derivation, it is quite frequently found in crystal forms that belong to other minerals, after which it has formed pseudomorphs. In spite of the fact that actual crystals of Serpentine are unknown, this mineral presents quite a varied range of forms of crystalline structure. Sometimes it is foliated, that is, formed in thin sheets, which cannot be easily separated like the sheets of mica; or again it occurs in masses of delicate, thread-like fibers. It is commonest, however, in fine granular or inpalpable masses which have a waxy appearance and a greasy feel.

The fibrous variety, which is called Chrysotile, occurs in veins of various thickness, traversing the massive mineral, and furnishes a considerable part of the asbestos of commerce. The fibers of Chrysotile are very easily separated into fine silky threads, and these can be woven into fabrics which will resist fire.

The color of Serpentine is usually a green of different shades, 
but it is also yellow, brown or nearly black or white, and it is frequently mottled in various colors resembling the skin of a snake, from which appearance it gets its name. The Serpentine of rich and mottled colors is sometimes polished and used as an ornamental stone, a use to which its softness renders it peculiarly adaptable.

Titanite, specimens of which will be found in Panel $\mathrm{Y}$, is the commonest and most important mineral in a small group of substances known as titano-silicates, because the combination of oxide of titanium and silica constitutes the basis of their composition. Titanite, which is also called Sphene, is a lime titano-silicate sometimes containing iron and other metallic bases. The monoclinic crystals are commonly wedge-shaped and often show the reëntrant angles, which are the indications of twinning. In color Titanite is usually brown, darker shades of which merge into black; more rarely it is yellow or green in color.

Titanite is chiefly important as an accessory rock-forming mineral in many igneous rocks of a granitic type, such as hornblende granites, syenites and diorites, as well as in metamorphic rocks, like schists, gneisses and crystalline limestones.

Another small group of minerals which consist mostly of rare species are the Niobates and Tantalates, compounds of the rare elements Niobium, also called Columbium, and Tantalum. The only species in this division that attain any degree of importance are an iron-manganese niobate, Columbite, and an iron tantalate, known as Tantalite, which grade into each other chemically to such an extent that it is impossible to definitely separate the two species.

Columbite occurs very sparingly in granite as black or reddish brown orthorhombic crystals. Columbite and Tantalite furnish a source of the element tantalum which is used in making filaments for incandescent electric lights. 


\section{Chapter XIII}

\section{PHOSPHATES AND SULPHATES}

WE HAVE passed in review two large and important classes of oxygen salts, the Carbonates and the Silicates, whose composition is based respectively on combinations of the element oxygen with carbon and with silicon, and we have seen in each class a number of common and important minerals. We come now to a consideration, in Panel $\mathrm{Z}$, of a class of minerals which included a great many species, most of which are of rare occurrence among the natural substances of the globe, but a few of which are common and important. These are compounds of oxygen and phosphorous with one or more of the metallic oxides, and they also include the closely related combinations of oxygen with the semi-metals arsenic, antimony and vanadium. The Phosphates, Arsenates, Antimonates and Vanadates are mostly secondary minerals derived from the alteration of other compounds of the metallic elements involved in their composition; for instance Pyromorphite, a phosphate of lead, is usually derived from the lead sulphide Galena, or from some other lead mineral. These secondary phosphates are ordinarily found in close association with the minerals from which they were derived, so that it is easy in the field to trace their origin, and less easy, but still quite possible, to follow the stages of their alteration in the specimens of a collection.

The commonest mineral among the phosphates is Apatite, a phosphate of lime with calcium chloride or calcium fluoride. Apatite is a notable exception to the general rule that the phosphates are secondary in origin. It is principally an accessory rock-forming mineral, often found in metamorphic crystalline 


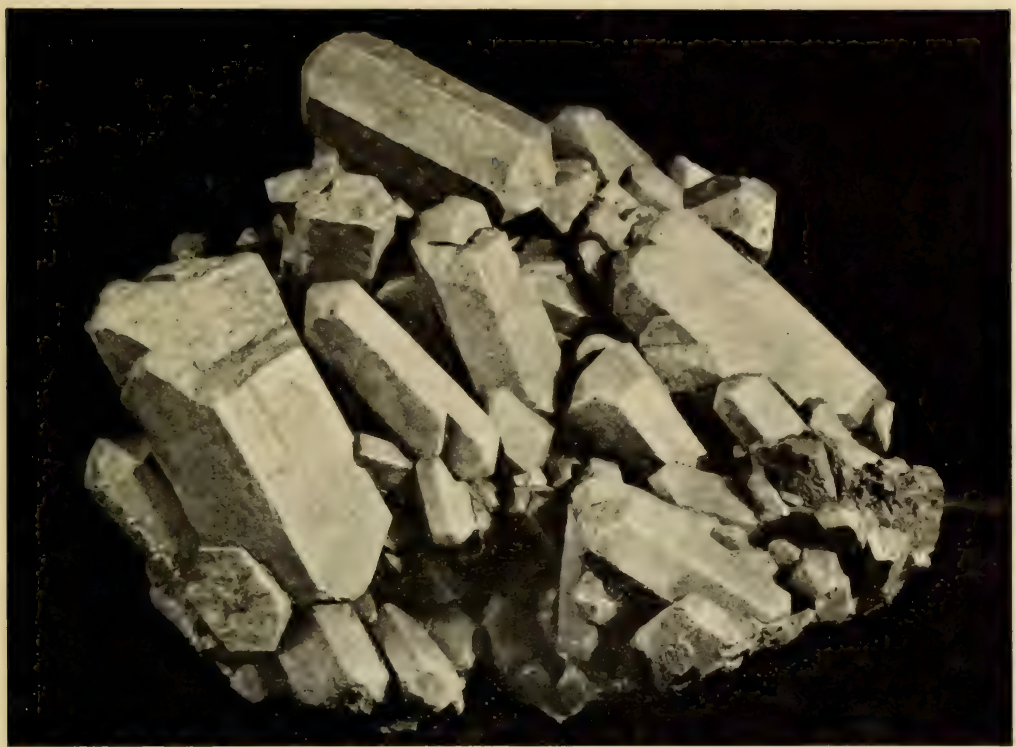

APATITE FROM RENFREW, ONTARIO, CANADA Panel Z

Hexagonal prisms capped by low pyramids are common among the crystal forms assumed by this rock-forming phosphate.

rocks, especially in crystalline limestone near the contact with an intrusive granite or pegmatite. Apatite crystallizes in sixsided prismatic crystals which are sometimes terminated by a low pyramid and are not easily confused with those of quartz or beryl, because they ordinarily present surfaces and edges that appear rounded as though dipped in fused glass. This appearance is largely confined to the Apatite from the crystalline limestone and may be also noted on other minerals, such as Wernerite and Titanite, from these occurrences. On account of its color, Apatite is sometimes called "asparagus stone," the shades of sea green and bluish green, which are so common with the mineral, much resembling those of the vegetable. The commoner kinds are also brown or flesh-red in color, and the 
less common transparent varieties colorless, yellow, greenish or violet.

When pure, Apatite is used in the manufacture of phosphorus, for which there are many uses in the arts. A massive, impure phosphatic material, known as rock phosphate, and occurring in extensive beds, is of considerable importance in the manufacture of fertilizers.

There are several phosphates that follow Apatite in the form of their crystals, and that are similar to it in chemical composition. Two of the most important members of this isomorphous group are Pyromorphite and Vanadinite.

Pyromorphite is a lead phosphate with lead chloride, corresponding in composition to a chlor-apatite in which the place of the calcium is taken by lead. Although the crystals are like those of Apatite, they differ slightly from them in showing a marked tendency to form in parallel groups or bundles of crystals, sometimes rounded, barrel-shaped, or branching, and less frequently in globular masses. Pyromorphite is sometimes called "green lead ore" because its color is very often some shade of green, but we may also expect to see yellow, brown, or even grayish white examples of it. As we saw at the beginning of the chapter, Pyromorphite is distinctly a secondary mineral, occurring with other lead ores in veins and pockets in the ore body. It is an unimportant ore of lead.

Vanadinite is a lead vanadate with lead chloride, very closely allied chemically to Pyromorphite, because the place of phosphorous in Pyromorphite is here taken by the rare element vanadium. The crystals are like those of Pyromorphite, and so is its crystal habit of forming aggregates, but the color inclines to the red, orange and yellow shades. Its occurrence is also like that of Pyromorphite, but it is rather more rare.

Vanadinite is an unimportant ore of lead, but an important source of vanadium, for which many uses are now being found.

Wavellite, a hydrous alumina phosphate, is an example of a numerous group among the phosphates, and one that includes a great many minerals that are relatively rare. All of these con- 
tain water, making them analogous to the hydrous oxides, the hydrous carbonates and the hydrous silicates. Wavellite rarely occurs in orthorhombic crystals that can be separately distinguished. The mineral is commonly found in close aggregates of radiating, fibrous crystals, that assume the form of beautifully rounded knobs or balls. When broken across, these aggregates show clearly their radiated character, concentric rings of slightly varying color indicating the stages in the growth of the aggregates from the center outward. The extreme regularity of these aggregates and their color, which is a light shade of yellow or green, renders this a very attractive mineral. Wavellite is a secondary mineral, a fact which is emphasized by its occasional occurrence in stalactitic forms.

Turquois, although not a common mineral, is nevertheless one that is of interest to many of us because of the attractive opaque stones that have been cut from it. Turquois is a hydrous phosphate of alumina and copper, and owes its very characteristic color to the latter element. Crystals of Turquois are so rare that up to a very recent date they were unknown. It is commonly found in thin seams and scattered grains in rocks of a volcanic character, notably in trachyte.

Carnotite is a mineral that has, in recent years, come into prominence on account of the small percentage of the element radium contained in it. It is a hydrated compound of the rare elements uranium and vanadium with potassium which is classed among the hydrated vanadates. Carnotite is rarely found in small orthorhombic crystalline plates, its more characteristic occurrence being in the form of a yellow crystalline powder which is usually deposited in the interstices of a white or gray sandstone. It is a source of the extremely rare element, radium, its value as an ore consisting in the comparatively large deposits of it located in western Colorado, and eastern Utah, rather than in the minute amount of radium contained in it.

In Panel AA we encounter another important class of minerals, the Sulphates. These are compounds of sulphur and oxygen with one or more of the metallic oxides, and with them 
are grouped the few compounds of chromium and oxygen with a metal, known as Chromates. Most of the Sulphates, particularly the hydrous sulphates, are rare and unimportant minerals, but several of them are sufficiently common and useful in the arts to merit our attention in our brief survey of the minerals. Barite is the sulphate of barium, and is also known as "barytes" or "heavy spar," the latter name being given to it because of its great weight compared with other minerals to which it bears a superficial resemblance.

Barite is a very common and widely distributed mineral. It is essentially a vein mineral, that is, one which has been deposited in a vein or crevice by mineralizing solutions; in this way it is commonly associated with metallic mineral deposits, particularly with the sulphides of lead, copper, iron and silver, and with carbonates and such oxides as Psilomelane (manganese oxide).

The specimens in Panel AA show some of the large and beautifully developed orthorhombic crystals that are characteristic of this mineral. These are notably simple in habit, and may be profitably studied as fine illustrations of the symmetry of the orthorhombic system.

Another reason for particularly noting the crystal forms of Barite is that this mineral is the first and most important member of an isomorphous group of sulphates, all of which form in orthorhombic crystals of closely similar shape in the same way as the minerals of the Calcite group of carbonates form in rhombohedral crystals. Sometimes the crystals of Barite are united in divergent groups, producing aggregates with a crested appearance and passing by insensible gradations into straight or curved masses of plates. Barite breaks with an easy cleavage parallel to, and at right angles, to the faces of the rhombic prisms.

Like Calcite, the colors of Barite vary through quite a wide range, it is commonly white and often colorless and transparent, but shades of yellow, brown, red and blue are by no means uncommon, inasmuch as the mineral is often tinted by slight amounts of iron or other impurities. 


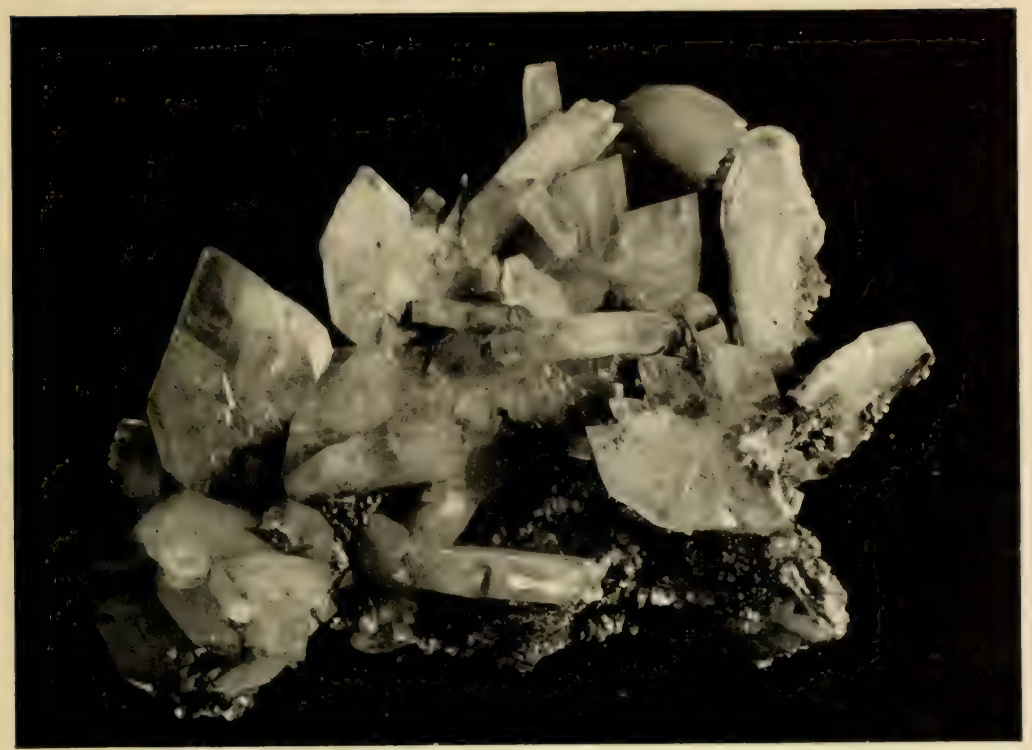

BARITE FROM FRIZINGTON, CUMBERLAND, ENGLAND Panel AA

The flat tabular crystals of this mineral furnish splendid examples of the symmetry typical of the orthorhombic system.

White varieties of Barite are ground for white paint and are often used as an adulterant of white lead. This variety is also used to give weight to paper and to certain kinds of cloth. The colored varieties are sometimes polished for ornamental purposes. Barium hydroxide, which is obtained from Barite, is used in the refining of sugar.

Closely related to Barite both from the point of view of its composition and its crystallization, is Celestite, the sulphate of Strontium, examples of which will be found in Panel BB. Although not so widely distributed as Barite, Celestite is of frequent occurrence as a secondary mineral in limestone and sandstone. It is also found in close proximity to beds of gypsum and rock salt, and in volcanic regions associated with Sulphur 
(consult also the series under Sulphur in Panel A). The orthorhombic crystals are similar to those of Barite, and are sometimes developed to large size. They also form parallel aggregates of plate-like individuals and close masses of parallel fibers. Is its name implies, Celestite is usually pale blue in color, although it is also sometimes white or even yellowish.

As a source of strontium, Celestite is much used in the manufacture of fire works to give the red colored pyrotechnic display.

Anglesite, a sulphate of lead, is another mineral in the isomorphous group with Barite and Celestite, crystallizing in orthorhombic forms like those of its related species. Its occurrence, however, is much more restricted, and is confined to certain lead deposits where it is formed as a secondary mineral by the alteration of Galena. Massive forms are very common with this mineral, which often forms in concentric massive layer, around a central core or nucleus of Galena. Anglesite is white, gray or, more rarely, bluish or yellowish in color. The crystals are often transparent and colorless, with an adamantive luster. It is mined with other lead minerals as an ore of lead.

Among the hydrated sulphates, which are sulphates containing water of crystallization, the commonest and most important mineral is Gypsum, a hydrated sulphate of calcium. Gypsum crystallizes in forms of the monoclinic system which are commonly quite simple, and in which the monoclinic symmetry is obvious. Occasionally these are developed to very unusual size, as in the examples shown in Panel BB.

A striking feature of crystallized Gypsum is the very easy cleavage that enables the crystals to be split with great facility parallel to the plane of symmetry, and to yield thin polished sheets, like the sheets of mica, but not elastic. Crystals of Gypsum are usually clear and colorless, often with a slightly pearly luster, which, from its resemblance to moonlight, has led to the name of selenite being applied to this variety. A fibrous variety in which the crystals are developed to a very long and thin habit, and are grouped in a close parallel aggrega- 
tion, is called from its silky luster "satin spar." There is also a compact massive kind known as "alabaster," which, because of its fine texture and its softness, is much used for carved objects. Gypsum is usually white or light shaded gray, flesh-red, yellow or blue.

Like all of the hydrous sulphates, Gypsum is a mineral of secondary origin, frequently occurring in close association with deposits of salt. It is also formed from the sulphuric acid generated around the craters of volcanoes, which reacts on the lime of the decomposing lavas.

Gypsum finds its principal use as the material from which plaster of paris is manufactured by the driving off of its water of crystallization. Extensive deposits of massive gypsum suitable for this purpose have resulted from the evaporation and concen. tration of the ancient seas and land-locked waters.

In thus concluding our tour of the key collection contained in the wall cases that we have passed in review, we must not lose sight of the fact that it is a key collection, and, as such, must logically unlock something.

It is the hope of the writer that this key will help to throw open the wealth of knowledge regarding the earth's substances to be found in the Main Collection. This is itself a text book, every page and every line of which is copiously illustrated with the best pictures one could possibly have-the things themselves. 



\section{INIEX}

The asterisk denotes that the mineral or structure is figured on the page referred to.

Heavy-faced type denotes that the subject is specially treated on the page indicated.

Actinolite, 69*, 96

Adularia, 91

Agate, 43, 44*, 70

Albite, 90,92

Almandite, 90, 99

Alteration of minerals, 47

Amazon Stone, 91

Amethyst, 70

Amphibole, 50, 95*, 97

Analcite, 108

Andalusite, 102

Andesine, 91

Andradite, 99

Anglesite, 120

Ankerite, 81

Anorthite, 92

Antimonates, 11

Antimonides, 10

Antimony, 54

Apatite, 114, 115*

Apophyllite, 107

Aquamarine, 98

Aragonite, 40, 41, 83*, 84*, 85

Arsenates, 11, 114

Arsenic, 54

Arsenides, 10, 57

Asbestos, 96, 112

Augite, 93
Axinite, 27

Azurite, 87

Bailey Collection, 2

Baker, George Fisher, 4

Barite, 26, 36, 118, 119*

Bement, Clarence S., 2, 4

Bement Collection, 2, 4

Beryl, 24, 97, 98*

Biotite, 111

Bismuth, 54

Borates, 10

Bromides, 10, 65

Calamine, 36, 103*, 104

Calcite, 12, 40, 41, 78, 79*, 80*,

85,118

Carbonates, 10, 51, 78

hydrous, 9,89

Carnotite, 117

Celestite, 119

Cerussite, 34, 85

Chabazite, 108

Chalcedony, 43, 44*, 71

Chalcopyrite, 22, 61, 65, 86

Chalcotrichite, 72

Chiastolite, 102

Chlorides, 10, 65 
Chlorite, 69, 100

Chondrodite, 50

Chromates, 11

Chrysolite, 50, 112

Chrysotile, 112

Cinnabar, 61

Cleavage, 61, 80, 82

Columbite, 113

Columnar Structure, 33* 75

Contact Zones, 93

Copper, 54, 55*

Corundum, 73

Crested Structure, 36

Crystal forms, 17

habit, 29*

Crystalline aggregates, $32 *$

Crystallization, 13

Crystallizing forces, 14

Crystals, cubic, 14, 15*, 60* 62 ,

$$
67,72
$$

dodecahedral, 18, 19*

hexagonal, 23*, 68, 71* 97 ,

$$
98^{*}, 100,115^{*}
$$

how formed, 13

isometric, 18*, 19, 99*, 108

monoclinic, 26*, 86, 92, 95,

$103,108,110,111,113$

octahedral, $17^{*}, 18,74$

orthorhombic, 16, 25*, 57, 63,

83*, 102* $109,113,119^{*}$,

120

rhombohedral, 24, 73*, 79*,

$80 *, 105^{*}, 108$

tetragonal, 20, 21* 22* $^{*}$ 29, 75,

101, 108

triclinic, 27, 91*, 92, 94, 102
Cuprite, 49, 72, 86

Cyanite, 102, 106

Dana, Edward S., 52 James D., 52, 92

Datolite, 102

Dendritic structure, 32*, 34

Diabase, 88, 94, 95, 107

Diamond, 54

Dimorphism, 62, 83

Diopside, 90, 93, 96

Dioptase, 100

Diorite, 95, 111, 113

Dolomite, 81, 85

Earth-forming forces, 38

Elements, the, 7, 10, 52 list of the common, 8

Emerald, 98

Emery, 73

Epidote, 103

Feldspar group, the, 6, 90, 97, 110

Flint, 72

Flos ferri, 84*, 85

Fluorides, 10, 65

Fluorite, 12, 16, 49, 66** 67

Fluor spar, 66* 67

Franklinite, 74

Gabbro, 94, 95

Galena, 16, 46, 50, 59, 60* 61,

$67,78,85,114,120$

Garnet, 50, 90, 98, 99*, 110

Geodes, 43, 4+*, 71 
Gneiss, 88, 91, 96, 102, 110, 113 Malachite, 49, 86

Geothite, 76*

Gold, 54

Granite, 6, 88, 91, 95, 96, 97, 101, $102,104,111,113,115$

Granular structure, coarse, 37 fine, 37

Graphite, 54

Gypsum, 26, 85, 120

Halite, 66

Halogens, 10, 65

Haloids, 10, 65

Hematite, 35, 36*, 73, 74*

Hornblende, 95*, 96

Hydrocarbon compounds, 11

Iceland spar, 81

Iodides, 10, 65

Imitative shapes, $33^{*}, 34$

Iron, 8, 54, 55, 73 roses, 35,36 *

Isomorphous groups, 81

Jade, 96

Jasper, 72

Kelvin, Lord, 13

Kunz, George F., 1

Labradorite, 92

Luray Cave, 40

Limestone, 81, 93, 96, 100, 101, $104,112,113,115,119$

Limonite, 41, 45, 50, 76

Magnetite, 74
Mammoth Cave, 40, 43

Manganite, 84

Marble, 81

Marcasite, 41, 63, 64*, 83

Massive structure, 37

Mellates, 11

Metals, the, 52, 54

Mexican onyx, 41

Mica group, the, 6, 109

Microcline, 91*

Mineral Classification, the, 9, 10

Mineral balls, 35

Mineral veins, 45, 60*

Molecules, 13 cohesion between, 13 size of, 13

Molybdates, 11

Molybdenite, 59

Morgan, John Pierpont, 1, 2, 4

Morganite, 98

Muscovite, 110, 111*

Natrolite, 34, 35*, 108, 109

Nephrite, 96

Niobates, 10, 113

Nitrates, 11

Non-metals, the, 52

Oligoclase, 92

Opal, 48*, 72

Orpiment, 57

Orthoclase, 90, 91*

Oxalates, 11

Oxides, 10

hydrous, 9 
Panel A, 52, 53

B, 53, 57

C, 57,59

D, 59

E, 61

F, 63

G, 67

H, 68

I, 70

J, 70

$\mathrm{K}, 70$

L, 72

M, 73

$\mathrm{N}, 75$

$\mathrm{O}, 78$

$\mathrm{P}, 78$

Q, 78

R, 82, 85

S, 85

$\mathrm{T}, 85$

$\mathrm{U}, 90$

$\mathrm{V}, 92$

W, 98

X, 104

Y, 107, 109

Z, 107, 112

$$
\begin{aligned}
& \text { AA, } 118 \\
& \text { BB, } 119
\end{aligned}
$$

Pegmatite, 97

Petrified wood, $47,48^{*}, 72$

Phantom crystals, 69

Phlogopite, 112

Phosphates, 10, 11, 51, 114

hydrous, 9, 116

Polybasite, 65

Prehnite, 104
Proustite, 63

Pseudomorphs, 49, 75, 100, 112

Psilomelane, 42* , 77, 118

Pyrargyrite, 63, 64

Pyrite, 16, 35, 45, 50, 61, 62* 83

Pyrolusite, 32*

Pyromorphite, 50, 114, 116

Pyroxene, 50, 90, 92, 93*, 94, 95, $96,97,98,110$

Quartz, 6, 43, 44*, 68, 69, 71, 97 capped, 70

rose, 70

smoky, 70, 71*

Radiating structure, $35^{*}, 76^{*}$, 117

Realgar, 57

Rhodochrosite, 82, 85

Rhodonite, 94

Rhyolite, 102

Rock phosphate, 116 salt, 65

Rocks, 6

crystalline, $\mathbf{8 8}$

Ruby, 73

silvers, 63

Rutile, 29*, 33*, 34, 69, 75

Salts of organic acids, 11

Sandstone, 119

Sapphire, 73

Satin spar, 121

Scapolites, the, 100

Schist, 96, 102, 10t, 110, 113 
Secondary minerals, the, $45,50, \quad$ Sulpho-salts, 10, 63

$111,11+$

Selenite, 120

Serpentine, 50, 96, 100, 112

Semi metals, the, 53, 54

Senarmontite, 72

Siderite, 50, 81, 85

Silica, 39, 43, 47, 70, 71, 88

Silicates, 9, 11, 51, 88 composition of the, 88 hydrous, 9, 89, 107

Silver, $54,56 *$

Smithsonite, 82

Smithson, James, 96

Snow crystals, $31^{*}, 33$

Spang Collection, 2

Sphalerite, 45, 60, 67, 78

Spinel, 75

Spodumene, 94

Stalactites, 40, 41, 43, 63, 64*

Stalactitic structure, $42 *$, 71, 72,

$$
75,77,82,84^{*}, 86^{*}
$$

Stalagmites, $40,41,43$

Staurolite, 105, 106

Stibnite, $57,58 *$

Stilbite, 43, 108, 109*

Substance of the earth, the, 5, Underground water, 39, 40, 43, 6,7

Sulphantimonides, 63

Sulphantimonites, 10

Sulpharsenides, 63

Sulpharsenites, 10

Sulphates, 11, 51, 117, 118

hydrous, 9, 118, 121

Sulphides, 10, 45, 51, 57

metallic, 59
Sulphur, 8, 53*, 119

Syenite, 95, 113

Symmetry, axes of, 19, 20, 22, $23,24,25,27,29$

of crystals, 19, 20, 22, 23, 24, 25,27

plane of, 26

Talc, 96

Tantalates, 10, 113

Tantalite, 113

Tellurates, 11

Tetrahedrite, 65

Titanates, 10

Titanite, 112, 115

Topaz, 101

Tourmaline, 69, 97, 104, 105*, 106

Trachyte, 117

Tremolite, 110

Troostite, 100

Tungstates, 11

Turgite, 76

Turquois, 117 47

Uranates, 11

Vanadates, 11, 114

Vanadinite, 116

Water as a mineral solvent, 38 45,81 of constitution, 109 
Water

of crystallization, 107, 110 omnipresence of, 39

Wavellite, 35, 116, 117

Wernerite, 100, 101, 115
Willemite, 100

Window frost, 32

Zeolites, the, 102, 107, 110

Zircon, 22, 97, 101 




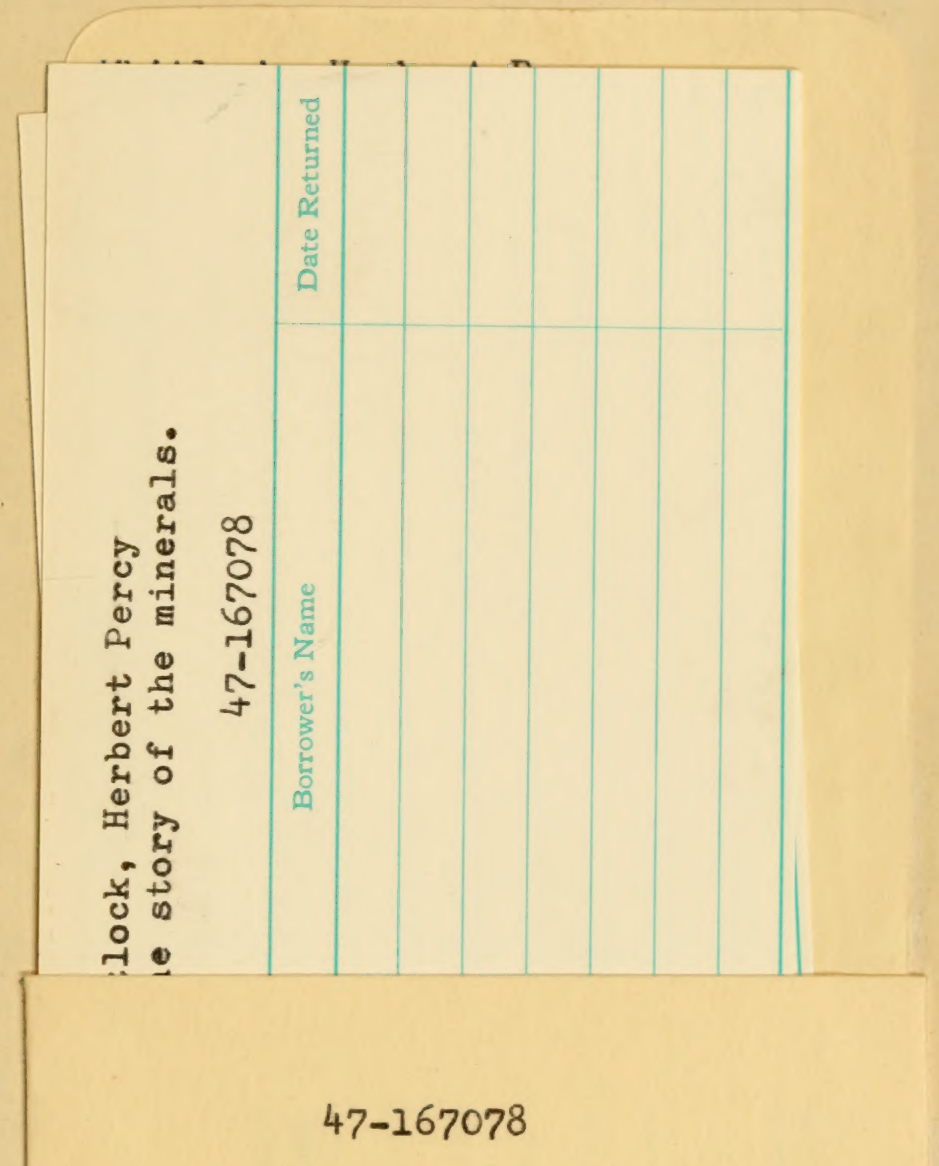


